\title{
Prenatal influences on temperament development: The role of environmental epigenetics
}

\author{
MARIA A. GARTSTEIN AND MICHAEL K. SKINNER \\ Washington State University
}

\begin{abstract}
This review summarizes current knowledge and outlines future directions relevant to questions concerning environmental epigenetics and the processes that contribute to temperament development. Links between prenatal adversity, epigenetic programming, and early manifestations of temperament are important in their own right, also informing our understanding of biological foundations for social-emotional development. In addition, infant temperament attributes represent key etiological factors in the onset of developmental psychopathology, and studies elucidating their prenatal foundations expand our understanding of developmental origins of health and disease. Prenatal adversity can take many forms, and this overview is focused on the environmental effects of stress, toxicants, substance use/psychotropic medication, and nutrition. Dysregulation associated with attention-deficit/hyperactivity-disruptive disorders was noted in the context of maternal substance use and toxicant exposures during gestation, as well as stress. Although these links can be made based on the existing literature, currently few studies directly connect environmental influences, epigenetic programming, and changes in brain development/ behavior. The chain of events starting with environmental inputs and resulting in alterations to gene expression, physiology, and behavior of the organism is driven by epigenetics. Epigenetics provides the molecular mechanism of how environmental factors impact development and subsequent health and disease, including early brain and temperament development.
\end{abstract}

Environmental exposures can alter maternal physiology in a manner that results in "programming" effects on the fetus. This programming is understood in terms of adaptations to the prenatal environment, which may or may not be beneficial after birth. That is, the course of fetal development is altered as a function of critical environmental conditions in a manner that shapes growth and health outcomes into adulthood. According to Hochberg et al. (2011) and others, offspring faces risk in the form of vulnerability to adversity and/or a lack or resilience if in utero programming is discordant with the postnatal environment. This programming effect was first noted in the context of undernutrition and is often referred to as Barker's hypothesis. Barker and Osmond (1986) relied on epidemiological data to ascertain that gestational undernutrition was correlated with adult onset heart disease. Multiple investigations have since identified fetal programming contributions to adult disorders (e.g., Tobi et al., 2014), and interest in developmental origins of health and disease (DOHaD; Wadhwa, Buss, Entringer, \& Swanson, 2009) continues to grow. This research encompasses prenatal effects associated

We thank Eric Nilsson for critical review of the manuscript and Heather Johnson for assistance in the preparation of the manuscript. This study was supported by a John Templeton Foundation grant and NIH grants (to M.K.S.).

Address correspondence and reprint requests to: Maria A. Gartstein, Department of Psychology, Washington State University, PO Box 4820, Pullman, WA 99164-4820; E-mail: gartstma@wsu.edu; or Michael K. Skinner, Center for Reproductive Biology, School of Biological Sciences, Washington State University, PO Box 4236, Pullman, WA 99164-4236; E-mail: skinner@wsu.edu. with exposure to stress, toxicants, substance use/psychotropic medication, and nutrition. Programming effects of these environmental factors linked with temperament development will be considered in the present review, focused on the underlying biological mechanisms.

Fetal programming is thought to transform the structure and function of tissues/organs, shaping physiological outcomes associated with adult disease. Biological processes underling these programming effects represent a more recent emphasis, as DOHaD research has become increasingly concerned with the role of epigenetic mechanisms that alter gene expression (Hochberg et al., 2011). Understood to mediate the effects of environmental input on the developing organism by shaping gene expression, epigenetics has been defined as "molecular factors/processes around the DNA that regulate genome activity independent of DNA sequence, and are mitotically stable" (Skinner, 2014). Epigenetic mechanisms play a critical role in fetal programming, providing the basis for either healthy outcomes or disruption of physical and mental health. Environmental epigenetics encompasses a variety of environmental factors that serve to establish and maintain epigenetic modifications, influencing gene expression and the resulting phenotype. Fetal programming associated with maternal stress, toxicants, substance/psychotropic medication use, and nutrition reflects diverse biological pathways. All these exposures are nonetheless relevant to environmental epigenetics, as epigenetic processes provide conduits for conferring their effects to the gestating organism. 
Consequences of fetal programming in humans have been documented most widely for physical health/medical outcomes (e.g., Roseboom et al., 2011), with behavioral effects often examined in animal models (Babenko, Kovalchuk, \& Metz, 2015). Outcomes have not been typically framed as temperament per se, but rather discussed in terms of stress reactivity, susceptibility to anxiety, or impulsivity, without making links to this overarching theoretical framework. Connecting these disparate findings under the umbrella of the psychobiological model of temperament makes it possible to view these in terms of their implications for social-emotional development and developmental psychopathology, and to provide prevention/intervention related recommendations. Understanding developmental origins of temperament via fetal programming potentiated through epigenetic mechanisms could make earlier preventative efforts possible. Considering prenatal effects of maternal stress, toxicant exposure, substance/psychotropic medication use, and nutrition in the context of the environmental epigenetics framework provides an opportunity to compare resulting offspring epigenetic and behavioral signatures. These exposures often work in tandem (e.g., inadequate nutrition coupled with stress), and advances in environmental epigenetics will inform whether similar epigenetic mechanisms, overlapping genomic regions, and/or interacting gene networks are responsible for compound effects.

This review begins with epigenetic mechanisms critical to current research, and those likely to gain importance going forward. Links between temperament and developmental psychopathology are addressed next. We then turn to environmental factors that shape the intrauterine milieu and fetal development: stress, toxicant, substance use/psychotropic medication, and nutritional exposures. Finally, evidence linking DNA methylation and temperament, and implications for behavioral/emotional health are described, followed by conclusions and recommendations for future research.

\section{Epigenetic Mechanisms}

A number of epigenetic mechanisms have been identified, including DNA methylation, histone modifications, chromatic structure/remodeling, and noncoding RNAs (Figure 1).

\section{DNA methylation}

DNA methylation occurs when a small (methyl) chemical group is attached to the DNA base cytosine (C) in a cytosine nucleotide-phosphate-guanine nucleotide $(\mathrm{CpG})$ sequence. Covalent modification of DNA by methylation of cytosine residues serves to alter transcription and genome activity. DNA methylation is responsible for silencing of transposable elements and pericentromeric repeats to ensure genome integrity (Chen, Tsujimoto, \& Li, 2004; Kaneko-Ishino \& Ishino, 2010; Xu, Bai, Collins, \& Ghishan, 1999), inactivation of the X-chromosome (Lock, Takagi, \& Martin, 1987; Sado, Okano, Li, \& Sasaki, 2004), and genomic imprinting (Feil
\& Khosla, 1999; Reik, Collick, Norris, Barton, \& Surani, 1987). Critical to multiple developmental outcomes, DNA methylation is also emerging as important for temperament development (e.g., Fuemmeler et al., 2016).

\section{Histone modifications}

Histones represent the chief protein component of chromatin, functioning as beads around which DNA winds, and is compressed into nucleosomes. Histones, and their various modifications, or marks, play an important role in regulating gene expression. Covalent posttranslational modifications to histone proteins including methylation, phosphorylation, acetylation, ubiquitylation, and sumoylation impact gene expression by altering chromatin structure and/or recruiting histone modifiers. Whereas some result in transcription activation, others have a repressive effect, effectively shutting down transcription. Lysine acetylation, for example, results in more accessible chromatin and tends to be associated with active transcription. Conversely, deacetylases remove acetyl groups from the histones, allowing the DNA to be wrapped more tightly and repressing transcription activity. Histone methylation effects depend on the location and number of methyl groups involved, potentially leading to activation or repression of gene expression (Barski et al., 2007). Exposure to adverse environments has been shown to result in alterations in histone acetylation and methylation status in animals (Weaver et al., 2004). Specifically, histone acetylation of the glucocorticoid receptor, nuclear receptor subfamily 3 , group $\mathrm{C}$, member $1(\mathrm{NR} 3 \mathrm{Cl}$ ) gene differentiated offspring born to high and low licking and grooming mothers along with DNA methylation.

\section{Chromatin structure/remodeling}

A number of factors come into play as DNA is packaged into progressively larger units, starting with the assembly of nucleosomes and concluding with mitotic condensation, resulting in chromosomes. A variety of factors (e.g., stage of cell life) affect chromatin state, resulting in either euchromatin or heterochromatin. The euchromatin, "beads-on-a-string" structure makes DNA more accessible, promoting transcription and gene expression. The euchromatin state is associated with activating histone marks and remodeling complex recruitment that facilitate transcription factor binding. Heterochromatin, in contrast, represents a repressed state with respect to gene expression, and is associated with repressive histone and DNA methylation.

\section{Noncoding RNAs}

Noncoding RNAs include short microRNAs, Piwi-interacting RNAs, and long noncoding RNAs, regulating genes translation/transcription and chromatin stability (Zhou, $\mathrm{Hu}$, $\&$ Lai, 2010). Noncoding RNAs can directly bind to promoters and interfere with polymerases by mobilizing transcriptionally repressive complexes conducive to heterochromatin 
DNA Methylation<smiles>CC1CN(C)C(=O)N=C1N</smiles>

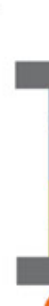

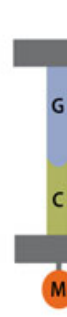

Methyl

group

\section{Histone Modifications}

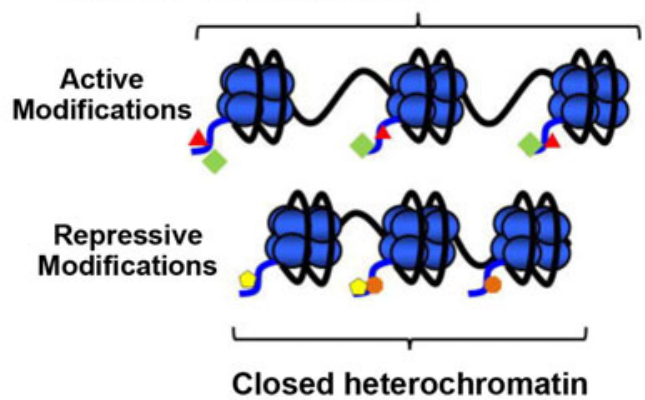

\section{Chromatic Structure/Remodeling}

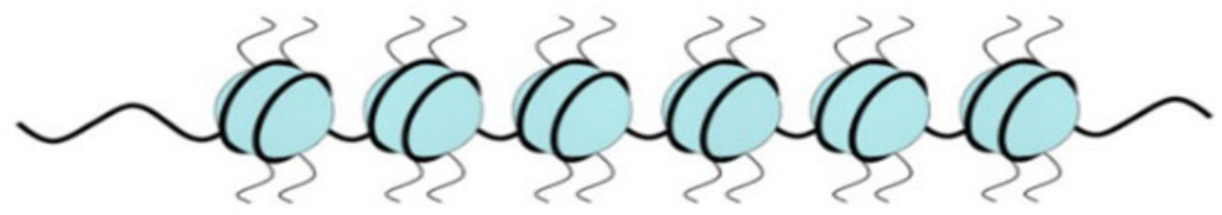

(Ac) (4) (HDAC)
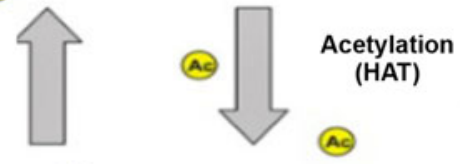

(A)

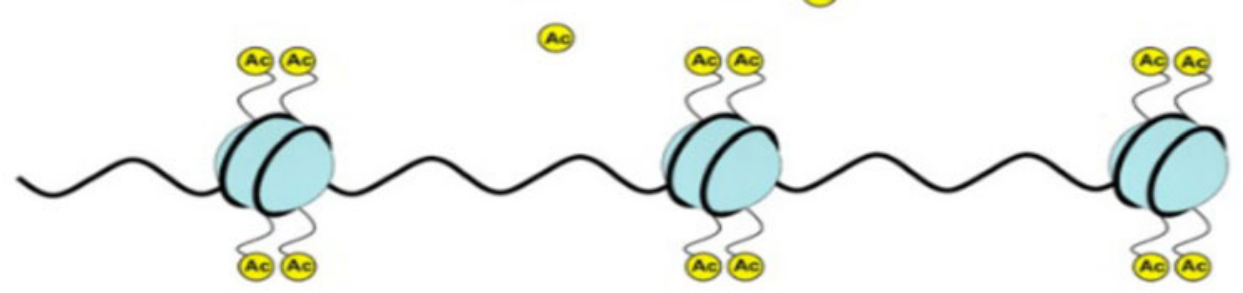

\section{Non-coding RNAs}

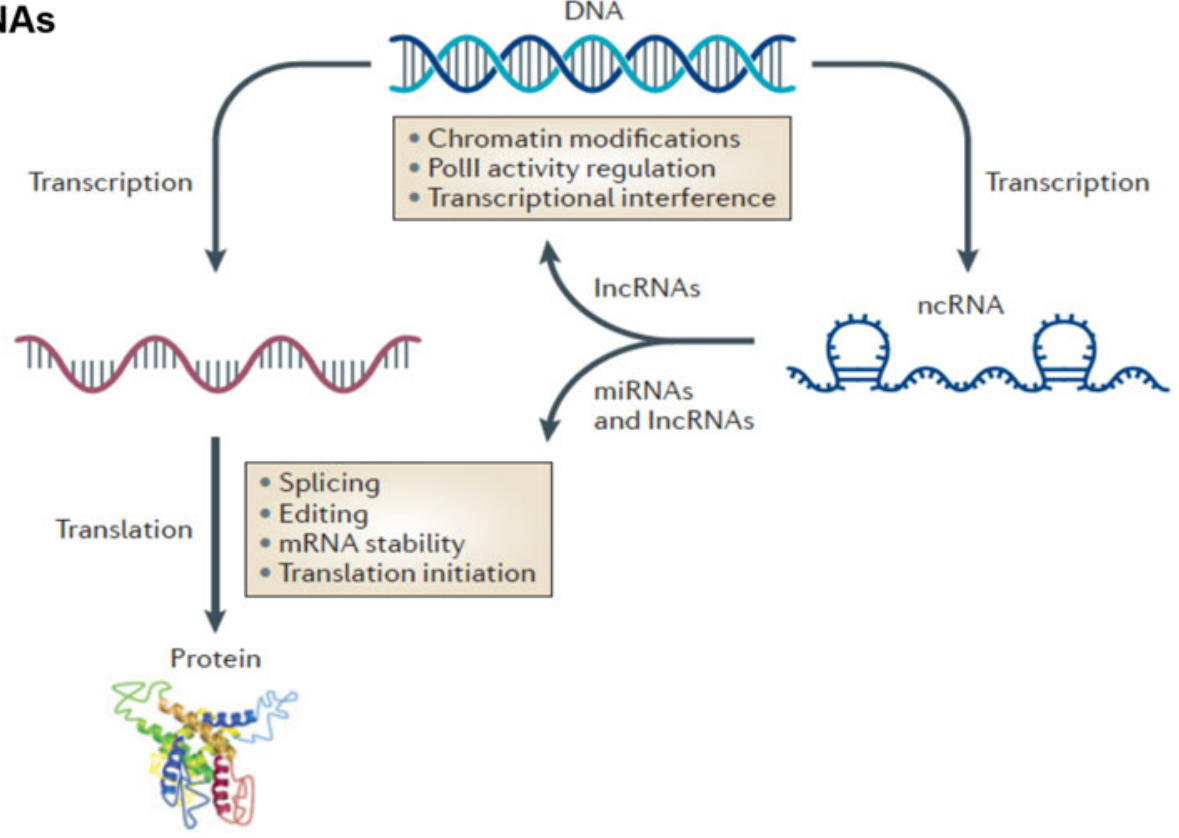

Figure 1. Epigenetic mechanisms: DNA methylation, histone modification, and noncoding RNA. Methylation: DNA methylation is the addition of a methyl group (M) to the DNA base cytosine (C) in a $\mathrm{CpG}$ sequence; $\mathrm{CH} 3$, the methyl group, is added to a carbon of the cytosine ring via a covalent bond, resulting in 5-hydroxymethyl cytosine. Chromatic structure/remodeling: Chromatin structure in heterochromatin states, silencing transcriptional activities, euchromatin HAT catalyzes histone tails leading to active transcription. Histone modifications: 
(Zaratiegui, Irvine, \& Martienssen, 2007) and through posttranscriptional binding (Filipowicz, Bhattacharyya, \& Sonenberg, 2008). Noncoding RNAs are involved in a number of activities, with current evidence suggesting the largest class may be that of chromatin modifiers (Horabin, 2013). Whereas some noncoding RNA actions are sequence dependent, and thus not epigenetic in nature, examples of sequenceindependent effects have been reported (Cao, 2014).

Although a number of epigenetic mechanisms have been documented, initial implementation in $\mathrm{DOHaD}$ research has focused primarily on methylation. Additional epigenetic processes will likely be implicated in the future, likely working in concert, for example, as histone modifications contribute to chromatin remodeling (Figure 1). Accumulating evidence from animal studies supports the important role of epigenetic mechanisms in shaping physiological maturation and behavioral development, conferring effects of various exposures (e.g., Skinner, Anway, Savenkova, Gore, \& Crews, 2008). The human literature lags behind and is subject to greater methodological challenges. Nonetheless, epigenetic effects have been identified utilizing brain tissue and peripheral cells (Nieratschker et al., 2014; Szyf \& Bick, 2013). That is, signatures of environment triggers that lead to epigenetic/molecular changes in the brain can also be identified in peripheral tissues, because of systemic consequences of exposure (Lester, Conradt, \& Marsit, 2016; Szyf \& Bick, 2013), and afford identification in humans. Moreover, issues around cell specificity of epigenetic programming can be addressed by comparative studies, wherein human peripheral cell epigenetic signature is compared to a brain tissue signature obtained from animals, with the focus on conserved genomic regions and/or gene networks (Nieratschker et al., 2014). This environmental epigenetics review will focus on stress, toxicant, substance use/pharmaceuti$\mathrm{cal}$, and nutritional prenatal exposures. Pathways that involve maternal physiology and offspring brain development will be discussed as the foundation for temperament and risk/protection with respect to psychopathology. Epigenetic mechanisms mediate environmental effects on temperament phenotypes. Effects set in motion during gestation likely contribute to developmental psychopathology by impacting temperament growth and could also play a role as risky temperament profiles transform into symptoms and disorders (e.g., infant fear/ behavioral inhibition culminate in childhood social anxiety). Temperament-related effects are likely to be especially salient in early childhood, as behavioral attributes "come online."

\section{Temperament Development and Symptoms of Psychopathology}

We now turn to temperament research addressing negative emotionality, surgency/extraversion, regulatory capacity/effortful control, and links with developmental psychopathology. The study of temperament has a long-standing history. Childhood research began with the work of Thomas and Chess (1977) focused on "difficult temperament," which reflects high levels of negative affects, coupled with few manifestations of positive emotions and poor regulation. A number of temperament definitions and frameworks have been proposed, several emphasizing biological underpinnings. The study of behavioral inhibition and exuberance, for example, has linked approach and avoidance tendencies to an asymmetry in frontal brain activation (Hane, Fox, Henderson, $\&$ Marshall, 2008). The polyvagal theory (Porges, 2007) addressed how physiological states support different classes of behavior (e.g., vagal withdrawal supports mobilization, fight, and flight) and primary emotions are related to autonomic functioning. Currently, Rothbart's psychobiological model (Rothbart \& Derryberry, 1981), an integration of existing temperament and personality frameworks with other relevant areas, such as neuroscience and comparative studies, represents the most widely referenced approach.

According to the psychobiological model, temperament represents constitutionally based individual differences in emotional and motor reactivity, as well as self-regulation, demonstrating consistency across situations and relative stability over time (Rothbart \& Derryberry, 1981). Emotional reactivity encompasses fear, anger, sadness, and positive emotions. Processes serving to modulate reactivity, including attentional focus, shifting, and inhibitory control, provide the basis for selfregulation. The psychobiological approach identifies unique domains of temperament, mapping these onto underlying neurobehavioral systems, and outlines their developmental pathways and interactions. The term "constitutional" emphasizes the connection between temperament and biology. Historically, individual differences in temperament have been linked to the constitution of the organism, as it was understood at the time. Although "constitutionally based" has been typically interpreted as genetically driven, accumulating evidence suggests epigenetic processes make important contributions and have been incorporated in the definition of temperament more recently (Putnam \& Gartstein, 2016). The 
psychobiological temperament framework applies across the life span, with reactive and regulatory domains developing especially rapidly in early childhood. Temperament attributes are understood to encompass physiological reactivity, including elements of the hypothalamus-adrenal-pituitary (HPA) axis response and patterns of brain activation. These are generally measured along with behavioral markers, typically ascertained through direct observations, and in humans also via caregiver report (Gartstein, Putnam, Aaron, \& Rothbart, 2016).

Structurally, temperament encompasses negative emotionality, surgency/extraversion, and orienting regulation/ effortful control. Distress proneness is the first to emerge (e.g., Putnam, Rothbart, \& Gartstein, 2008; Rothbart, 1989). At the same time, negative emotionality has strong conceptual and empirical links to the adult personality trait of neuroticism (Evans \& Rothbart, 2007). Fearful reactivity/behavioral inhibition, a component of negative emotionality, tends to occur in the context of relative right-hemisphere dominance (right dorsolateral prefrontal cortex and temporal regions), associated with limbic system (i.e., amygdala, basal ganglia, and hypothalamus) activation (Davidson, 1998; Sutton \& Davidson, 1997). HPA axis functioning alterations marked by higher cortisol were also noted for children demonstrating behavioral inhibition/fear (Perez-Edgar, Schmidt, Henderson, Schulkin, \& Fox, 2008).

Surgency in infancy is largely manifested through displaying pleasure (e.g., smiling and laughing) and approach behaviors (Gartstein \& Rothbart, 2003; Rothbart, 1989), incorporating characteristics of activity and enthusiasm (Rothbart \& Ahadi, 1994). Individuals higher in positive affect have the tendency to be engaged, rather than disengaged, with their environment (Lonigan, Phillips, \& Hooe, 2003), as approach tendencies are potentiated by increased behavior activation system input (Gray, 1994; Rothbart \& Hwang, 2005). The corticolimbic-striatal-thalamic network that operates via dopaminergic projections from the ventral tegmental area to the subcortical and frontal cortical regions (Depue \& Collins, 1999) favors left frontal regions (Coan \& Allen, 2004) and provides the foundation for surgency/extraversion. In infancy, relative left frontal asymmetry was associated with approach behaviors, including positive vocalization and facial expressions of joy (Diaz \& Bell, 2012; Hane et al., 2008).

Infant regulatory/attentional skills set the stage for the more flexible, frontally mediated effortful control (e.g., Gartstein, Bridgett, Young, Panksepp, \& Power, 2013). The emergence of effortful control coincides with rapid development of the executive attention system, including the lateral prefrontal cortex and anterior cingulate regions (Rothbart, Derryberry, \& Posner, 1994; Rueda, 2012). This critical milestone involves a shift from reliance on the alerting attention network, supported by parietal lobe areas and governed by the norepinephrine system, to a more flexible executive attention network. Anterior cingulate, basal ganglia, and areas of the prefrontal cortex are included in the executive attention network, modulated by dopamine (Posner, Rothbart, Sheese, $\&$ Voelker, 2012). Whereas the alerting system is responsible for filtering sensory input, the executive network is engaged in conflict resolution and selecting between alternative response options (Posner \& Peterson, 2011).

A growing body of research indicates that the risk for externalizing problems (conduct difficulties, hyperactivity, and impulsivity; Campbell, 1995; Kovacs \& Devlin, 1998) is greatest for highly reactive children with pronounced negative emotionality and/or surgency, coupled with deficits in attention and regulatory functioning (Diaz et al., 2015; Gartstein \& Fagot, 2003; Martel, Gremillion, \& Roberts, 2012; Muris \& Ollendick, 2005). Internalizing difficulties that involve personal distress and are affective in nature (e.g., depression/ anxiety) can occur as a function of high negative emotionality and low surgency (Fowles, 1994; Lonigan et al., 2003; Murray \& Kochanska, 2002), with nontemperament pathways also relevant for depressive symptoms (Hammen, 2005).

Thus, early manifestations of temperament not only are important as key components of social-emotional development but also are significant as early markers of psychopathology risk (Figure 2). A number of explanations for the relationship between temperament and psychopathology have been proposed. Vulnerability and pathoplasty models generally assign temperament a causal role in psychopathology. Vulnerability explanations cast temperament as increasing the probability of symptom onset (e.g., Perez-Edgar et al., 2008). In contrast, temperament and psychopathology can have independent etiology in pathoplasty models, wherein temperament (or personality) is viewed as impacting the course and/or severity of disorders (e.g., De Bolle, De Clercq, De Caluwe, \& Verbeke, 2016). Alternative differential susceptibility (Belsky \& Pluess, 2009) and biological sensitivity to context (Boyce \& Ellis, 2005) models are relevant primarily to negative emotionality, viewed as a plasticity, rather than a vulnerability factor. Thus, the differential susceptibility/biological sensitivity to context models make "for better or for worse" predictions with respect to negative emotionality. There is growing empirical support for the positive response of those high in negative emotionality to good environments and interventions (e.g., Hentges, Davies, \& Cicchetti, 2015), and new evidence that negative affectivity primarily confers adjustment risk (e.g., Moran et al., 2016). Predictive links between temperament and symptoms were also framed in terms of underlying neurobiology. Whittle, Allen, Lubman, and Yucel (2006) proposed a model focused on six brain structures: amygdala, hippocampus, nucleus accumbens, orbitofrontal cortex, anterior cingulate cortex, and the dorsolateral prefrontal cortex, describing joint effects for negative emotionality, surgency/extraversion, regulation, and related symptoms/disorders. Environmental epigenetics can elucidate biological underpinnings of temperament development, in turn expanding our understanding of developmental psychopathology and $\mathrm{DOHaD}$ more broadly, as temperament attributes represent key contributing factors.

Human and animal studies showing connections between prenatal environmental exposures and temperament-related phenotypes suggest these exposures, and the cascades of 


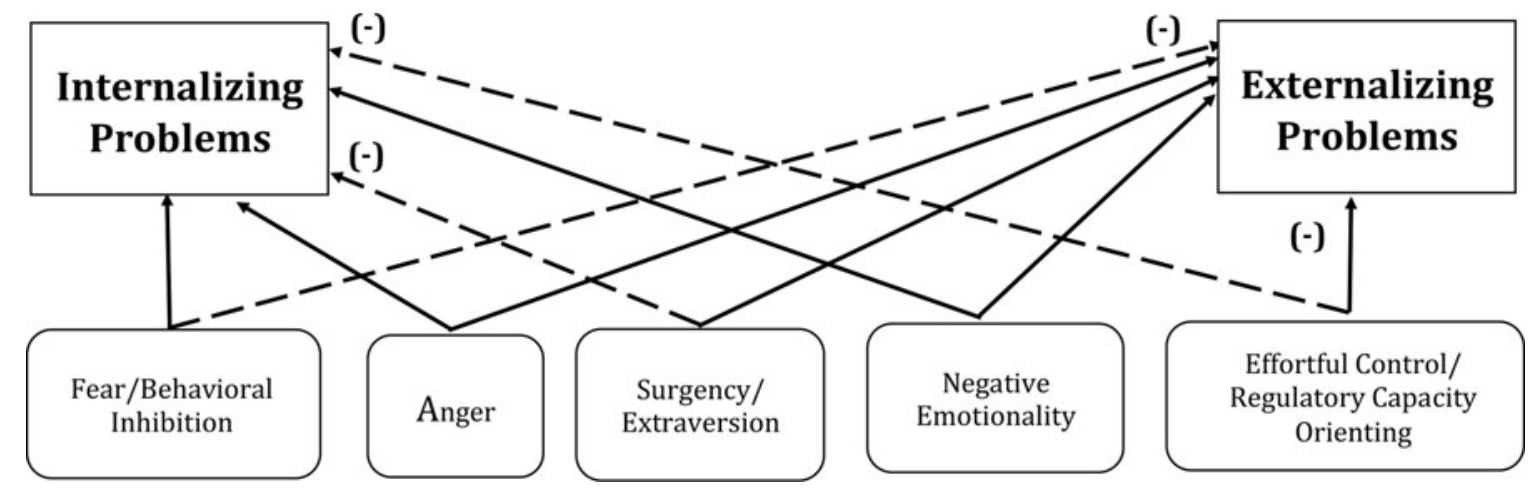

Figure 2. Links between temperament attributes and developmental psychopathology. Depicted are the most prominent relationships between child temperament traits and broad symptom/behavior problem clusters (internalizing and externalizing). (-) A negative relationship and (---) a less well-established relationship.

epigenetic effects that follow, impact how reactivity and regulation "come online." Studies addressing the impact of maternal stress response and HPA axis functioning make some of the least ambiguous connections between prenatal exposure and alteration in offspring temperament across species, elucidating epigenetic processes that mediate prenatal environment-postnatal behavior relationships. Evidence linking maternal stress during pregnancy and offspring HPA axis dysregulation also suggests the latter likely manifests in reactive and regulatory components of temperament, as well as their contributions to symptoms/disorders (Figure 2).

\section{Environment Effects That Shape Intrauterine Environment and Fetal Development}

As environmental epigenetics concerns itself with a spectrum of exposures capable of exerting developmental effects, we now describe these, and established links with behavioral phenotypes relevant to temperament. Stress exposure has been one of the most widely studied prenatal adversities. Human and animal studies indicate behavioral consequences for the offspring typically involve fear/anxiety and/or behavioral/emotional dysregulation.

\section{Stress: Mechanisms, Definitions, Critical Developmental Periods, and Epigenetic Effects}

\section{Stress response: The neuroendocrine system}

In response to stress, paraventricular nucleus of the hypothalamus produces corticotropin-releasing hormone (CRH). CRH stimulates the anterior pituitary to synthesize proopiomelanocortin. Adrenocorticotropic hormone (ACTH), a peptide derived from proopiomelanocortin, is subsequently released into the bloodstream. ACTH induces the adrenal glands to produce cortisol in humans (corticosterone in rodents), the end product of the HPA axis, often labeled the stress hormone (Charmandari, Tsigos, \& Chrousos, 2005). A negative feedback loop is created as cortisol binds to glucocorticoid receptors in the hippocampus. This modulation of the HPA axis response results in downregulation of CRH and ACTH (Deppermann, Storchak, Fallgatter, \& Ehlis, 2014).

A mechanism wherein information from the environment is conferred to the offspring via maternal stress hormones during gestation appears to be conserved across multiple species (Table 1). For instance, predation risk was shown to cause female fish to produce larger eggs with higher concentrations of cortisol (Giesing, Suski, Warner, \& Bell, 2011). Behavioral effects were also noted, as juveniles exposed to prenatal stress formed denser shoals, an effective antipredator strategy. In hares, in utero predator stress was positively correlated to offspring physiological stress reactivity, compromising subsequent reproductive fitness (Sheriff, Krebs, \& Boonstra, 2009, 2010). High maternal cortisol concentrations were linked with nonviable births, smaller offspring size, increased cortisol reactivity, vigilance, and anxiety-like behaviors. Prenatally stress-exposed hares also dispersed more effectively, promoting juvenile survival at a cost of reproductive output, in an example of the "increasing glucocorticoid concentrations to survive at the cost of reproduction" strategy (Sheriff et al., 2009).

Stress-related prenatal effects reflect a "calculation" aimed at improving the odds of survival and are not uniformly maladaptive. These adaptations are of interest precisely because of an attempt to balance the needs of the developing organism: the need for optimal development along a speciestypical timeline versus faster development advantageous for immediate survival. The speeded-up gestation translates into alterations in cellular structure/function. Short-term benefits (i.e., faster gestation and survival) are self-evident, yet adverse health consequences in the long term are also likely. DOHaD research with humans suggests that gestational adversity, presumably resulting in fetal development shortcuts, translates into compromised health in adulthood, including mental health (e.g., Froehlich et al., 2009; Roseboom, de Rooij, \& Painter, 2006).

The range of prenatal adversity is notably broader in humans, including stressful or life-threatening situations and maternal reactivity to these circumstances (e.g., posttraumatic stress disorder [PTSD]), signaled to the fetus by maternal HPA axis response (Babenko et al., 2015). Certain 
Table 1. Maternal neuroendocrine system response: Examples of effects on offspring development in animal and human studies

\begin{tabular}{|c|c|c|c|c|}
\hline Exposure & $\begin{array}{l}\text { Significant Developmental/ } \\
\text { Behavioral Outcome }\end{array}$ & Sample Characteristics & $\begin{array}{l}\text { Developmental } \\
\text { Timing of Exposure }\end{array}$ & Reference \\
\hline \multicolumn{5}{|c|}{ Animal Studies } \\
\hline \multirow[t]{4}{*}{ Predator } & $\begin{array}{l}\uparrow \text { Egg cortisol concentrations } \\
\uparrow \text { Density of shoaling }\end{array}$ & $\begin{array}{l}n=6-30 \text { fish } \\
\text { Measured prehatching, } \\
\text { in juveniles }\end{array}$ & $\begin{array}{l}\text { Pre-post egg formation: } \\
\text { average } 25 \text { days }\end{array}$ & $\begin{array}{l}\text { Giesing et al. } \\
(2011)\end{array}$ \\
\hline & $\uparrow$ Fecal cortisol concentrations & $n=12-14$ hares & Late gestation: last 15 days & Sheriff et al. (2009) \\
\hline & $\begin{array}{l}\downarrow \text { Body mass/length } \\
\downarrow \text { Nestling size }\end{array}$ & $\begin{array}{l}\text { Measured at } 30 \mathrm{hr} \text { after birth } \\
n=137-162(68-92 \text { female })\end{array}$ & Before $\&$ during ovulation: & Cosloysky \& \\
\hline & $\uparrow$ Longer wing span & Measured at $2,8, \& 14$ days & prior to laying eggs & Richner (2011) \\
\hline \multicolumn{5}{|c|}{ Human Studies } \\
\hline \multirow[t]{6}{*}{$\begin{array}{l}\text { Pregnancy } \\
\text { anxiety }\end{array}$} & $\begin{array}{l}\downarrow \text { Gray matter volume, prefrontal } \\
\text { cortex }\end{array}$ & $\begin{array}{l}N=35(17 \text { female }) \\
\text { Measured at } 6 \& 9 \text { years }\end{array}$ & $\begin{array}{l}\text { Midpregnancy: measured at } \\
19,25, \& 31 \text { weeks }\end{array}$ & \\
\hline & $\begin{array}{l}\downarrow \text { Cognitive control/response } \\
\text { inhibition }\end{array}$ & $N=49$ (20 female) & Entire pregnancy: measured & Mennes et al. \\
\hline & $\begin{array}{l}\text { 1nnibition } \\
\downarrow \text { Performance decrement with dual }\end{array}$ & & $\begin{array}{l}\text { at } 12-22,23-31, \& 32-40 \\
\text { weeks }\end{array}$ & \\
\hline & task demands & & & \\
\hline & $\begin{array}{l}\uparrow \text { Alterations in the dorsal prefrontal } \\
\text { cortex region activation }\end{array}$ & & & \\
\hline & All effects for 12-20 weeks only & & & \\
\hline
\end{tabular}

Note: Sample characteristics are provided in a different manner for human and animal studies, because of differences in design and presentation format. The number of participants per condition $(n)$ is indicated for animal experimental investigations, whereas the overall number of participants $(N)$ is presented for human correlational studies. Additional information concerning numbers of male versus female participants is also provided when both sexes were included/specified. Developmental timing of exposure indicators varies across studies. For humans, the timing is provided in terms of the number of gestational weeks. In animals these indicators are typically more specific, often presented in terms of the number of days. ( $\uparrow$ ) Increases in offspring physical/structural and functional characteristics; $(\downarrow)$ decreases in offspring physical/structural and functional characteristics.

stressors can be considered normative, as these generally occur in the context of daily life. Even routine hassles can become problematic, however, especially in concert with symptoms of depression and anxiety (Diego et al., 2006). Although the majority of maternal cortisol $(80 \%-90 \%)$ in the placenta is metabolized, higher concentrations of cortisol can disrupt this process, exposing the fetus to higher levels (Meyer, 1985). Increased maternal HPA axis activity and resultant cortisol production is thought to downregulate placental corticosteroid 11- $\beta$-dehydrogenase isozyme 2 (11ß-HSD-2), which metabolizes cortisol into inactive cortisone (O'Donnell et al., 2012). This reduced ability to increase placental $11 \beta$-HSD-2 with an acute stressor is likely critical to intergenerational transmission. That is, women who do not present with elevated cortisol during pregnancy, demonstrating a "blunted" response to chronic stress (Keeshin, Strawn, Out, Granger, \& Putnam, 2014; Yehuda \& Seckl, 2011), can nonetheless transmit exceedingly high levels of cortisol to the fetus with $11 \beta$-HSD-2 downregulation.

\section{Prenatal stress exposure: Evidence of behavioral/ temperament risk}

Human conceptualizations of stress and empirical studies. Highly conceptual definitions of human stress evolved to include cognitive and allostatic processes, vulnerabilities that result from early experiences and impact adaptation (Maccari et al., 2016), yet research examining prenatal effects of stress has generally relied on unidimensional operational definitions. In fetal programming research, operationalizations of stress include traumatic events (e.g., exposure to interpersonal violence or natural disasters), psychosocial stress (e.g., daily hassles/ stressful events), physiological stress reactivity (e.g., cortisol concentrations), and symptoms of anxiety and depression (Table 2). Multiple studies rely on broad definitions of stress, for example, combining indicators of psychosocial stress and symptoms of psychopathology (e.g., anxiety and depression; Nieratschker et al., 2014). Thus, the literature does not currently provide the basis for making meaningful distinctions with respect to the type of stressor in terms of consequences for the offspring. Another challenge in examining stress with human populations is that exposures are often confounded, such as psychosocial/sociodemographic stress being accompanied by maternal substance use. Confounding effects are somewhat mitigated in quasi-experimental studies wherein stress response/adaptation data are collected in the aftermath of a disaster (Tees et al., 2010; Yong Ping et al., 2015). This approach takes advantage of events that impact large numbers of individuals in a manner that is random with respect to potential confounds. However, stress in the aftermath of a disastrous event does not impact all affected to the same extent, and indi- 
Table 2. Examples of in utero stress exposure effects: Temperament-related outcomes for human and animal studies

\begin{tabular}{|c|c|c|c|c|}
\hline Exposure & $\begin{array}{l}\text { Significant Developmental/Behavioral } \\
\text { Outcome }\end{array}$ & Sample Characteristics & $\begin{array}{l}\text { Developmental } \\
\text { Timing of Exposure }\end{array}$ & Reference \\
\hline \multicolumn{5}{|c|}{ Human Studies } \\
\hline \multicolumn{5}{|c|}{ Maternal Stress } \\
\hline 911 & $\begin{array}{l}\downarrow \text { Basal cortisol concentrations, especially } \\
\text { with 3rd trimester exposure }\end{array}$ & $\begin{array}{l}N=38 \text { (male \& female) } \\
\text { Measured at } 12 \text { months }\end{array}$ & $\begin{array}{l}\text { Entire pregnancy: measured } \\
\text { postpartum }\end{array}$ & Yehuda et al. (2005) \\
\hline Hurricane Katrina & $\begin{array}{l}\uparrow \text { Temperamental difficulty with } \uparrow \text { perinatal } \\
\text { PTSD }\end{array}$ & $\begin{array}{l}N=288 \text { (male \& female) } \\
\text { Measured at } 2 \text { and } 12 \\
\text { months }\end{array}$ & $\begin{array}{l}\text { Entire pregnancy: measured } \\
\text { at delivery }\end{array}$ & Tees et al. (2010) \\
\hline Iowa floods & $\begin{array}{l}\uparrow \text { Cortisol reactivity/separation with } \\
\uparrow \text { maternal prenatal stress }\end{array}$ & $\begin{array}{l}N=94 \text { (48 female) } \\
\text { Measured at } 29-34 \text { months }\end{array}$ & $\begin{array}{l}\text { Entire pregnancy: measured } \\
\text { within } 3 \text { months of delivery }\end{array}$ & $\begin{array}{l}\text { Yong Ping et al. } \\
\text { (2015) }\end{array}$ \\
\hline Anxiety, depression & $\begin{array}{l}\uparrow \text { Attenuation (flattening) of diurnal } \\
\text { cortisol profile with } \uparrow \text { anxiety at } 12-22 \\
\text { weeks }\end{array}$ & $\begin{array}{l}N=58(29 \text { female }) \\
\text { Measured at } 14-15 \text { years }\end{array}$ & $\begin{array}{l}\text { Entire pregnancy: measured } \\
\text { at } 12-22 \text {, } \\
23-32, \& 32-40 \text { weeks }\end{array}$ & $\begin{array}{l}\text { van den Bergh et al. } \\
\text { (2008) }\end{array}$ \\
\hline $\begin{array}{l}\text { Emotional stress, general } \\
\text { psychopathology }\end{array}$ & $\begin{array}{l}\downarrow \text { Fearful reactivity to novelty with } \\
\uparrow \text { emotional stress across pregnancy }\end{array}$ & $\begin{array}{l}N=102(45 \text { female }) \\
\text { Measured at } 4 \text { months }\end{array}$ & $\begin{array}{l}\text { Entire pregnancy: measured } \\
\text { at } 2 \text { weeks postpartum }\end{array}$ & Möhler et al. (2006) \\
\hline Anxiety & $\downarrow$ Regulatory capacity/orienting & $\begin{array}{l}N=90(44 \text { female }) \\
\text { Measured at } 10 \text { months }\end{array}$ & $\begin{array}{l}\text { Early-mid pregnancy: } \\
\text { measured at } 20 \text { weeks }\end{array}$ & $\begin{array}{l}\text { van den Heuvel } \\
\text { et al. (2016) }\end{array}$ \\
\hline $\begin{array}{l}\text { Stress, anxiety depression, } \\
\text { HPA-axis response }\end{array}$ & $\begin{array}{l}\uparrow \text { Negative emotionality, with } \uparrow 3 \text { rd } \\
\text { trimester maternal cortisol } \\
\uparrow \text { Negative emotionality with } \uparrow \text { prenatal } \\
\text { anxiety/depression scores across } \\
\text { pregnancy }\end{array}$ & $\begin{array}{l}N=247 \text { (male \& female) } \\
\text { Measured at } 2 \text { months }\end{array}$ & $\begin{array}{l}\text { Entire pregnancy: measured } \\
\text { at } 18-20,24-26, \& 30-32 \\
\text { weeks }\end{array}$ & Davis et al. (2007) \\
\hline Stress, anxiety, depression & $\begin{array}{l}\uparrow \text { Temperamental difficulty with prenatal } \\
\text { depression, not anxiety }\end{array}$ & $\begin{array}{l}N=107 \text { (male } \& \text { female) } \\
\text { Measured at } 3 \text { months }\end{array}$ & $\begin{array}{l}\text { Entire pregnancy: measured } \\
\text { at } 28-36 \text { weeks, postpartum }\end{array}$ & $\begin{array}{l}\text { Della Vedova et al. } \\
\text { (2006) }\end{array}$ \\
\hline
\end{tabular}


Stress, anxiety depression, HPA-axis response

Stress, anxiety, depression

Trauma (lifetime/prenatal), PTSD, depression $\uparrow$ Cortisol reactivity/painful event with $\uparrow$ maternal cortisol late $2 \mathrm{nd} / 3$ rd trimester

$\downarrow$ Behavioral recovery with $\uparrow$ maternal

cortisol early 2 nd trimester, $\uparrow$ stress across pregnancy

$\uparrow$ Negative emotionality \& fear

$\downarrow$ Falling reactivity/recover from distress

$\downarrow$ Behavioral recovery/social stressor with

$\uparrow$ maternal traumatization (controlling for symptoms)

\author{
$N=116(55$ female $)$ \\ Measured at $24 \mathrm{hr}$ afte \\ birth \\ $N=282(126$ female $)$ \\ Measured at 6 months \\ $N=23$ (12 females) \\ Measured at 6 months
}

Entire pregnancy: measured

at $15,19,25,31, \& 36$

weeks

Entire pregnancy: measured

at $14,24, \& 34$ weeks

Majority of pregnancy \&

postnatal period: measured

at 6 months
Davis et al. (2007)

Nolvi et al. (2016)

Bosquet Enlow et al. (2011)

Animal Studies

\begin{tabular}{ll}
\hline & Stress
\end{tabular}

Foot shock

$\uparrow$ Anxiety-like behavior

$n=11$

$n=11-28$ mice/con
$(5-14$ females $)$
Measured at PND
$n=10$ rats/condition

$n=10$ rats/condition

(5 females)

Forced swim \& observing

$\uparrow$ Anxiety-like behavior

(females)

PND40

$n=6$ rats/condition (males Mid-late gestation:

E13-20

$\begin{array}{ll}\uparrow \text { Anxiety/depression-like behavior } & n=6 \\ \uparrow \text { Basal corticosterone } & \text { only) }\end{array}$

Measured at PND60 \& 120

$n=6-13$ monkeys/

$\uparrow$ Corticosterone reactivity

condition

Measured at 12-14 months

Mid-late gestation: 22

weeks-birth

Midgestation: E12

Golub et al. (2016)

administration

Note: Sample characteristics are provided in a different manner for human and animal studies, beause of differences in design and presentation format. For human correlational studies, the overall number of parprovided, when both sexes were included/specified. Developmental timing of exposure indicators vary across studies. For humans, the timing is generally provided in terms of the number of gestational weeks, whereas in animals these indicators are typically more specific, counting embryonic days. ( $\uparrow$ ) Increases in temperament-related behaviors/displays and/or stress exposure; $(\downarrow)$ decreases in temperament-related behaviors/displays and/or stress; HPA, hypothalamus-pituitary-adrenal; PTSD, posttraumatic stress disorder; E, embryonic day; PND, postnatal day. 
viduals subject to prior socioeconomic or psychosocial stress likely fare worse.

In one study making use of this quasi-experimental design, women exposed to the World Trade Center attacks during pregnancy were followed, along with their offspring. This research focused on PTSD and physiological stress reactivity in the wake of this human-made disaster (Yehuda, 2002; Yehuda et al., 2005). Maternal PTSD symptoms were associated with lower infant cortisol concentrations, with most pronounced effects in their third trimester (Yehuda et al., 2005). Toddlers whose mothers were exposed to Iowa floods during pregnancy demonstrated increased cortisol reactivity to a separation. Higher subjective distress was linked with greater HPA axis reactivity for girls only, and more pronounced effects were associated with later term exposure (Yong Ping et al., 2015). Prenatal stress effects were also noted earlier in gestation, with higher self-reported maternal anxiety at 12-22 weeks predicting child HPA axis alterations. Female offspring only exhibited depression in association with hyporeactivity (Van den Bergh, Van Calster, Smits, Van Huffel, \& Lagae, 2008). In the short term, stress is expected to produce an increased HPA axis response that translates into higher cortisol concentrations, yet the HPA axis downregulates after chronic periods of elevated stress (Gunnar \& Vazquez, 2001). Child stress reactivity is associated with negative emotionality (e.g., fear/ behavioral inhibition; Perez-Edgar et al., 2008), which can be measured via behavioral and physiological indicators (e.g., cortisol), and has been examined in conjunction with a spectrum of maternal prenatal symptoms.

A number of studies indicated associations between maternal anxiety and depression during pregnancy and infant negative emotionality as well as dysregulation. Mothers with higher prenatal emotional stress were more likely to have infants lower in fearfulness (Mohler, Parzer, Brunner, Wiebel, \& Resch, 2006). This diminished fear was interpreted as potential behavioral risk, possibly contributing to externalizing disorders, such as attention-deficit/hyperactivity disorder (ADHD; Mohler et al., 2006). Maternal anxiety during pregnancy was associated with poor infant self-regulation, likely setting the stage for later behavioral and emotional difficulties (van den Heuvel, Johannes, Henrichs, $\&$ Van den Bergh, 2015). In the Davis et al. (2007) study, prenatal anxiety and depression averaged across pregnancy were both significantly correlated with infant negative reactivity. Della Vedova (2014) obtained somewhat divergent results controlling for socioeconomic and partner/relationship factors in predicting difficult temperament, a construct reflecting high negative emotionality. Prenatal depression and state anxiety in the postnatal periods emerged as independent predictors (Della Vedova, 2014).

Whereas late-term effects of stress exposure are thought to interfere with critical steps in fetal HPA axis development, early gestation effects likely result from cortisol impacting cell migration and interacting with additional pathways (e.g., serotonin signaling pathway) involved in brain development (Beijers, Buitelaar, \& de Weerth, 2014). Recent reviews have noted consistent links between exposure to prenatal stress and compromised neurodevelopment (e.g., neurogenesis; Antonelli, Pallares, Ceccatelli, \& Spulber, 2016; Fatima, Srivastav, \& Mondal, 2017). Stress-related fetal programming research in humans is limited by its correlational nature and reliance on quasi-experimental designs that inherently lack internal validity afforded by the animal models, with the latter serving to further inform these connections.

Animal models of prenatal stress exposure. Investigations of prenatal stress effects in animals provide an opportunity to directly manipulate key parameters (i.e., frequency, severity, and duration) of stress induction procedures, such as exposure to novel environments, subcutaneous injections of saline, restraint, and predator proximity. Injections of synthetic glucocorticoids have also been utilized to induce conditions that parallel high levels of physiological stress reactivity. These exposures impact the developing fetus, altering offspring neurobiology and behaviors into adulthood (Table 2).

A widely used restraint stress procedure resulted in anxiety-like behavior (decreased time spent in open arms of the elevated plus maze) for prenatally stressed males, with downregulation of glucocorticoid receptors described as a potential mechanism behind these effects and long-term HPA axis alterations (Maccari et al., 2003). Another prenatal stress paradigm involves the use of electric shock as an analogue for human trauma exposure (Golub, Kaufman, Campbell, Li, \& Donald, 2006). Prenatally stress-exposed offspring demonstrated increased duration and frequency of ultrasonic calls (sign of distress) during separation from mothers and spent less time in open arms of the elevated plus maze, compared to controls. Another stress induction manipulation relies on a forced swim test in the physical stress condition, with the psychological stress group observing those experiencing physically stressful conditions. Female, but not male, rat offspring exposed to both stress conditions demonstrated a decreased number of entrances into open arms of the elevated plus maze indicative of anxiety, relative to controls (Nazeri et al., 2015). Abe at al. (2007) induced psychological stress in pregnant rats during the last trimester of gestation by having animals observe an electric shock administration procedure. In comparison with control animals, exposed male offspring showed enhanced emotionality in an open field test, depression-like behavior in a forced swim test, and increased HPA axis activity (higher basal plasma corticosterone levels). In nonhuman primates, administration of dexamethasone resulted in an exaggerated corticosterone response to a mild stressor (blood sampling) for the offspring of mothers who received the highest dose (de Vries et al., 2007). In this paradigm, there is no environmental exposure to stress per se; however, the synthetic glucocorticoid administration is intended to mimic stress exposure effects, specifically HPA axis reactivity. Although this approach in a sense provides a "short cut" eliminating the need for an exposure manipulation, it does not reflect complexities of the physio- 
logical stress response, which may also involve dampening of HPA axis reactivity with prolonged exposure.

Thus, prenatal stress has been shown to significantly alter offspring development across human and animal studies, with a range of physiological and behavioral effects. Whereas animal studies suggest primarily anxiety-like behavioral effects, human outcomes were more varied, with some indication of risk for externalizing symptoms (Mohler et al., 2006). Prominent late-gestation effects were reported (e.g., Yehuda et al., 2005) and suggest disruption of fetal HPA axis development, yet early gestational impact of stress was noted as well (Golub et al., 2016). Crews (2010) argued neuronal and behavioral plasticity, or the genotype's ability to produce variable phenotypes in response to environmental inputs, peaks during embryonic development. Thus, early and later term gestational exposure to stress appears to impact behavioral phenotypes related to temperament, albeit via different developmental pathways. Sex differences were documented (e.g., Nazeri et al., 2015); however, a consistent pattern has not emerged. Further study is required in part because females have not always been included. Epigenetic mechanisms are critical to connections between prenatal stress and subsequent behavioral/temperament development. We now turn to the emerging literature demonstrating epigenetic processes play a key role in the intergenerational transmission of stress-related risk, conferring environmental adversity to the offspring.

\section{Prenatal stress exposure: Epigenetic effects}

Human studies. Consistent with the environmental epigenetics perspective, multiple studies indicate that epigenetic processes, DNA methylation in particular, provide a critical bridge between prenatal stress exposure, offspring brain development, and shifts in physiology/behavior relevant to temperament. Maternal depression and anxiety during pregnancy were associated with increased infant methylation of $\mathrm{NR3Cl}$, which predicted higher infant salivary cortisol stress response (Oberlander et al., 2008). Maternal pregnancy-related anxiety was also positively associated with infant $\mathrm{NR} 3 \mathrm{Cl}$ methylation (Hompes et al., 2013). There is some indication of sex differences in the $\mathrm{NR} 3 \mathrm{Cl}$ stress-related methylation shifts. Methylation levels were elevated as a function of prenatal stress for female, but not male, infants, and increased methylation was positively associated with fearfulness for females only (Ostlund et al., 2016). Methylation of the serotonin transporter gene (solute carrier family C6, member 4 [SLC6A4]) was also affected by neonatal intensive care unit-related stress. Increased methylation of the SLC6A4 gene was noted for preterm, compared to full-term, infants. SLC6A4 methylation status was negatively correlated with mother report of infant duration of orienting and approach for the preterm infants only (Montirosso et al., 2016). However, $N R 3 C 1$ and $S L C 6 A 4$ are not the only genomic conduits of prenatal stress effects, and a recent review implicated altered expression of 31 genes in prenatal origins of anxiety-like behavior (Nieto, Patriquin, Nielsen, \& Kosten, 2016). Perhaps in the most definitive study to date, Nieratsch- ker et al. (2014) examined the impact of prenatal stress on methylation in human infants, monkeys, and rats, utilizing a genome-wide approach and identifying conserved differentially methylated genes. Across species, 30 genes were associated with differential methylation as a result of prenatal stress. The protein coding the microrchidia homolog (mouse) family $\mathrm{CW}$-type zinc finger protein 1 gene $(M O R C 1)$ was emphasized as a candidate genetic marker of prenatal stress, due to its prior associations with major depressive disorder (Nieratschker et al., 2014). Thus, most human research to date addressed methylation of candidate genes, and the only genome-wide study did not make any connections with behavioral outcomes, which remains to be accomplished in future investigations.

Animal studies. In animal studies, DNA methylation changes explained the influence of maternal prenatal stress on the density of glucocorticoid receptors in the fetal brain (hippocampus in particular), thought to alter sensitivity to stress throughout the life of the offspring (Babenko et al., 2015; Weaver et al., 2004). Restraint stress during gestation resulted in altered CRH DNA methylation in the hypothalamus and increased anxiety-like behavior (e.g., decreased entries into open maze arm; Xu, Sun, Gao, Cai, \& Shi, 2014). Restraint stress during the last 10 days of gestation also resulted in anxiety-like behavior for adult offspring and altered $R L N$ gene expression. Specifically, higher levels of DNA methylation in the promoter region were associated with decreasing mRNA expression in the cortex following exposure. The latter is significant because $R L N$ is responsible for the protein Reelin, which regulates brain development through cytoskeleton modifications. Thus, DNA methylation appears to provide a critical bridge between prenatal stress, offspring brain development, and shifts in physiology/behavior relevant to temperament.

\section{Toxicant Exposure: Pesticides and Environmental Contaminants}

A similar picture emerges for toxicant in utero programming, wherein epigenetic processes link exposure to temperament outcomes. A variety of environmental contaminants, such as lead, dichlorodiphenyltrichloroethane (DDT), polychlorinated biphenyls (PCBs), and bisphenol A (BPA), have been investigated. As noted in a recent review, multiple animal studies and a more limited human literature suggest that prenatal toxicant exposure alters neurodevelopment, setting the stage for potentially risky temperament and symptoms/behavior problems (Antonelli et al., 2016).

\section{Endocrine disruptors (BPA, Vinclozolin, DDT, diethylstilbestrol [DES], PCB): Developmental effects}

Endocrine disruptors are exogenous substances capable of dysregulating the endocrine system primarily by binding to hormone receptors, disrupting cell signaling pathways, and 
Table 3. Examples of in utero toxicant exposure effects: Temperament-related outcomes in human and animal studies

\begin{tabular}{|c|c|c|c|c|}
\hline Exposure & $\begin{array}{l}\text { Significant Developmental/ } \\
\text { Behavioral Outcome }\end{array}$ & Sample Characteristics & $\begin{array}{l}\text { Developmental } \\
\text { Timing of Exposure }\end{array}$ & Reference \\
\hline \multicolumn{5}{|c|}{ Human Studies } \\
\hline \multirow[t]{3}{*}{ BPA } & $\uparrow$ Emotional reactivity, aggressive (males) & $N=198$ (111 female $)$ & Entire pregnancy: measured & Perera et al. (2012) \\
\hline & $\begin{array}{l}\downarrow \text { Anxiety/depression, aggression (temales) } \\
\uparrow A D H D \text { at } 4 \text { years; stronger }\end{array}$ & $N=438(206$ female $)$ & 1 st trimester \& entire & \multirow{2}{*}{ Casas et al. (2015) } \\
\hline & $\begin{array}{l}\text { effect for males \& 3rd } \\
\text { trimester concentrations }\end{array}$ & Measured at $1,4, \& 7$ years & $\begin{array}{l}\text { pregnancy: measured at } 12 \& \\
32 \text { weeks }\end{array}$ & \\
\hline DDT & $\begin{array}{l}\uparrow \text { Total difficulties (emotional, conduct, } \\
\text { hyperactivity, \& peer problems); females } \\
\text { only }\end{array}$ & $\begin{array}{l}N=270(140 \text { female }) \\
\text { Measured at } 7-8 \text { years }\end{array}$ & $\begin{array}{l}\text { Entire gestation: measured at } \\
\text { birth }\end{array}$ & Sioen et al. (2013) \\
\hline DES & $\uparrow$ Depression, anxiety & $\begin{array}{l}N=660(315 \text { female }) \\
\text { Measured in adulthood }\end{array}$ & $\begin{array}{l}\text { 1st-3rd trimesters: treatment } \\
6-35 \text { weeks }\end{array}$ & Vessey et al. (1983) \\
\hline \multirow[t]{2}{*}{ PCB } & $\uparrow$ Impulsivity & $\begin{array}{l}N=293 \text { (male } \& \text { female) } / n=173 \\
\text { nonexposed; } n=40 \text { (lower, middle, \& } \\
\text { upper exposure groups) }\end{array}$ & $\begin{array}{l}\text { Entire pregnancy: measured } \\
\text { at birth }\end{array}$ & Stewart et al. (2005) \\
\hline & $\uparrow$ ADHD symptoms & $\begin{array}{l}\text { Measured at } 8 \& 9.5 \text { years } \\
N=607(288 \text { female }) \\
\text { Measured at } 7-11 \text { years }\end{array}$ & $\begin{array}{l}\text { Entire pregnancy: measured } \\
\text { at birth }\end{array}$ & Sagiv et al. (2010) \\
\hline \multirow[t]{3}{*}{ Lead } & $\begin{array}{l}\uparrow \text { Anxious/depressed, withdrawn, sleep } \\
\text { problems, somatic problems, aggressive, \& } \\
\text { destructive behavior }\end{array}$ & $\begin{array}{l}N=577 \text { (males \& females) } \\
\text { Measured at } 3 \text { years }\end{array}$ & $\begin{array}{l}\text { Entire pregnancy: measured } \\
\text { at birth }\end{array}$ & $\begin{array}{l}\text { Factor-Litvak et al. } \\
\text { (1999) }\end{array}$ \\
\hline & $\begin{array}{l}\uparrow \text { Adolescent delinquent \& antisocial } \\
\text { behaviors }\end{array}$ & $\begin{array}{l}N=195(\text { males } \& \text { female }) \\
\text { Measured } 15-17 \text { years }\end{array}$ & Early pregnancy: 1 st trimester & Dietrich et al. (2001) \\
\hline & $\begin{array}{l}\uparrow \text { Hyperactivity, emotional problems (males } \\
\text { only) }\end{array}$ & $\begin{array}{l}N=270(140 \text { female }) \\
\text { Measured at } 7-8 \text { years }\end{array}$ & $\begin{array}{l}\text { Entire pregnancy: measured } \\
\text { at birth }\end{array}$ & Sioen et al. (2013) \\
\hline
\end{tabular}


$\uparrow$ Activity at 12 months (stronger for males)

$\uparrow$ Inattention, withdrawal

$\uparrow$ Total problems at 24 \& 36 month

$\uparrow$ Disrupted activity level (males only)
$N=206$ (107 females)

Measured at $12,24, \& 36$ months

$n=6-9 /$ condition (males \& females)

Measured at 1 year
Entire gestation: measured at birth

Periconceptional/postnatal: until PND10
Vermeir \& Viaene (2007)

Leasure et al. (2008)

\begin{tabular}{|c|c|c|c|c|}
\hline \multicolumn{5}{|c|}{ Animal Studies } \\
\hline BPA & $\begin{array}{l}\uparrow \text { Anxiety-like behaviors } \\
\text { (females)/ } \downarrow \text { males } \\
\downarrow \text { Chasing behavior (males) } \\
\uparrow \text { Aggression }\end{array}$ & $\begin{array}{l}n=16-30 \text { rats/condition (9-14 female) } \\
\text { Measured at PND30-40 }\end{array}$ & $\begin{array}{l}\text { Entire gestation: administered } \\
\text { until birth }\end{array}$ & $\begin{array}{l}\text { Kundakovic et al. } \\
\text { (2013) }\end{array}$ \\
\hline Vinclozolin & $\begin{array}{l}\downarrow R \text { Response extinction following } \\
\text { reinforcement withdrawal (males) } \\
\uparrow \text { Immature social play, hyperactivity-like } \\
\text { behaviors; effect stronger for males }\end{array}$ & $\begin{array}{l}n=14-20 \text { rats/condition ( } 7-10 \text { female) } \\
\text { Measured at PND60-80 } \\
n=12-22 \text { rats/condition (6-11 female) } \\
\text { Measured at PND22 \& } 34\end{array}$ & $\begin{array}{l}\text { Perinatal: E14-PND3 } \\
\text { Perinatal: E14-PND3 }\end{array}$ & $\begin{array}{l}\text { André \& Markowski } \\
(2006) \\
\text { Colbert et al. (2005) }\end{array}$ \\
\hline DES & $\uparrow$ Aggression & $\begin{array}{l}n=16-26 \text { mice /condition (12-13 } \\
\text { female) } \\
\text { Measured at PND60-90 }\end{array}$ & Midgestation: E11-17 & Palanza et al. (1999) \\
\hline PCB & $\uparrow$ Passive avoidance test deficits (males) & $\begin{array}{l}n=10-12 \text { rats/condition ( } 5-6 \text { female) } \\
\text { Measured at PND60 }\end{array}$ & Perinatal: E15-19, PND1-21 & Colciago et al. (2009) \\
\hline Mercury & $\begin{array}{l}\uparrow \text { Responding during the reinforcement } \\
\text { omission trials }\end{array}$ & $\begin{array}{l}n=3-8 \text { rats/condition (males } \& \\
\text { females) } \\
\text { Measured in adulthood }\end{array}$ & $\begin{array}{l}\text { Periconceptional/postnatal: } \\
\text { until PND16 }\end{array}$ & Reed et al. (2006) \\
\hline
\end{tabular}

Note: Sample characteristics are provided in a different manner for human and animal studies, because of differences in design and presentation format. For human correlational studies, the overall number of participants $(N)$ is presented, whereas the number of participants per condition $(n)$ is indicated for animal experimental investigations. Additional information concerning numbers of male versus female participants is provided, when both sexes were included/specified. Developmental timing of exposure indicators vary across studies. For humans, the timing is generally provided in terms of the number of gestational weeks, although in some instances measures are just taken at birth, or not specified beyond a particular trimester or month. For animals, these indicators are more specific, counting embryonic or postnatal days. ( $\uparrow$ ) Increases in temperament-related behaviors/displays; $(\downarrow)$ decreases in temperament-related behaviors; BPA, bisphenol A; ADHD, attention-deficit/hyperactivity disorder; DDT, dichlorodiphenyltrichloroethane; DES, diethylstilbestrol; PCB, polychlorinated biphenyls; E, embryonic day; PND, postnatal day. 
inhibiting hormone synthesis. These contaminants interfere with physical development, especially of the reproductive and central nervous systems, which translates into alterations in emotional functioning, attentional, and behavioral regulation components of temperament. Epigenetic mechanisms are critical to the profound effects of endocrine disruptors on developmental cascades, as exposure to these toxic agents introduces changes in gene expression (Manikkam, GuerreroBosagna, Tracey, Haque, \& Skinner, 2012). Existing studies with humans indicate consistent links between gestational endocrine disruptor exposure and behavioral shifts, albeit typically without addressing epigenetics.

Human studies. Prenatal BPA exposure and child behavior problems were linked, controlling for postnatal BPA effects, with a sex-dependent pattern of results (Perera et al., 2012). Boys with greater exposure received elevated emotionally reactive and aggressive ratings (Table 3). Among girls, higher exposure was associated with significantly lower anxious/depressed and aggressive scores. Casas et al. (2015) examined programming effects of prenatal BPA exposure and reported increased ADHD symptoms at 4 years of age.

Stronger associations were observed for boys, compared to girls, with greater third, rather than with first, trimester effects. These results suggest sex-specific mechanisms of BPA exposure may in part be determined by the timing of prenatal effects.

DDT is arguably the most widely used agricultural insecticide, with adverse health effects. Technical grade DDT includes a number of impurities and its breakdown product dichlorodiphenyldichloroethylene (DDE) is able to cross the placenta and pass into breast milk (You et al., 1999). We located one study linking DDE exposure and emotional/behavioral indicators. Sioen et al. (2013) reported a significant positive association between prenatal DDE exposure and overall emotional/behavioral difficulties for 7- to 8-year-old girls, but not boys.

DES, an estrogenic drug, was wrongly administered to millions of pregnant women (until 1971 in the United States) in an effort to prevent spontaneous abortions and promote healthy development (Swan \& vom Saal, 2001). In humans, adverse effects of DES exposure were documented for the women as well their offspring (Giusti, Iwamoto, \& Hatch, 1995; Greenberg et al., 1984). Most relevant with respect to temperament, adult offspring exposed to DES during most of gestation were more likely to experience symptoms of depression and anxiety, along with other psychiatric concerns, compared to those not exposed in utero (Vessey, Fairweather, Norman-Smith, \& Buckley, 1983).

PCBs are the most common among endocrine disruptors (Casati, Sendra, Sibilia, \& Celotti, 2015) because of their extensive use in dielectric and coolant fluids, no longer produced due to their toxicity and persistence. Chronic exposure to low levels of PCBs is of particular concern given evidence of cumulative endocrine, metabolic, and behavioral effects (Casati et al., 2015; Colciago et al., 2009; Stewart et al., 2008). Disruption of neurodevelopment for prenatally exposed offspring was associated with manifestations relevant to temperament: decreased novelty preference in infancy (Boucher, Bramoullé, Djebbari, \& Fortin, 2014) and higher ADHD problems for school-age children (Sagiv et al., 2010).

Although most often examined in the context of physical development and cognitive functioning, associations with behavioral changes reflective of temperament were also noted for all of the considered contaminants.

Animal studies. The animal literature speaks to similar links between toxicant exposures and behavioral/temperament outcomes, indicating that prenatal effects can be transgenerational in nature. BPA exposure induced largely sexually dimorphic behavioral changes in young adult mice (Table 3 ). Chasing behavior in males was reduced to levels similar to females. Anxiety-like behaviors in an open field increased in females, decreasing in males, with elevations in aggression noted for both sexes as a result of prenatal BPA exposure (Kundakovic et al., 2013).

André and Markowski (2006) examined learning behavior following perinatal exposure to vinclozolin, an endocrine disruptor with antiandrogenic effects. Acquisition of a reinforced response was not affected. However, males exposed to vinclozolin perinatally did not demonstrate any response extinction once food was no longer available, suggesting an alteration in sensitivity to reward/approach. In addition, Colbert et al. (2005) demonstrated an effect of perinatal vinclozolin exposure on social behaviors. Males exposed during gestation and lactation demonstrated an increase in social play marked by more frequent initiation behavior, interpreted as a sign of hyperactivity and developmental delay.

Behavioral consequences of DES exposure were characterized in animal studies investigating developmental effects, also using this compound as a positive control. (Palanza, Parmigiani, Liu, and vom Saal (1999) reported that prenatal exposure to DDT and DES increased the frequency of same-sex aggression for male and female mice, at low doses only. There was a difference in DDT and DES effects, as males exposed to the lowest DDT dose only exhibited less intense attacks than controls.

PCB exposure in rodents has been largely studied perinatally, with animals affected during lactation as well as gestation, because this time frame corresponds to a critical brain sex differentiation period (Colciago et al., 2009). Perinatal PCB exposure was shown to result in a dimorphic pattern of hypothalamic testosterone activating enzyme expression. A learning deficit on a passive avoidance test was also noted, as exposed males failed to develop an increased latency to enter an area associated with a previously delivered foot shock (Colciago et al., 2009). This apparent decrease in sensitivity to cues of danger represents an aspect of fearful reactivity and reflects PCB effects on temperament development.

Prenatal endocrine disruptor exposure resulted in temperament development alterations, including increased anxietylike and playful/aggressive behavior. There is also indication of sex differences. Learning paradigms are not directly applicable to temperament; however, sensitivity to cues of re- 
ward versus punishment can be a function of relative approach and avoidance activation. Both neurobehavioral systems appear compromised by prenatal exposure to androgen disruptors. Before we consider epigenetic mediation of environmental toxicant in utero effects, other contaminant exposures should be noted.

\section{Lead and mercury prenatal exposure: Developmental effects}

Human studies. In humans, prenatal exposure effects of lead have been demonstrated into adolescence, with more frequent/severe behavior problems, delinquent and antisocial behaviors, considering multiple covariates (Dietrich, Ris, Succop, Berger, \& Bornschein, 2001). Sioen et al. (2013) reported a significant positive association between prenatal lead exposure and hyperactivity for 7- to 8-year-old children, controlling for other contaminants. Prenatal lead exposure effects included increased activity and deficits in focused attention at 12 months, as well as greater behavioral difficulties in the toddler period (Vermeir \& Viaene, 2002-2007). Lead exposure was associated with compound effects, acting in concert with prenatal substance use. Specifically, the risk for ADHD increased for children prenatally exposed to nicotine along with lead (Froehlich et al., 2009).

Thus, in utero lead exposure in humans has been well characterized in terms of contributing to impulsivity/approach aspects of temperament and difficulties with attention/regulation.

Animal studies. Animal studies offer more conclusive links, examining prenatal mercury as well as other contaminant exposures, noting potential sex differences and potency of lowdose exposures. Perinatal methylmercury (derived from mercury) exposure has been studied primarily in tandem with $\mathrm{PCB}$, as these contaminants are typically traced to the same source (Newland \& Paletz, 2000). Learning-related effects of prenatal exposure have been the main focus of research, with some findings relevant to temperament (Table 3). Specifically, prenatal mercury exposure in rats resulted in elevated rates of responding in an operant learning procedure, even when selenium intended to ameliorate adverse effects of methylmercury was administered to the animals. High rates of responding during reinforcement omission trials indicated prenatal mercury exposure enhanced the efficacy of reinforcement (Reed \& Newland, 2007), potentially leading to manifestations of impulsivity and/or reward dependency relevant to temperament. Male, but not female, mice demonstrated decreased spontaneous motor activity, yet increased amphetamine-induced motor activity, and altered dopamine levels. With respect to prenatal lead exposure, related sequelae were consistently more notable in animals assigned to the low-dose condition (Leasure et al., 2008).

The range of prenatal contaminant effects is extensive, with a number of behavioral consequences relevant to temperament. Animal studies demonstrate fearful/anxious behaviors, disruptions of social behavior, and reinforcement learning in exposed animals, with human research showing an increased risk for ADHD and behavior problems more broadly (Dietrich et al., 2001; Kundakovic et al., 2013; Piedrafita, Erceg, Cauli, \& Felipo, 2008). This pattern of results implicates reactivity (e.g., reward/approach orientation vs. fearfulness/behavioral inhibition) and regulation (i.e., deficits in emotional/behavioral control), indicating temperament is impacted by maternal contact with toxicants during gestation. There is evidence that male offspring may be more affected (Andre \& Markowski, 2006; Colciago et al., 2009), and lower concentrations of contaminants, as opposed to higher levels of exposure, may be more detrimental in some instances (Leasure et al., 2008; Palanza, Parmigiani, \& vom Saal, 2001). Critical shifts in the epigenome were shown to occur as a function of prenatal environmental contaminant exposure.

\section{Environmental contaminants: Epigenetic effects}

Human studies. A recent review considered 23 studies linking environmental contaminant exposure and offspring DNA methylation changes to autism spectrum disorders (Keil \& Lein, 2016). Consistent with the environmental epigenetics framework, methylation changes were described as mediating environmental risk and conferring these effects onto behavioral phenotypes via alterations in gene expression and brain development. Shifts in the methylome and brain development that result from in utero contaminant exposures and contribute to risk for autism spectrum disorders can also be expected to affect temperament.

Animal studies. Animal studies provide additional insights into epigenetics bridging toxicant exposure in the womb and behavioral effects. Studies using BPA and vinclozolin provide evidence of transgenerational inheritance via permanent alterations in the epigenome of the germ line (Anway \& Skinner, 2008). Skinner et al. (2008) reported a sexually dimorphic disruption of transcription in the hippocampus and amygdala, and associated behavioral effects. Third-generation female rats from the vinclozolin-exposed line exhibited increased anxiety-like behaviors, whereas male rats displayed a decrease. Crews et al. (2007) examined rat mate preference in a task that engaged multiple brain regions including amygdala, hippocampus, cingulated cortex, and anterior hypothalamus. Third-generation vinclozolin lineage males were less attractive to females, reflecting a differential mate preference. This study offers evidence of epigenetic transgenerational inheritance with evolutionary implications, as exposure effects translated into methylome shifts, in turn producing changes critical to reproductive success.

Luo et al. (2014) investigated histone modifications as the mediator of lead-related effects in rats, linking prenatal exposure to ADHD-like behaviors. A dose-response relationship was observed, as increased lead exposure resulted in greater locomotor activity, an analogue of human hyperactivity. Histone acetylation was significantly increased in the hippocampus as a result of chronic lead exposure, supporting the role of this epi- 
Table 4. Examples of in utero substance/psychotropic Medication exposure effects: Temperament-related outcomes in human and animal studies

\begin{tabular}{|c|c|c|c|c|}
\hline Exposure & $\begin{array}{l}\text { Significant Developmental/ } \\
\text { Behavioral Outcome }\end{array}$ & Sample Characteristics & $\begin{array}{l}\text { Developmental } \\
\text { Timing of Exposure }\end{array}$ & Reference \\
\hline \multicolumn{5}{|c|}{ Human Studies } \\
\hline \multirow[t]{3}{*}{ Alcohol } & $\begin{array}{l}\uparrow \text { Cortisol reactivity, heart rate, \& negative } \\
\text { affect }\end{array}$ & $\begin{array}{l}N=55(21 \text { female }) \\
5-7 \text { months }\end{array}$ & $\begin{array}{l}\text { Entire pregnancy: measured at } \sim 28 \\
\text { weeks, } 6 \text { months postpartum }\end{array}$ & Haley et al. (2006) \\
\hline & $\uparrow$ Difficult temperament & $\begin{array}{l}N=1330(625 \text { female }) \\
\text { Measured at } 6 \text { months }\end{array}$ & $\begin{array}{l}\text { Early pregnancy }(0-6 \text { weeks }) \text { : } \\
\text { measured at } 17 \text { weeks }\end{array}$ & Alvik et al. (2011) \\
\hline & $\begin{array}{l}\uparrow \text { Emotional withdrawal, conception } \\
\text { exposure only } \\
\downarrow \text { Activity level, prenatal exposure only }\end{array}$ & $\begin{array}{l}N=144(67 \text { female }) / 92 \\
\text { exposed } \\
\text { Measured at } 6.5 \text { months }\end{array}$ & $\begin{array}{l}\text { Perinatal/postpartum: measured at } \\
\text { about } 24 \text { weeks, } 1 \text { month } \\
\text { postpartum }\end{array}$ & Molteno et al. (2014) \\
\hline \multirow[t]{2}{*}{ Nicotine } & $\begin{array}{l}\downarrow \text { Response in the anterior cingulate cortex } \\
\text { during a conflict task engaging executive } \\
\text { functions }\end{array}$ & $\begin{array}{l}N=178 / 38 \text { exposed }(104 \\
\text { female) } \\
\text { Measured at } 25 \text { years }\end{array}$ & $\begin{array}{l}\text { Entire pregnancy: measured } \\
\text { postpartum }\end{array}$ & Holz et al. (2014) \\
\hline & $\uparrow$ Temperamental anger & $\begin{array}{l}N=611 / 366 \text { exposed }(370 \\
\text { female })\end{array}$ & $\begin{array}{l}\text { Entire pregnancy: measured in 3rd } \\
\text { trimester }\end{array}$ & Liu et al. (2011) \\
\hline \multirow[t]{2}{*}{ Cannabis } & $\uparrow$ Depression, 1st \& 3rd trimester effects & $\begin{array}{l}\text { Measured at } 38-48 \text { years } \\
N=633(317 \text { female }) \\
\text { Measured at } 10 \text { years }\end{array}$ & $\begin{array}{l}\text { 1st \& 3rd trimesters: measured at } \\
\text { 3rd \& 7th month prenatally }\end{array}$ & Gray et al. (2005) \\
\hline & $\uparrow$ Aggression, females only & $\begin{array}{l}N=4077(2060 \text { female }) / 88 \\
\text { exposed } \\
\text { Measured at } 18 \text { months }\end{array}$ & $\begin{array}{l}\text { Early pregnancy: measured in } 1 \text { st } \\
\text { trimester }\end{array}$ & El Marroun et al. (2011) \\
\hline \multirow[t]{2}{*}{ Cocaine } & $\begin{array}{l}\uparrow \text { Behavior problems only for } \uparrow \text { reactive } \\
\text { exposed children, with low maternal warmth }\end{array}$ & $\begin{array}{l}N=220(112 \text { females }) / 119 \\
\text { exposed } \\
\text { Measured at } 7,13, \& 18 \\
\text { months }\end{array}$ & $\begin{array}{l}\text { Entire pregnancy: measured } 4-8 \\
\text { weeks postpartum }\end{array}$ & Eiden et al. (2011) \\
\hline & $\begin{array}{l}\uparrow \text { Hyperactivity, with any prenatal exposure; } \\
\text { males only }\end{array}$ & $\begin{array}{l}N=473(50 \text { females }) / 204 \\
\text { exposed } \\
\text { Measured at } 6-7 \text { years }\end{array}$ & $\begin{array}{l}\text { Entire pregnancy: measured } \\
\text { throughout pregnancy \& at birth }\end{array}$ & $\begin{array}{l}\text { Delaney-Black et al. } \\
\text { (2004) }\end{array}$ \\
\hline \multirow[t]{2}{*}{ SSRI } & $\begin{array}{l}\downarrow \text { Motor, social-emotional, \& adaptive } \\
\text { behavior }\end{array}$ & $\begin{array}{l}N=83(59 \text { females }) / 31 \\
\text { exposed } \\
\text { Measured at } 10 \text { months }\end{array}$ & $\begin{array}{l}\text { Entire pregnancy: measured at } 36 \\
\text { weeks }\end{array}$ & Hanley et al. (2013) \\
\hline & $\downarrow$ Early evening basal cortisol levels & $\begin{array}{l}N=76(42 \text { female }) / 31 \\
\text { exposed } \\
\text { Measured at } 3 \text { months }\end{array}$ & $\begin{array}{l}\text { Entire pregnancy: measured at } \\
\text { 2nd trimester \& birth }\end{array}$ & Oberlander et al. (2008) \\
\hline
\end{tabular}


$\uparrow$ Fetal motor activity at $15-19$ \& $27-29$ weeks, standard/high doses only

$\downarrow$ Behavioral pain responses

$\uparrow$ Parasympathetic cardiac modulation

$\uparrow$ Serum CBG levels, following vaginal delivery only

$\uparrow \mathrm{CBG}$ levels linked to $\downarrow$ diurnal change in cortisol
$N=263(136$ female $) / 133$

exposed

Measured at 15-19,

27-29, \& 38 weeks

$N=61$ (males \& females) $/ 38$ exposed

Measured at 2nd day

$N=65$ (35 females)/exposed

$n=25$

Measured at birth
Entire pregnancy: measured at 15-19 weeks \& birth

Entire pregnancy: measured at 2nd trimester \& birth

Entire pregnancy: measured at

2nd trimester \& birth
Mulder et al. (2011)

Oberlander et al. (2002)

Pawluski et al. (2012)

\begin{tabular}{|c|c|c|c|c|}
\hline \multicolumn{5}{|c|}{ Animal Studies } \\
\hline \multirow[t]{4}{*}{ Alcohol } & $\uparrow$ ADHD-like behaviors (males) & $\begin{array}{l}n=8 \text { rats/condition (males } \\
\text { only) }\end{array}$ & Mid-late gestation: E8-20 & Atalar et al. (2016) \\
\hline & $\uparrow$ Aggressive play behavior (males) & $\begin{array}{l}\text { Measured at PND30-55 } \\
n=16 \text { rats/condition (males } \\
\text { only) }\end{array}$ & Entire gestation: E1-PND1 & Hamilton et al. (2014) \\
\hline & $\uparrow$ Anxiety-like behavior (males) & $\begin{array}{l}\text { Measured at PND90 } \\
n=6 \text { rats/condition (males } \\
\text { only) }\end{array}$ & $\begin{array}{l}\text { Late gestation, shortly after birth: } \\
\text { 3rd trimester equivalent, PND3-5 }\end{array}$ & Baculis et al. (2015) \\
\hline & $\begin{array}{l}\uparrow \text { CORT in restrain stress task (males) } \\
\uparrow A C T H \text { in restrain stress task (females) } \\
\uparrow \text { Anxiety-like behavior (males) } \\
\downarrow \text { Anxiety-like behavior (females) }\end{array}$ & $\begin{array}{l}\text { Measured at PND36-50 } \\
n=25-34 \text { rats/condition } \\
(12-17 \text { female }) \\
\text { Measured at PND60-120 }\end{array}$ & Early gestation: E7 & Wieczorek et al. (2015) \\
\hline \multirow[t]{3}{*}{ Nicotine } & $\uparrow$ Hyperactivity/impulsivity & $\begin{array}{l}n=55-58 \text { (males only) } \\
\text { Measured between PND25 \& } \\
\text { PND50 }\end{array}$ & $\begin{array}{l}\text { Entire gestation: } 3 \text { weeks before } \\
\text { mating till birth }\end{array}$ & Schneider et al. (2012) \\
\hline & $\uparrow$ Self-administration of methamphetamine & $\begin{array}{l}n=18-19(10 \text { females }) \\
\text { Measured at PND90 }\end{array}$ & Mid-late gestation: E8-21 & Lacy et al. (2014) \\
\hline & $\begin{array}{l}\uparrow \text { Anxiety-like behavior } \\
\uparrow \text { Impulsivity }\end{array}$ & $\begin{array}{l}N=5-6 \text { (about half female) } \\
\text { Measured at PND21-22 }\end{array}$ & Perinatal: E15-PND18 & Lee et al. (2016) \\
\hline Cannabis & $\begin{array}{l}\uparrow \text { USVs/distress (males) } \\
\downarrow \text { Social interaction (males) } \\
\uparrow \text { Anxiety-like behavior (males) }\end{array}$ & $\begin{array}{l}n=12-26 \text { rats/condition } \\
\text { (males only) } \\
\text { Measured at PND12, PND35, } \\
\& \text { PND80 }\end{array}$ & Perinatal: E15-PND9 & Trezza et al. (2008) \\
\hline Cocaine & $\uparrow$ Hyperphonation-like quality in USVs & $\begin{array}{l}n=34-50 \text { rats/condition } \\
(17-25 \text { female }) \\
\text { Measured at PND5 }\end{array}$ & Entire gestation: E1-20 & Zeskind et al. (2014) \\
\hline
\end{tabular}


Table 4 (cont.)

\begin{tabular}{|c|c|c|c|c|}
\hline Exposure & $\begin{array}{c}\text { Significant Developmental/ } \\
\text { Behavioral Outcome }\end{array}$ & Sample Characteristics & $\begin{array}{l}\text { Developmental } \\
\text { Timing of Exposure }\end{array}$ & Reference \\
\hline & $\begin{array}{l}\uparrow U S V \text { s/distress, PND25 only } \\
\uparrow \text { Social interaction, PND25 \& PND35 only }\end{array}$ & $\begin{array}{l}n=18-26 \text { mice/condition } \\
\text { (males only) } \\
\text { Measured at PND25, PND35, } \\
\& \text { PND45 }\end{array}$ & Mid-late gestation: E8-17 & Kabir et al. (2014) \\
\hline & $\begin{array}{l}\downarrow \text { Fear extinguishing } \\
\uparrow \text { Freezing response }\end{array}$ & $\begin{array}{l}n=8-9 \text { mice/condition } \\
\text { (males only) } \\
\text { Measured in adult animals }\end{array}$ & Mid-late gestation: E8-17 & Kabir et al. (2013) \\
\hline & $\begin{array}{l}\uparrow \text { Anxiety-like behavior } \\
\downarrow \text { Social play, self-grooming }\end{array}$ & $\begin{array}{l}n=10-12 \text { rats/condition } \\
\text { (males only) } \\
\text { Measured at PND28-35 \& } \\
\text { PND87-177 }\end{array}$ & Mid-late gestation: E11-PND1 & Olivier et al. (2011) \\
\hline & $\uparrow$ Aggressive behavior (males) & $\begin{array}{l}n=20 / \text { condition } \\
(10 \text { females }) \\
\text { Measured at PND28-31 \& } \\
\text { PND49-52 }\end{array}$ & Entire gestation: E1 until birth & Svirsky et al. (2016) \\
\hline & $\begin{array}{l}\downarrow \text { Anxiety \& depression-like behavior } \\
\text { (females) }\end{array}$ & $\begin{array}{l}n=16-17 / \text { condition } \\
\text { (females only) } \\
\text { Measured at PND73-83 }\end{array}$ & Perinatal: E15-PND12 & McAllister et al. (2012) \\
\hline & $\begin{array}{l}\downarrow \text { Impulsivity (males) } \\
\uparrow \text { Depression-like behavior (females) }\end{array}$ & $\begin{array}{l}n=22-31 / \text { condition }(9-14 \\
\text { female) } \\
\text { PND30 \& } 70 \text { (females) } \\
\text { PND40 \& } 70 \text { (males) }\end{array}$ & Perinatal: E1-PND 21 & Lisboa et al. (2007) \\
\hline
\end{tabular}

Note: Sample characteristics are provided in a different manner for human and animal studies, because of differences in design and presentation format. For human correlational studies, the overall number of participants $(N)$ is typically presented. When indicated, the number of participants in the exposed subsample $(n)$ is also included. The number of participants per condition $(n)$ is always indicated for animal experimental investigations. Additional information concerning numbers of male versus female participants is provided when both sexes were included/specified. Developmental timing of exposure indicators varies across studies. For humans, the timing is provided in terms of the number of gestational weeks, although in some instances measures are just taken at birth, or not specified beyond a particular trimester or month. In animals these indicators are typically more specific, counting embryonic days or postnatal days. ( $\uparrow)$ Increases in temperament-related behaviors/displays; $(\downarrow)$ decreases in temperament-related behaviors/displays; SSRI, selective serotonin reuptake inhibitor; CBG, corticosteroid-binding globulin; ADHD, attention-deficith/hyperactivity disorder; E, embryonic day; PND, postnatal day; CORT, corticosterone; ATCH, adrenocorticotropin hormone; USV, ultrasonic vocalization. 
genetic mechanism as a mediator between toxicant exposure and offspring symptoms. Thus, the Luo et al. (2014) investigation suggests prenatal lead exposure alters a temperamental phenotype associated with developmental psychopathology, namely, activity level, via an epigenetic mechanism. Together, these studies are compelling in pointing to epigenetic mechanisms as the primary vehicle of environmental exposure effects, as changes in the epigenome alter gene expression, with subsequent developmental shifts often related to temperament.

\section{Substance Use and Effects of Psychotropic Medication}

Turning to the substance use/psychotropic medication literature, again there is evidence that environmental exposures alter the epigenome, disrupting brain development and inducing temperament risk for later psychopathology. Epigenetic processes are just now being studied in this context, yet maternal substance use during pregnancy is known to markedly impact offspring development, with public health implications prompting consumption warnings.

\section{Substance (alcohol, tobacco, marijuana, cocaine) use}

Human studies. The hazards of prenatal substance use exposures are well documented. There is a wealth of human research linking in utero exposures and offspring outcomes, including temperament, with some longitudinal studies following affected children into adulthood.

Alcohol passes through the placenta, directly affecting the developing fetus and impacting placental functioning (e.g., Ahluwalia et al., 2000). Fetal brain development effects are considerable, evidenced by population-based estimates indicating that maternal alcohol use during pregnancy was associated with $2.84 \%-4.89 \%$ of intellectual disabilities cases (O'Leary et al., 2013). The range of effects caused by prenatal alcohol exposure in totality is referred to as fetal alcohol spectrum disorders (FASD), associated with deficits in intelligence and adaptive functioning, memory, language, attention/executive functions, and motor skills (e.g., Mattson \& Riley, 1998). Most relevant for this review, prenatal alcohol exposure was linked with temperament development (Table 4). Haley, Handmaker, and Lowe (2006) evaluated infant HPA axis response and heart rate indictors in the context of a social stressor: a Still Face paradigm. Percentage of prenatal drinking days from conception to pregnancy recognition (extending several weeks into gastrulation) was related to increased infant cortisol reactivity, heart rate, and negative affect, controlling for maternal depression and income. In a subsequent study, maternal weekly binge drinking ( $\geq 5$ drinks) during the first 6 weeks of pregnancy predicted infant difficult temperament and sleeping problems, controlling for confounds (Alvik, Torgersen, Aalen, \& Lindemann, 2011). Prenatally alcohol-exposed infants also exhibited increased emotional withdrawal and lower activity level, especially those later diagnosed with FASD (Molteno, Jacobson, Carter, Dodge, \& Jacobson, 2014).
Tobacco use during pregnancy was also implicated in adverse offspring temperament outcomes. Holz et al. (2014) performed functional magnetic resonance imaging, examining novelty seeking and lifetime ADHD symptoms for adults prenatally exposed to tobacco. Participants with a history of in utero exposure exhibited a weaker response in the anterior cingulate cortex to a conflict task engaging the executive attention system, coupled with novelty seeking/approach tendencies. Liu et al. (2011) also studied adults prenatally exposed to maternal tobacco use and demonstrated increased anger proneness.

The main psychoactive component of cannabis, $\Delta^{9}$-tetrahydrocannabinol, is able to cross the placenta during gestation (Hutchings, Gamagaris, Miller, \& Fico, 1989). According to a recent review, chronic/heavy cannabis use during pregnancy appears to disrupt brain maturation, predisposing the offspring to neurodevelopmental disorders (Alpar, Di Marzo, \& Harkany, 2016). Six- and 10-year-old children prenatally exposed to cannabis presented with more frequent/severe externalizing symptoms, impulsivity and hyperactivity in particular (Goldschmidt, Day, \& Richardson, 2000). Chronic maternal marijuana use in the first and third trimesters was associated with offspring depression at 10 years of age (Gray, Day, Leech, \& Richardson, 2005). Sex differences were noted, as prenatally exposed girls (but not boys) exhibited higher aggression and inattention at 18 months of age (El Marroun et al., 2011).

Child behavior problems were examined in the aftermath of prenatal cocaine exposure, with mixed results. Several studies reported significant associations between prenatal cocaine exposure and child behavior problems (Bada et al., 2007; Richardson, Goldschmidt, \& Willford, 2009), yet others did not find direct links (Delaney-Black et al., 2004; Eiden, Granger, Schuetze, \& Veira, 2011).

Thus, prenatal alcohol exposure clearly disrupts neurodevelopment in humans. Nicotine and marijuana programming effects have also been described. Finally, somewhat equivocal findings were reported with respect to maternal cocaine use during pregnancy.

Animal studies. Animal studies inform this literature, suggesting similar differences in the level of developmental impact for the substances examined. Prenatal alcohol effects have been widely studied via animal models, intended to serve as analogues for FASD (Table 4). Atalar, Uzbay, and Karakas (2016) demonstrated ADHD-like behaviors in rats following prenatal alcohol exposure throughout gestation. Exposed pups required more sessions to reach criterion relative to the control group on a reversal learning task, because of difficulty inhibiting a previously reinforced response in favor of an unreinforced/inhibited response. Moderate levels of prenatal exposure across pregnancy achieved through voluntary consumption of ethanol resulted in offspring play behavior changes (e.g., increased wrestling) reflective of aggression (Hamilton et al., 2014).

Increased anxiety-like behavior in rodents was demonstrated across multiple studies considering effects of prenatal ethanol exposure. High ethanol doses (delivered in vapor) 
during the rat equivalent to the human third trimester of pregnancy resulted in anxiety-like behavior (Baculis, Diaz, \& Valenzuela, 2015). Moreover, basolateral amygdala, glutamatergic, and GABAergic synaptic transmission was implicated in the observed behavioral alteration (Baculis et al., 2015). Maternal alcohol treatment limited to very early stages of pregnancy (equivalent to the third week postfertilization in humans) also disrupted brain development (Godin, Poizat, Hickey, Maschat, \& Humbert, 2010) and HPA axis functioning in mice, increasing anxiety-related behaviors (Wieczorek, Fish, O'Leary-Moore, Parnell, \& Sulik, 2015). Sex differences were noted: males showed elevated corticosterone following an alcohol injection, whereas females displayed a blunted adrenocorticotropic response. Anxiety-like behavior declined in exposed female mice, whereas males demonstrated heightened anxiety marked by decreased exploration (Wieczorek et al., 2015). Altering the timing of alcohol administration resulted in different brain malformations and variable patterns of behavioral disruption (Murawski, Moore, Thomas, \& Riley, 2015). Animal models suggest that even moderate levels of prenatal exposure lead to behavioral changes that parallel human symptomatology (Valenzuela, Morton, Diaz, \& Topper, 2012).

In utero exposure to nicotine produced deleterious behavioral effects in rats. Exposed males showed increased hyperactivity (more frequent entries) and impulsivity (increased anticipatory responses; Schneider, Bizarro, Asherson, \& Stolerman, 2012). Increased responding and larger doses of self-administered methamphetamine were interpreted as signs of neurobehavioral changes in the exposed offspring' motivational systems linked with reward and vulnerability to substance use (Lacy, Morgan, \& Harrod, 2014). Nicotine exposure resulted in anxiety-like and impulsive behaviors, reducing exploration and increasing instant reward choices (Lee, Chung, \& Noh, 2016).

Several studies provide evidence of increased hyperactivity and altered emotionality following prenatal cannabinoid exposure, consistent with human research. Exposed rat pups emitted more frequent ultrasonic vocalizations (USVs) indicative of distress and anxiety when removed from the nest (Trezza, Cuomo, \& Vanderschuren, 2008). Adult animals also demonstrated anxiety-like behavior, spending more time in the closed arms of the maze, compared to controls (Trezza et al., 2008). Prenatal cannabinoid exposure is thought to alter offspring emotional functioning via serotonergic and dopaminergic systems (Trezza et al., 2012).

Zeskind and Stephens (2004) examined the impact on prenatal cocaine exposure on distress vocalizations in human infants and rat pups. A shift in the acoustic structure of rodent USVs subsequent to in utero cocaine exposure paralleled hyperphonation (high-pitched cry sound) observed in humans. Prenatal cocaine exposure effects on social interactions and vocalizations were studied in mice (Kabir, Kennedy, Katzman, Lahvis, \& Kosofsky, 2014). Exposed mice emitted more frequent USVs and demonstrated increased interactions with other animals during initial evaluations. These effects were not observed during follow-up testing and thus may not be long term (Kabir et al., 2014). Kabir, Katzman, and Kosofsky (2013) evaluated the impact of prenatal cocaine exposure on rodent recall of extinguished cue-conditioned fear using foot shock and observed significant increases in freezing for prenatally exposed mice. According to Kabir et al. (2013), prenatal cocaine exposure could increase the risk for PTSD by disrupting fear cue learning.

These animal studies compliment the human literature, indicating profound neurodevelopmental effects as a result of in utero exposure to alcohol. Less prominent disruptions were noted for prenatal cocaine administration; nonetheless, temperament alterations increasing the risk for psychopathology were observed. Prenatal cannabinoid and nicotine exposures were also implicated in long-term effects on offspring emotional functioning/temperament, potentially signaling lifelong mental health risk.

\section{Psychotropic medication/selective serotonin reuptake inhibitor (SSRI) use}

Human studies. Prescribed psychotropic medications, SSRIs in particular, have also been linked with adverse offspring developmental effects when administered during pregnancy. Prenatal SSRI exposure has been linked with multiple fetal, neonatal, and infant behavioral disturbances (Table 4). For example, SSRI-exposed infants displayed decreased physiological and behavioral responses relevant to negative emotionality in the context of a typical neonatal painful event (Oberlander et al., 2002). Altered neonatal cortisol levels were also reported (Pawluski, Brain, Underhill, Hammond, \& Oberlander, 2012), controlling for maternal symptoms. In light of these observations, Gur, Kim, and Epperson (2013) suggested that prenatal SSRI exposure could buffer infants from increased HPA reactivity.

Temperament in SSRI-exposed and nonexposed children was compared. Nulman et al. (1997) did not identify significant differences in temperament for children of mothers using SSRI medication during pregnancy (ages 16-86 months) and those not exposed. However, temperament was only assessed directly among children younger than 24 months, with behavior problems examined for older participants. Nulman et al. (2002) again failed to identify differences with a very small sample $(n=18)$ of SSRI-exposed children, using similarly limited measures of temperament.

Animal studies. SSRI exposure has also been evaluated in animals, often with perinatal/neonatal administration (Table 4). Rodent studies demonstrate lifelong biobehavioral alterations following perinatal exposure, including disruption of the serotonin signaling pathway development (Maciag et al., 2006) and increased depression-like behavior in adulthood (Ansorge, Zhou, Lira, Hen, \& Gingrich, 2004; Olivier et al., 2011).

Olivier at al. (2011) examined SSRI exposure from midgestation till birth. Prenatally exposed animals responded with increased anxiety, demonstrating greater latency to begin feeding in a novel setting and increased avoidance in a conditioned 
aversion test. Juvenile SSRI-treated animals engaged in fewer social play behaviors. Svirsky, Levy, and Avitsur (2016) also noted prenatal SSRI exposure effects on social behavior, with increased aggression for adult males, but not females. Smit-Rigter et al. (2012) provided evidence of a potential mechanism for serotonergic developmental effects, as SSRI exposure influenced dendritic complexity in the cortex, specifically serotonin receptors linked with anxiety.

McAllister, Kiryanova, and Dyck (2012) reported a decrease in anxiety-like behavior, as perinatally SSRI exposed mice spent less time in the closed arms in the elevated plus maze. Depression-like behavior, reflected in longer latencies to immobility in the forced swim test, declined as a result as exposure as well. However, perinatal SSRI exposure was also associated with increased immobility (Lisboa, Oliveira, Costa, Venancio, \& Moreira, 2007). These discrepant results could be attributed to the SSRI delivery differences. SSRIs were administered orally in the McAllister et al. (2012) study and expected to reach the offspring in relatively lower concentrations.

Thus, the totality of human and animal research addressing in utero exposure to maternal substance use indicates considerable impact on offspring emotional/behavioral functioning relevant to temperament. Emotional withdrawal and lower activity level in the context of prenatal alcohol exposure (Molteno et al., 2014), as well as novelty seeking and ADHD symptoms for those prenatally exposed to tobacco (Holz et al., 2014), have temperament implications. Cannabinoid exposure during gestation was associated with adverse behavioral effects primarily related to the dopaminergic system (Alpar et al., 2016) involved in approach/positive affectivity and regulation/effortful control. Sex differences were noted, with increased aggression in SSRIexposed males (Svirsky et al., 2016). Exposure effects vary by substance in terms of strength and consistency. Most detrimental outcomes were reported for prenatal alcohol use, followed by nicotine and marijuana, with less consistent effects for in utero exposure to cocaine and SSRIs. Additional data concerning the timing of most pronounced prenatal effects is required, yet maternal alcohol use creates adversities for offspring health/ development throughout gestation.

\section{Prenatal substance and psychotropic medication use: Epigenetic effects}

Human studies. We now consider the extent to which epigenetic processes are responsible for conferring prenatal substance use exposure risk. Consistent with the environmental epigenetics framework, prenatal maternal substance/medication use has been associated with offspring methylation changes. Portales-Casamar et al. (2016) examined genomewide DNA methylation patterns, identifying differentially methylated regions (DMR) in buccal cells of children with FASD and typically developing controls. Of 658 DMR, 41 displayed differences in percentage methylation change $>5 \%$. Children were between 5 and 18 years of age; thus, possible confounding postnatal variables were introduced. Laufer et al. (2015) also identified DMR associated with
FASD in a comparative study, assessing methylation patterns in children (3-6 years of age) and mice prenatally exposed to alcohol. A total of 269 DMR were reported, with 21 involved in regulation of clustered protocadherin genes responsible for synaptic complexity in the developing brain (Kalmady \& Venkatasubramanian, 2009). In their review of the literature, Kobor and Weinberg (2011) described critical developmental windows for alcohol exposure epigenetic effects: prior to conception on the paternal side and maternal alcohol consumption between fertilization and implantation.

A number of studies considered the role of prenatal tobacco exposure in altering DNA methylation in humans. Tobacco exposure was linked with a decrease in methylation of Sat2, one of the repetitive elements commonly used as a proxy for measuring genomic DNA methylation changes (Flom et al., 2011). Genome-wide methylation differences in cord blood cells of prenatally tobacco exposed and nonexposed infants were identified (Ivorra et al., 2015). Significant differences for $31 \mathrm{CpG}$ sites associated with 25 genes were observed, adjusting for multiple comparisons. Ladd-Acosta et al. (2016) also identified a methylation signature of prenatal tobacco exposure via a machine learning classification model, reliably differentiating exposed and nonexposed groups. Methylation specific to 26 sites was described as a potential biomarker of in utero tobacco exposure. Ivorra et al. (2015) concluded that DNA methylation status at birth could serve as a marker of risk associated with prenatal environmental adversity. However, future studies are required to discern clinical significance of these epigenetic findings, as methylation changes identified in humans thus far have not been linked with behavioral alterations.

DNA methylation differences between prenatally exposed to SSRIs and nonexposed neonates were recently reported. In a genome-wide investigation, Gurnot et al. (2015) identified cytochrome $\mathrm{P} 450$, family 2 , subfamily $\mathrm{E}$, polypeptide 1 (CYP2E1), the gene encoding an ethanol-metabolizing enzyme by the same name, as providing the greatest discrimination between SSRI-exposed and nonexposed neonates. The role of prenatal SSRI exposure and SLC6A4 promoter methylation status in shaping soothability, an early aspect of temperamental regulation, was examined (Gartstein, Hookenson, et al., 2016). For SSRI-exposed infants only, more advanced development of soothability was observed with higher SLC6A4 methylation levels.

Animal studies. Animal studies inform regarding epigenetic mechanisms as bridges between in utero substance use/exposure and offspring development, especially with respect to epigenetic shifts impacting gene expression in the brain. Rodent models developed to understand the etiology of FASD in humans enable links between analogue phenotypes to epigenetic mechanisms. Immediate and long-lasting alterations of DNA methylation and microRNAs, crucial for synaptic plasticity and behavioral/emotional functioning, have been reported. Marjonen et al. (2015) noted shifts in offspring DNA methylation, gene expression, and brain structure following chronic moderate ethanol exposure in early gestation, 
Table 5. Examples of in utero nutrition exposure effects: Temperament-related outcomes in human and animal studies

\begin{tabular}{|c|c|c|c|c|}
\hline Exposure & $\begin{array}{c}\text { Significant Developmental/Behavioral } \\
\text { Outcome }\end{array}$ & Sample Characteristics & $\begin{array}{l}\text { Developmental } \\
\text { Timing of Exposure }\end{array}$ & Reference \\
\hline \multicolumn{5}{|c|}{ Human Studies } \\
\hline Undernutrition & $\begin{array}{l}\uparrow \text { Major affective disorder incidence } \\
\text { (bipolar \& unipolar); 2nd \& 3rd } \\
\text { trimester effects, stronger for men } \\
\uparrow \text { Anxiety }\end{array}$ & $\begin{array}{l}N=163,282 / 41,847 \text { exposed } \\
(77,056 \text { female) } \\
\text { Measured in adulthood } \\
N=819 \text { (450 female) } \\
\text { Measured at about } 58 \text { years }\end{array}$ & $\begin{array}{l}\text { Entire pregnancy: measured at } 1 \text { st, } \\
2 \text { nd, \& 3rd trimester estimates from } \\
\text { records } \\
\text { Entire pregnancy: measured at } 1 \text { st, } \\
2 \text { nd, \& 3rd trimester; estimates } \\
\text { from records }\end{array}$ & $\begin{array}{l}\text { Brown et al. (2000) } \\
\text { de Rooij et al. (2011) }\end{array}$ \\
\hline \multirow[t]{2}{*}{$\begin{array}{l}\text { Overnutrition/ } \\
\text { high-fat diet }\end{array}$} & $\uparrow$ Externalizing problems & $\begin{array}{l}N=23,020 \text { (male and female) } \\
\text { Measured at } 1.5,3, \& 5 \text { years }\end{array}$ & $\begin{array}{l}\text { Midpregnancy: measured at } 16 \text { to } \\
20 \text { weeks }\end{array}$ & Jacka et al. (2013) \\
\hline & $\begin{array}{l}\downarrow \text { Temperamental surgency \& } \\
\text { regulation }\end{array}$ & $\begin{array}{l}N=48(24 \text { female }) \\
\text { Measured at } 4 \text { months }\end{array}$ & $\begin{array}{l}\text { Entire pregnancy: measured at } \\
13-16,24-27 \text {, and } 34-37 \text { weeks }\end{array}$ & Gustafsson et al. (2016) \\
\hline $\begin{array}{l}\text { Micronutrients } \\
\text { Iron }\end{array}$ & $\begin{array}{l}\downarrow \text { Autonomous nervous system } \\
\text { functioning, } 1 \text { st \& } 2 \text { nd trimester } \\
\uparrow \text { Signs of stress }\end{array}$ & $\begin{array}{l}N=216(109 \text { female }) \\
\text { Measured at } 48-72 \mathrm{hr} \text { postpartum }\end{array}$ & $\begin{array}{l}\text { Entire pregnancy: measured at } \\
10-15,24-27, \& 33-34 \text { weeks }\end{array}$ & $\begin{array}{l}\text { Hernández-Martínez } \\
\text { et al. (2011) }\end{array}$ \\
\hline \multicolumn{5}{|c|}{ Animal Studies } \\
\hline Undernutrition & $\begin{array}{l}\uparrow \text { Anxiety-like behavior } \\
\text { (males) }\end{array}$ & $\begin{array}{l}n=5-6 \text { rats/condition (males } \\
\text { only) } \\
\text { Measured at PND63-70 }\end{array}$ & $\begin{array}{l}\text { Periconceptional-postnatal/ } \\
\text { lactation }\end{array}$ & Levay et al. (2008) \\
\hline & $\begin{array}{l}\downarrow \text { Motivation to work for reward } \\
\downarrow \text { Emotional arousal } \\
\uparrow \text { Variable activity level } \\
\downarrow \text { Persistence/attention (females) }\end{array}$ & $\begin{array}{l}n=7-12 \text { baboons/condition } \\
(3-8 \text { females }) \\
\text { Measured at about } 3 \text { years }\end{array}$ & $\begin{array}{l}\text { Perinatal: pregnancy recognition- } \\
\text { lactation }\end{array}$ & Keenan et al. (2013) \\
\hline $\begin{array}{l}\text { Overnutrition/ } \\
\text { high-fat diet }\end{array}$ & $\uparrow$ Anxiety-like behavior & $\begin{array}{l}n=21-22 \text { mice/condition }(9-10 \\
\text { female) } \\
\text { Measured at PND90+ }\end{array}$ & $\begin{array}{l}\text { Periconceptional-postnatal/ } \\
\text { lactation }\end{array}$ & $\begin{array}{l}\text { Peleg-Reibstein et al. } \\
(2012)\end{array}$ \\
\hline
\end{tabular}


$\uparrow$ Anxiety-like behavior

$\downarrow$ Basal corticosterone \& slower return to baseline

$\uparrow$ Gestational corticosterone

$\uparrow$ Anxiety-like behavior

$\uparrow$ Activity level

\section{Micronutrients}

Vitamin D

$\uparrow$ Impulsivity

$\uparrow$ MK-801 induced hyperlocomotion (late $\&$ full deprivation only)

$\uparrow$ Anxiety (deprivation and excess) PND40 only

$\downarrow$ Activity (deprivation) PND40 only

Iron

$\downarrow$ Spontaneous activity

$\downarrow$ Inhibitory response

Folate

$\uparrow$ Anxiety-like behavior $n=20-24$ rats/condition $(10-14$

females)

Measured at PND110

$n=6$ rats/condition (males only)

Measured at E19 \& PND80 \&

110

$n=7-8$ (female only) piglets/

condition

Measured at 4, 5, 6, \& 7 weeks

$n=12-16$ rats/condition $(6-8$

female)

Measured at 20 weeks

$n=32$ rats (males only)

Measured at PND70

$n=20-28$ rats (10-14 female)

Measured at PND35-40 \&

PND100-105

$n=12-14$ monkeys (4-8

females)

Measured at 4 months

$n=40$ mice (20 females)

Measured at PND63-65 \&

PND68-83

$N=13-20$ (7-9 females)

Measured at PND2-6, 2-6

months
Periconceptional-postnatal/

lactation:

4 weeks prior to mating-PND21

Periconceptional-postnatal/

lactation

Periconceptional-

postnatal/lactation:

8 weeks prior to conception- 8

weeks postpartum

Periconceptional-birth

Turner et al. (2013)

Periconceptional-birth: late

(conception-birth); full (6 weeks

before conception-birth)

Perinatal: mating-PND18

'Loan et al. (2007)

Pan et al. (2014)

Prenatal: entire gestation

Golub et al. (2006)

Periconceptional-late gestation:

8 weeks before mating-E18

Pre \& postnatal: entire gestation6 months

Sasaki et al. (2013)

Clouard et al. (2016)
Rodriguez et al. (2012)

$\uparrow$ Anxiety-like behavior

$\uparrow$ Hyperactivity

Note: Sample characteristics are provided in a different manner for human and animal studies, because of differences in design and presentation format. For human correlational studies, the overall number of participants $(N)$ is typically presented, whereas the number of participants per condition $(n)$ is indicated for animal experimental investigations. Additional information concerning numbers of male versus female participants is also provided when both sexes were included/specified. Developmental timing of exposure indicators varies across studies. For humans, the timing is provided in terms of the number of gestational weeks. In animals these indicators often refer to whether the nutritional exposure was periconceptional, beginning around conception and including the postnatal/lactation period, or starting at pregnancy recognition, with a number of studies providing specific weeks/days. ( $\uparrow$ ) Increases in temperament-related behaviors/displays; ( ) decreases in temperament-related behaviors/displays; E, embryonic day; PND, postnatal day; USV), ultrasonic vocalization; MK-801, $N$-methyl-D-aspartate receptor (NMDA-R) antagonist. 
corresponding to the first 3-4 weeks of human pregnancy. Gene expression analyses conducted with mouse hippocampal tissue of ethanol-exposed adolescent offspring revealed altered expression of 23 genes and three microRNAs. However, no connections were made between gene expression changes and brain structure/function changes.

Methylation of the insulin-like growth factor II (IGF-II), an imprinted gene with a role in memory consolidation and enhancement, was examined in the context of prenatal cocaine exposure with mice (Zhao et al., 2015). Offspring of mothers administered cocaine during pregnancy demonstrated increased anxiety, along with impaired memory. Hippocampal IGF-II mRNA and protein expressions were significantly decreased, likely contributing to the phenotypic changes (Zhao et al., 2015). Prenatal administration of cocaine to mice was also shown to alter genome-wide DNA methylation in the offspring hippocampal tissue (Novikova et al., 2008). Exposed and nonexposed mice were differentiated by methylation of $492 \mathrm{CpG}$ islands, a number associated with repetitive elements (e.g., LINE, Alu; Novikova et al., 2008).

Epigenetic alterations associated with prenatal cannabis exposure have also been considered, albeit not as extensively. DiNieri et al. (2011) examined fetal brain tissue and reported decreased dopamine receptor D2 (DRD2) mRNA expression in the human ventral striatum (nucleus accumbens). DRD2 mRNA levels were negatively associated with maternal report of prenatal cannabis use. Morris, DiNieri, Szutorisz, and Hurd (2011) reviewed contributions of cannabis and tobacco exposures, as these in utero effects commonly co-occur in humans. Consistent with the environmental epigenetics perspective, a critical role of epigenetic mechanisms, methylation in particular, was noted in shaping offspring neurodevelopment.

Thus, existing research provides evidence of gene expression changes, modulated via methylation and noncoding RNA mechanisms sensitive to prenatal substance use. The extent of epigenetic alterations may be related to the level of developmental disruption, with alcohol exposure expected to trigger greater gene expression changes. Multiple downstream behavioral effects relevant to temperament have been noted. However, in humans, connections between prenatal substance use exposure, epigenetic changes, and alterations in temperament development have not been made in a convincing manner.

\section{Nutrition: Undernutrition, overnutrition, and micronutrients}

Human studies. These links were somewhat better established in the context of studies addressing prenatal nutritional exposures, in part because of an opportunity for a natural experiment created by a World War II humanitarian disaster. Effects of gestational undernutrition in humans have been studied most extensively following individuals who were prenatally exposed to famine during the Dutch Hunger Winter (19441945): a period of severe food shortage in the western region of the Netherlands during the last winter of World War II (Barua \& Junaid, 2015). The Dutch Famine Birth Cohort
Study is a population-based investigation with volunteers prenatally affected by undernutrition (Roseboom et al., 2006). In utero undernutrition was predictive of psychopathology, insofar as the role of exposure in affective disorders was documented based on a large-scale archival study (Table 5). Undernutrition as a result of famine in middle or late gestation resulted in a higher risk for hospitalization for unipolar and bipolar depression, with a stronger effect observed for men (Brown, van Os, Driessens, Hoek, \& Susser, 2000). Famine and undernutrition exposure early in gestation increased the risk for anxiety in adulthood (de Rooij et al., 2011). Males exposed to famine during early gestation were again affected to a greater extent, self-reporting more frequent/severe symptoms of anxiety and depression. This pattern of results is consistent with the evidence indicating males may be more vulnerable to nutritional deprivation during certain periods of fetal development because of faster growth relative to females (Eriksson, Kajantie, Osmond, Thornburg, \& Barker, 2010). Other cohorts exposed to undernutrition and nutritional interventions have been evaluated; however, behavioral/emotional outcomes were not addressed. Interest in fetal programming related to overnutrition has grown as a result of the "obesity epidemic." Connections between excessive prenatal nutrition and behavioral/temperament outcomes are starting to emerge.

Prenatal nutrition characterized as "unhealthy" (high in fat) was predictive of multiple emotional/behavioral problems later in childhood (Jacka et al., 2013). Increased maternal intake of unhealthy foods (e.g., processed meat products) during pregnancy predicted child externalizing problems at 5 years of age, controlling for covariates including childhood diet. Most relevant to this review, Gustafsson, Kuzava, Werner, and Monk (2016) reported associations between maternal prenatal dietary fat intake and offspring temperament. Specifically, maternal total fat intake was linked with infant surgency and regulatory capacity at 4 months of age, so that higher fat content translated into lower positive affectivity and regulation indicative of temperament risk. Together, human studies indicate temperament alterations and an increased risk for behavior problems/symptoms as a consequence of prenatal exposure to under- and overnutrition.

Prenatal effects of multiple nutrients have been reported for child neurodevelopment (e.g., B vitamins, zinc, protein, iodine, etc.; Georgieff, 2007) and can be expected to influence temperament as a result. For example, Hernández-Martínez et al. (2011) reported that first- and second-trimester iron deficiency predicted neonatal autonomous nervous system functioning, including signs of stress reactivity. In a recent review, poor nutrition during pregnancy was described as contributing to deficits in neurocognitive development (e.g., sensory-perceptual skills, memory, an learning), especially in the context of maternal distress (Monk, Georgieff, \& Osterholm, 2013).

Animal studies. Connections between unhealthy in utero nutrition and subsequent adverse behavioral/temperament outcomes for the exposed offspring are further supported by 
animal research. A variety of animal models have been utilized to examine fetal programming associated with nutritional factors (Table 5), as these allow precisely timed diet manipulations inducing nutritional accesses and deficits. Levay et al. (2008) examined effects of moderate maternal calorie restriction in preconception and the perinatal period on adult offspring anxiety-like behaviors. Preconception deprivation (50\% caloric intake for 3 days) exerted the strongest effect with respect to most offspring anxiety-like behavior (e.g., less exploration in the open field). Nonhuman primates exposed to maternal undernutrition during gestation demonstrated greater variability in activity level and less emotional arousal (Keenan et al., 2013). Females, but not males, showed lower levels of attention/persistence, ascertained based on computerized task engagement and performance. Keenan et al. (2013) concluded that prenatal diet interventions could be effective in preventing common behavior problems in children.

Preconceptional/perinatal maternal high-fat diet effects on anxiety-related behaviors, as well as expression of GABAergic, serotonergic, and brain-derived neurotrophic factor (BDNF) receptors involved in anxiety and depression, were examined in mice. Offspring in the high-fat diet condition exhibited increased anxiety-like behaviors, with expression alterations noted in the hippocampus (i.e., increased BDNF and GABA receptors; Peleg-Raibstein, Luca, \& Wolfrum, 2012). Adult offspring exposed to a perinatal high-fat diet showed increased expression of corticosterone receptors in the amygdala and inflammatory gene expression in the hippocampus and amygdala. These changes were linked with increased anxiety behavior (e.g., less time in the open field; Sasaki, de Vega, St.-Cyr, Pan, \& McGowan, 2013). Males subjected to a high-fat diet through gestation and lactation demonstrated increased corticosterone serum levels. Anxiety-related effects were mixed, with offspring from the pregestation dietary intervention group (mothers returned to a healthy diet) showing partial recovery (Rodriguez et al., 2012). Substance-use related behavioral effects of prenatal high-fat exposure have been documented in rats (Karatayev et al., 2015). Exposed offspring engaged in more extensive nicotine and ethanol self-administration, relevant to temperament because of associated impulsivity/ behavioral undercontrol. This connection between prenatal high-fat diet exposure and offspring deficits in regulation was further supported by a recent review. Sullivan, Nousen, and Chamlou (2014) noted that primary offspring outcomes of perinatal high-fat diet programming involved behavioral/emotional dysregulation, further suggesting serotonergic system suppression as the likely mechanism.

The impact of a calorie-dense perinatal diet (high in saturated fat, refined sugar, and cholesterol) on the development of piglets was examined (Clouard, Gerrits, Kemp, Val-Laillet, \& Bolhuis, 2016). Prenatal exposure resulted in decreased basal salivary cortisol levels, relative to controls. Animals exposed to the high-fat/sugar/cholesterol diet spent more time walking in their pens, with control group animals inactive longer.

Micronutrient deficiencies have been studied extensively in animals. Iron deficiency during gestation was examined in nonhuman primates, with exposed offspring demonstrating reduced activity. Ratings of "fearful" affect emerged as the most critical temperament descriptor differentiating prenatally iron-deprived animals from controls (Golub et al., 2006). In rodents, females exposed to zinc deprivation throughout gestation exhibited higher levels of aggression, relative to females born to typically fed mothers and those exposed to overall undernutrition (Halas, Reynolds, \& Sandstead, 1977). Adult offspring perinatally exposed to vitamin $\mathrm{D}$ deficiency engaged in more frequent premature responses on a learning task, relative to control animals, interpreted as impulsivity induced by the deprivation (Turner et al., 2013). Hyperlocomotion in rats following vitamin D deficiency was also reported. Full and late term, but not early gestational, deprivation resulted in this behavioral phenotype (O'Loan et al., 2007). Late gestation was described as the likely "critical window" for vitamin D deprivation, corresponding to midgestation in humans (Clancy, Darlington, \& Finlay, 2001). Pan et al. (2014) considered effects of both deficient and excessive perinatal levels of vitamin D, following exposed offspring into adulthood. Exposure to vitamin D deficiency resulted in lower offspring activity and increased anxiety (e.g., fewer open arm entries). Vitamin D excess was also linked with adverse effects, and Pan et al. (2014) suggested high concentrations may be toxic.

Folate deficiency during gestation was associated with more frequent anxiety-related behavior in the elevated plus maze (Ferguson et al., 2005). At the same time, offspring exposed to high levels of folic acid exhibited increased USVs, anxiety, and hyperactivity-like behaviors (Barua et al., 2014). This pattern of result prompted Barua et al. (2014) to recommend moderation in folic acid supplementation.

Overall, behavioral effects as a result of prenatal under- and overnutrition have been observed across human and animal studies, with some indication of sex differences (de Rooij et al., 2011; Keenan et al., 2013). Both sets of investigations implicated symptoms of anxiety, relevant to temperament as fear/behavioral inhibition, represents a prominent risk factor. Moreover, animal studies provide evidence of brain development alterations (e.g., expression of receptors involved in anxiolytic medication effects). Behavioral/emotional dysregulation emerged as another consequence of prenatal nutritional adversity, with temperament-related outcomes implicated in studies addressing prenatal deficiencies/accesses of micronutrients. Impulsivity and activity-level increases were noted, with some indication of a critical window with respect to vitamin D effects. These effects are not surprising, as brain development is altered with under- and overnutrition, in part due to sensitivity to deficits or overabundance of specific nutrients (Georgieff, 2007). Cunha et al. (2015) argued for the "similarities in the inequalities" model, as offspring prenatally exposed to both undernutrition and high-fat conditions demonstrated similar effects (e.g., lower birth weight and decreased activity level), compared to controls. In a recent review, Langley-Evans (2015) suggested: "a limited number of common mechanisms may link nutritional 'stressors' to development 
changes that result in later disease." Prenatal nutritional effects are both unique and co-acting with respect to maternal stress and mood, leading to alterations in the offspring dopaminergic and serotonergic systems (Sullivan, Smith, \& Grove, 2011). Psychosocial stress is a known contributor to unhealthy eating during pregnancy (Hurley, Caulfield, Sacco, Costigan, \& Dipietro, 2005) and can alter the manner in which nutrients are metabolized (e.g., accelerating protein breakdown), with further negative consequences for the fetus (Monk et al., 2013). As noted earlier, co-occurrence with additional exposures (e.g., substance use) should be addressed in the future. Connecting these overlapping environment exposures to their epigenetic signatures will be important going forward.

\section{Prenatal Nutritional Exposure in Humans and Animals: Epigenetic Mechanisms}

The role of epigenetic processes in conferring effects of prenatal nutrition are already being addressed and will be discussed next. Prenatal undernutrition exposure research in humans provides further support for the environmental epigenetics framework. Results indicate a variety of epigenetic changes, in some cases linked with disease-related phenotypes, but not behavior/temperament (Heijmans et al., 2008; Tobi et al., 2014). Periconceptional exposure to famine during the Dutch Hunger Winter was associated with a lifelong methylation signature linked with physiological phenotypes. For example, methylation of DMR associated with the physical growth and insulin signaling gene (insulin receptor $[I N S R])$ was positively correlated with birth weight. Fatty acid oxidation gene (carnitine palmitoyltransferase $1 \mathrm{~A}$ $[C P T 1 A])$ methylation was positively correlated with lowdensity lipoprotein cholesterol levels, after adjusting for multiple covariates (e.g., age and smoking; Tobi et al., 2014). One study with humans utilized a genome-wide approach, demonstrating that micronutrient supplementation was associated with decreased methylation, interpreted as important to "programming gene activity" later in life (Khulan et al., 2012). Unfortunately, behavioral outcomes relevant to temperament were not examined.

In a mouse model, perinatal exposure to a high-fat diet was linked with DNA hypomethylation along with alterations in dopamine and opioid-related gene expression (Vucetic, Kimmel, Totoki, Hollenbeck, \& Reyes, 2010). Micronutrient deficits can also influence gene expression, as perinatal iron deficiency was associated with altered mRNA expression in the brain (Clardy et al., 2006). Konycheva et al. (2011) examined prenatal methyl donor deficiency effects on offspring hippocampal methylation of candidate genes involved in glucocorticoid metabolism and anxiety-related behaviors. Exposed animals demonstrated increased anxiety. However, methylation of candidate genes was not associated with any of these behavioral changes, suggesting the need for a genome-wide strategy. Nonhuman primates prenatally exposed to a chronic maternal high-fat diet evidenced epigenetically driven serotonin signaling pathway alterations linked with fearful/anxious behavior (Sullivan et al., 2010). Sex differences were noted in responses to threatening novel objects, as female high-fat exposed offspring exhibited increased anxiety, and males demonstrated higher levels of aggression. Overall $78 \%$ of animals born to mothers subjected to a chronic high-fat diet exhibited disordered behavior. Consistent with the environmental epigenetics perspective, deficits and accesses in prenatal nutrition were shown to result in epigenetic shifts for the offspring, yet only a limited number of studies demonstrated links between these alternations and behavioral outcomes.

In summary, the totality of existing studies suggests important links between environmental exposures, epigenetic alterations, and shifts in behavioral outcomes relevant to temperament (e.g., fear/anxiety). However, connections among these levels of analysis have not been made frequently, especially in humans. In addition, questions remain regarding optimal developmental widows and sex differences in programming effects. In terms of stress, human candidate gene studies suggest methylation of $N R 3 C 1$ and $S L C 6 A 4$ are critical to conferring prenatal effects for several temperament outcomes (e.g., infant HPA axis reactivity; Montirosso et al., 2016; Oberlander et al., 2008; Ostlund et al., 2016). However, enthusiasm for these as potential markers of exposure effects is dampened by the number of other genes implicated in stress-related methylation shifts, as evidenced by a genomewide approach (Nieratschker et al., 2014). Toxicant studies provide consistent evidence of environmental exposures translating into epigenetic shifts. These alterations of the epigenome affect developmental cascades relevant to temperament phenotypes (Keil \& Lein, 2016; Skinner et al., 2008). Among notable substance-use related findings, Zhao et al. (2015) reported transcription alterations in the hippocampus and increased anxiety-like behavior following prenatal cocaine exposure. Existing prenatal nutrition research indicates connections between methylation status and temperament, as expected based on the environmental epigenetic framework. Nutrition affects maternal health/physiology, a key determinant of the intrauterine milieu, shaping the progression from environmental exposure to changes in offspring epigenome, brain, and temperament development.

\section{DNA Methylation and Temperament: Implications for Behavioral/Emotional Health}

The course of prenatal development is altered by exposure to maternal stress, contact with toxicants, substance/psychotropic medication use, and nutrition. These environmental factors impact maternal physiology during gestation and program the offspring. As anticipated by the environmental epigenetics perspective, prenatal exposures appear to confer subsequent behavioral phenotypes via epigenetic mechanisms. Brain development is sensitive to multiple exposures during gestation, and this epigenetically driven fetal programming shapes regions/systems relevant to temperament. Even subtle alterations in brain structure/function during fetal 
development can become magnified over time, producing lifelong deficits (Buss et al., 2012). Development of the amygdala and hippocampus, relevant to fear/avoidance and other temperament-related behaviors, was disrupted by prenatal stress (Barros, Myers, Van Driesche, \& Tzagoloff, 2006), environmental contaminants (Skinner et al., 2008), maternal alcohol use (Baculis et al., 2015), and a high-fat diet (Sasaki et al., 2013). Prenatal stress effects on the synthesis and transport of dopamine, as well as relevant receptors, were also noted (Antonelli et al., 2016). Development of the dopaminergic system can be disrupted by prenatal lead and cannabinoid exposure, as well as maternal nutritional state (DiNieri et al., 2011; Leasure et al., 2008; Sullivan et al., 2014). The dopaminergic system plays multiple roles relevant to temperament as it functions to prioritize stimuli or responses, facilitating selection of alternatives in either a perceptual-cognitive or a motor-behavioral context (Trofimova \& Robbins, 2016). The serotonin signaling pathway also pertains to temperament given links to depression and anxiety associated with negative emotionality. Serotonergic effects were most pronounced in studies examining in utero SSRI exposure (Smit-Rigter et al., 2012). Changes in serotonin signaling were also observed in the context of prenatal restraint stress (Miyagawa, Tsuji, Fujimori, Saito, \& Takeda, 2011). Compound effects of maternal diet, stress, and mood, as well as sleep and exercise, can be expected to shape offspring serotonergic and dopaminergic neurotransmitter systems (Sullivan et al., 2011), and thus should be explored in future research. Overall, epigenetically mediated prenatal exposure effects on brain development have considerable implications for temperament, especially stress reactivity, fear/anxiety, impulsivity, and attention/regulation.

Epigenetic mechanisms have been linked with behavioral phenotypes relevant to temperament by multiple investigations. In one such study, genome-wide DNA methylation and mRNA expression analyses were conducted with primate amygdala tissue collected from juveniles exhibiting a fearful temperament (freezing, increased levels of cortisol; Kalin \& Shelton, 2003). Transcriptome analyses distinguished 22 genes with active expression changes, of which two glutamate receptor genes (glutamate ionotropic receptor NMDA type subunit 1 [GRINI] and metabotropic glutamate receptor 5 [GRM5]) play a role in fear and anxiety-like behaviors. $N R 3 C 1$ and SLC6A4 methylation has been linked with infant duration of orienting, approach, soothability, and fear, measured via parent report (Gartstein, Hookenson, et al., 2016; Montirosso et al., 2016; Ostlund et al., 2016). Methylation of imprinted genes was also associated with infant temperament: higher methylation of maternally expressed gene intergenic $(M E G 3-I G)$ linked with greater surgency and of the progression elevated gene 3 (PEG3) with higher levels of negative emotionality and externalizing problems (Fuemmeler et al., 2016). In adulthood, DNA methylation of the oxytocin structural gene (OXT) was associated with sociability and greater superior temporal sulcus activity during socialcognitive functional MRI tasks (Haas et al., 2016). Existing evidence points to the importance of epigenetic processes as mediators of prenatal effects, conferring environmental risk onto temperament-related phenotypes. As indicated by the environmental epigenetics perspective, a variety of environmental adversities impact maternal health/physiology, resulting in a cascade of epigenetic changes that shape central nervous system maturation and temperament, in turn, often translating into similar phenotypes across exposures.

Prenatal exposure to multiple adversities results in temperament profiles marked by high levels of fear/behavioral inhibition and risk for anxiety, with these effects mediated by epigenetic processes. On the animal side, exposure to prenatal stress resulted in a number of offspring "fearful" behaviors, such as higher levels of inhibition in response to foot shock, decreased time spent in the center of an open field and in open arms of the elevated-plus maze, increased defensive withdrawal, and conditioned fear (Dickerson, Lally, Gunnel, Birkle, \& Salm, 2005; Griffin \& Evans, 2003; Ward, Johnson, Salm, \& Birkle, 2000). Epigenetic mechanisms were implicated in the risk for increased fear/anxiety observed in the context of prenatal toxicant exposure (e.g., Skinner et al., 2008) and for humans prenatally exposed to undernutrition (de Rooij et al., 2011).

With respect to depression, temperament risk primarily involves increased negative emotionality, along with decreased approach/positive affectivity (Lonigan, Carey, \& Finch, 1994; Lonigan et al., 2003). This profile resulted from several reviewed exposures shown to operate via epigenetic processes. Alvik et al. (2011) demonstrated that maternal binge drinking in early pregnancy predicted offspring temperament marked by high negative affect, low regulatory capacity, and positive affectivity in infancy, which could bode future depressive symptoms. Prenatal high-fat diet was associated with lower infant surgency (Gustafsson et al., 2016), which could translate into long-term risk for depression given high negative emotionality. Prenatal stress and maternal high-fat diet were shown to disrupt serotonin neuronal development (Miyagawa et al., 2011; Peleg-Raibstein et al., 2012), likely contributing to temperament risk for depression. In utero exposure to SSRIs was associated with offspring serotonergic effects (Oberlander, 2012), although additional research is required to determine their long-term significance.

Tentative conclusions can be drawn regarding disruptive behaviors/disorders. General maternal anxiety during pregnancy was associated with increased infant surgency, negative affectivity, and poorer self-regulation (van den Heuvel et al., 2015), linked with risk for conduct disturbance. Offspring behavioral/emotional dysregulation reported following prenatal trauma-related exposures (i.e., trauma occurrence or maternal PTSD; Yong Ping et al., 2015) is also consistent with temperament risk for disruptive behaviors. Studies that measure offspring ADHD-like behaviors (Atalar et al., 2016; Holz et al., 2014; Luo et al., 2014; Sagiv et al., 2010) suggest multiple prenatal toxicant and maternal substance use effects. Luo et al. (2014) demonstrated histone modifications mediated prenatal lead exposure effects on ADHD-like behavior in 
juvenile rats, serving as a bridge between environmental toxicant exposure and offspring symptomatology.

Biologically speaking, phenotypes are considered beneficial to the extent that these increase survival and subsequent reproductive success. These need not be socially desirable or health promoting in the long term (Frankenhuis, Panchanathan, \& Belsky, 2016). Children who experience adverse fetal programming effects likely present with temperament profiles aimed at increasing their immediate probability of survival (e.g., greater reactivity/fearfulness), which may not align with caregivers' and societal demands/expectations. These temperament trajectories speak to long-term risk, increasing the likelihood of developing psychopathology/ behavior problems that typically emerge after the first year of life. Alternatively, these phenotypes may be reflective of increased sensitivity to context, with superior outcomes under optimal environmental conditions. Selection pressures may favor differential plasticity when environmental conditions vary across time, with epigenetic mechanisms explaining "bet hedging" that leads to varying offspring plasticity (Frankenhuis et al., 2016). As DOHaD research has already demonstrated, environmental epigenetic modifications immediately protective in adverse circumstances (e.g., inadequate prenatal nutrition and stress) result in a spectrum of risk-promoting developmental shifts relevant to temperament and mental health in the long term (Hochberg et al., 2011).

\section{Conclusion}

Considerable evidence points to the importance of in utero environmental exposures in shaping offspring temperament development, with epigenetic mechanisms conferring the risk, as indicated by the environmental epigenetics perspective. Greater understanding of these connections is critical for advancing $\mathrm{DOHaD}$ research and specifically for elucidating prenatal origins of developmental psychopathology, which could lead to more effective preventative efforts. Additional study is required to make these connections for eventual use of epigenetic information in targeted interventions.

First, research that starts with environmental adversities and considers epigenetic alterations as well as brain/behavior effects related to temperament has been limited to date. Investigations that link all components of the developmental progression and levels of analysis are needed, especially with humans. Animal studies provide an opportunity to directly manipulate independent variables related to environmental exposure, ensuring internal validity, yet their external validity with respect to human applications is necessarily limited. Thus, efforts with humans are required, translating animal findings in a manner that provides support for generalizability. Future research could focus on links between epigenetic mechanisms and temperament development in high- and low-risk populations. Despite a quasi-experimental design, multiple fetal programming pathways described in this review could be examined. For example, recruiting samples of pregnant women from the same community that differ in terms of psychosocial and/or physiological stress could provide comparisons with respect to effects of the HPA axis activation. It would be possible to examine other environmental exposures, such as healthy versus unhealthy prenatal nutrition, in a similar fashion. This approach could elucidate reliable connections between environmental adversity, maternal health, epigenetic mechanisms, and offspring behavioral outcomes with human participants, given appropriate statistical control of covariates (e.g., postpartum variables).

Second, some conclusions can be made about developmental windows associated with stronger effects; however, additional research is required to clarify these across species for different environmental exposures. Overall, earlier stages of prenatal development afford greater malleability of organ structure and function and are more "open" to environmental influences via epigenetic modifications (Crews, 2010). At the same time, a number of reviewed exposure effects occurred later in gestation (e.g., Yehuda et al., 2005), presumably because this timing coincides with the maturation of brain regions relevant to temperament. Comparative studies including animal and human participants with parallel exposure windows are likely to be especially informative, given divergent sensitive period findings thus far.

Third, interactions among different in utero exposure conditions should be examined more closely in future research, as compound effects are likely relevant to temperament. Epigenetic modifications invoked by different prenatal environmental circumstances may have substantial overlap, leading to diverse developmental and health risks. Comparative studies are likely to inform this effort. Multiple exposures can be manipulated with respect to dose, timing, and duration with animals, in a manner that parallels human prenatal effects. For example, comparative research could address joint effects of prenatal stress and inadequate nutrition, as well as maternal polysubstance use.

Fourth, the pattern emerging from existing studies suggests that males may be more vulnerable to physiological and behavioral effects of prenatal environmental exposures (Andre \& Markowski, 2006; Colciago et al., 2009; Eriksson et al., 2010; Leasure et al., 2008). Sex differences are generally predicted in the direction of females exhibiting greater anxiety/ depression and males presenting with higher aggression/ impulsivity, with a number of studies providing support (Nazeri et al., 2015; Sullivan et al., 2010; Svirsky et al., 2016). However, males born to mothers exposed to psychological stress during pregnancy demonstrated more depression-like behavior (Abe et al., 2007) and females increased in aggression following DET/DES and zinc deficiency in utero exposure (Halas et al., 1977; Palanza et al., 1999). Interpretation of sex differences is complicated by the fact that a number of studies were conducted with male animals only (e.g., Abe et al., 2007; Maccari et al., 2003). Nonetheless, existing evidence suggests fetal programming may have sexually dimorphic effects (Baillargeon, Keenan, \& Cao, 2012; Hyde, Mezulis, \& Abramson, 2008; Skinner et al., 2008). Thus, offspring sex 
should be considered as a moderator of links between prenatal exposures, epigenetic shifts, and behavioral outcomes.

Fifth, potential transgenerational effects linked with epigenetic mechanisms addressed in this review (e.g., Skinner, 2014) highlight the need for additional study of etiology, as well as preventative efforts. It is critical to understand biolog$\mathrm{ical} /$ developmental processes involved in the chain of events that starts with prenatal environmental exposures. Subsequent changes in maternal health/physiology, offspring epigenome, and gene expression result in temperament profiles that typically bode risk for symptoms/behavior problems. It will be important to determine if certain exposures result in epigenetic shifts that afford plasticity, rather than risk. Studies that make connections between methylation signatures of prenatal environmental exposures and temperament profiles linked to risk could facilitate screening and preventative interventions. Szyf, Tang, Hill, and Musci (2016) noted that DNA methylation could be used as a biomarker for effects of prenatal exposures on individuals' risk and a measure of treatment progress. Thus, screening/assessment applications could be implemented once sufficient empirical evidence is generated. Links between methylation patterns resulting from in utero exposures and risky temperament phenotypes represent the first step to enable targeted selection for preven-

\section{References}

Abe, H., Hidaka, N., Kawagoe, C., Odagiri, K., Watanabe, Y., Ikeda, T., . . . Ishida, Y. (2007). Prenatal psychological stress causes higher emotionality, depression-like behavior, and elevated activity in the hypothalamopituitary-adrenal axis. Neuroscience Research, 59, 145-151. doi:10. 1016/j.neures.2007.06.1465

Ahluwalia, B., Wesley, B., Adeyiga, O., Smith, D. M., Da-Silva, A., \& Rajguru, S. (2000). Alcohol modulates cytokine secretion and synthesis in human fetus: An in vivo and in vitro study. Alcohol, 21, 207-213.

Alpar, A., Di Marzo, V., \& Harkany, T. (2016). At the tip of an iceberg: Prenatal marijuana and its possible relation to neuropsychiatric outcome in the offspring. Biological Psychiatry, 79, e33-e45. doi:10.1016/j.biopsych. 2015.09.009

Alvik, A., Torgersen, A. M., Aalen, O. O., \& Lindemann, R. (2011). Binge alcohol exposure once a week in early pregnancy predicts temperament and sleeping problems in the infant. Early Human Development, 87, 827-833. doi:10.1016/j.earlhumdev.2011.06.009

Andre, S. M., \& Markowski, V. P. (2006). Learning deficits expressed as delayed extinction of a conditioned running response following perinatal exposure to vinclozolin. Neurotoxicology and Teratology, 28, 482-488. doi:S0892-0362(06)00054-7

Ansorge, M. S., Zhou, M., Lira, A., Hen, R., \& Gingrich, J. A. (2004). Earlylife blockade of the 5-HT transporter alters emotional behavior in adult mice. Science, 306, 879-881. doi:10.1126/science.1101678

Antonelli, M. C., Pallares, M. E., Ceccatelli, S., \& Spulber, S. (2016). Longterm consequences of prenatal stress and neurotoxicants exposure on neurodevelopment. Progress in Neurobiology, 155, 21-35. doi:10.1016/ j.pneurobio.2016.05.005

Anway, M. D., \& Skinner, M. K. (2008). Epigenetic programming of the germ line: Effects of endocrine disruptors on the development of transgenerational disease. Reproductive BioMedicine Online, 16, 23-25.

Atalar, E. G., Uzbay, T., \& Karakas, S. (2016). Modeling symptoms of attention-deficit hyperactivity disorder in a rat model of fetal alcohol syndrome. Alcohol and Alcoholism. Advance online publication. doi:10. 1093/alcalc/agw019

Babenko, O., Kovalchuk, I., \& Metz, G. A. (2015). Stress-induced perinatal and transgenerational epigenetic programming of brain development and mental health. Neuroscience \& Biobehavioral Reviews, 48, 70-91. doi:10.1016/j.neubiorev.2014.11.013 tative treatment. A noninvasive biomarker (e.g., buccal cell methylation signature) could enable this intervention targeting early in infancy, rather than awaiting behavioral testing at a later time point. Thus, preventative programs could address parenting/parent-child interactions, modifiable contributors to risk for psychopathology, before maladaptive patterns become the norm. Research that identifies connections between exposures, their epigenetic signatures, and behavioral outcomes is needed to support this preventative approach. Temperamental precursors of symptoms/psychopathology offer advantages relative to the study of full-blown disorders, as these temperament risk factors can be reliably measured in the first year of life. Thus, fetal programming/epigenetic investigations with temperament outcomes will not require lengthy longitudinal efforts, although the latter are important as well. Environmental epigenetics can make a substantial contribution to the study of temperament development, informing our understanding of debilitating mental health symptoms/disorders, as well as efforts aimed at their prevention.

\section{Supplementary Material}

To view the supplementary material for this article, please visit https://doi.org/10.1017/S0954579417001730.
Baculis, B. C., Diaz, M. R., \& Valenzuela, C. F. (2015). Third trimesterequivalent ethanol exposure increases anxiety-like behavior and glutamatergic transmission in the basolateral amygdala. Pharmacology Biochemistry Behavior, 137, 78-85. doi:10.1016/j.pbb.2015.08.009

Bada, H. S., Das, A., Bauer, C. R., Shankaran, S., Lester, B., LaGasse, L., . . Higgins, R. (2007). Impact of prenatal cocaine exposure on child behavior problems through school age. Pediatrics, 119, e348-e359. doi:10.1542/ peds.2006-1404

Bagga, S. (2012). Introduction to DNA methylation. BioFiles, Epigenetics, 7 , 4-5.

Baillargeon, R. H., Keenan, K., \& Cao, G. (2012). The development of opposition-defiance during toddlerhood: A population-based cohort study. Journal of Developmental and Behavioral Pediatrics, 33, 608-617. doi:10.1097/DBP.0b013e3182653c6c

Barker, D. J., \& Osmond, C. (1986). Infant mortality, childhood nutrition, and ischaemic heart disease in England and Wales. Lancet, 1, 1077-1081.

Barros, M. H., Myers, A. M., Van Driesche, S., \& Tzagoloff, A. (2006). COX24 codes for a mitochondrial protein required for processing of the COX1 transcript. Journal of Biological Chemistry, 281, 3743-3751. doi:10.1074/jbc.M510778200

Barski, A., Cuddapah, S., Cui, K., Roh, T. Y., Schones, D. E., Wang, Z., . . Zhao, K. (2007). High-resolution profiling of histone methylations in the human genome. Cell, 129, 823-837. doi:S0092-8674(07)00600-9

Barua, S., Chadman, K. K., Kuizon, S., Buenaventura, D., Stapley, N. W., Ruocco, F., ... Junaid, M. A. (2014). Increasing maternal or post-weaning folic acid alters gene expression and moderately changes behavior in the offspring. PLOS ONE, 9, e101674. doi:10.1371/journal.pone.0101674

Barua, S., \& Junaid, M. A. (2015). Lifestyle, pregnancy and epigenetic effects. Epigenomics, 7, 85-102. doi:10.2217/epi.14.71

Beijers, R., Buitelaar, J. K., \& de Weerth, C. (2014). Mechanisms underlying the effects of prenatal psychosocial stress on child outcomes: Beyond the HPA axis. European Child and Adolescent Psychiatry, 23, 943-956. doi:10.1007/s00787-014-0566-3

Belsky, J., \& Pluess, M. (2009). Beyond diathesis stress: Differential susceptibility to environmental influences. Psychological Bulletin, 135, 885908. doi:10.1037/a0017376

Bosquet Enlow, M., Kitts, R. L., Blood, E., Bizarro, A., Hofmeister, M., \& Wright, R. J. (2011). Maternal posttraumatic stress symptoms and infant 
emotional reactivity and emotion regulation. Infant Behavior \& Development, 34, 487-503. doi:10.1016/j.infbeh.2011.07.007

Boucher, V., Bramoullé, Y., Djebbari, H., \& Fortin, B. (2014). Do peers affect student achievement? Evidence from Canada using group size variation. Journal of Applied Econometrics, 29, 91-109. doi:10.1002/ jae.2299

Boyce, W. T., \& Ellis, B. J. (2005). Biological sensitivity to context: I. An evolutionary-developmental theory of the origins and functions of stress reactivity. Development and Psychopathology, 17, 271-301.

Brown, A. S., van Os, J., Driessens, C., Hoek, H. W., \& Susser, E. S. (2000). Further evidence of relation between prenatal famine and major affective disorder. American Journal of Psychiatry, 157, 190-195. doi:10.1176/ appi.ajp.157.2.190

Buss, C., Davis, E. P., Muftuler, T., Head, K., \& Sandman, C. A. (2010). High pregnancy anxiety during mid-gestation is associated with decreased gray matter density in 6-9 year-old children. Psychoneuroendocrinology, 35, 141-153. doi:10.1016/j.psyneuen.2009.07.010

Buss, C., Davis, E. P., Shahbaba, B., Pruessner, J. C., Head, K., \& Sandman, C. A. (2012). Maternal cortisol over the course of pregnancy and subsequent child amygdala and hippocampus volumes and affective problems. Proceedings of the National Academy of Sciences, 109, E1312-E1319. doi:10.1073/pnas.1201295109

Campbell, S. B. (1995). Behavior problems in preschool children: A review of recent research. Journal of Child Psychology and Psychiatry, 36, 113-149.

Cao, J. (2014). The functional role of long non-coding RNAs and epigenetics. Biological Procedures Online, 16, 11. doi:10.1186/1480-9222-16-11

Casas, M., Forns, J., Martínez, D., Avella-García, C., Valvi, D., BallesterosGómez, A., . . . Vrijheld, M. (2015). Exposure to bisphenol A during pregnancy and child neuropsychological development in the INMA-Sabadell cohort. Environmental Research, 142, 671-679. doi:10.1016/j. envres.2015.07.024

Casati, L., Sendra, R., Sibilia, V., \& Celotti, F. (2015). Endocrine disrupters: The new players able to affect the epigenome. Frontiers in Cell and Developmental Biology, 3, 37. doi:10.3389/fcell.2015.00037

Charmandari, E., Tsigos, C., \& Chrousos, G. (2005). Endocrinology of the stress response. Annual Reviews of Physiology, 67, 259-284. doi:10.1146/ annurev.physiol.67.040403.120816

Chen, T., Tsujimoto, N., \& Li, E. (2004). The PWWP domain of Dnmt3a and Dnmt3b is required for directing DNA methylation to the major satellite repeats at pericentric heterochromatin. Molecular and Cellular Biology, 24, 9048-9058. doi:10.1128/MCB.24.20.9048-9058.2004

Clancy, B., Darlington, R. B., \& Finlay, B. L. (2001). Translating developmental time across mammalian species. Neuroscience, 105, 7-17.

Clardy, S. L., Wang, X., Zhao, W., Liu, W., Chase, G. A., Beard, J. L., . . . Connor, J. R. (2006). Acute and chronic effects of developmental iron deficiency on mRNA expression patterns in the brain. Journal of Neural Transmission Supplementa, 71, 173-196.

Clouard, C., Gerrits, W. J., Kemp, B., Val-Laillet, D., \& Bolhuis, J. E. (2016). Perinatal exposure to a diet high in saturated fat, refined sugar and cholesterol affects behaviour, growth, and feed intake in weaned piglets. PLOS ONE, 11, e0154698. doi:10.1371/journal.pone.0154698

Coan, J. A., \& Allen, J. J. (2004). Frontal EEG asymmetry as a moderator and mediator of emotion. Biological Psychology, 67, 7-49. doi:10.1016/ j.biopsycho.2004.03.002

Colbert, N. K., Pelletier, N. C., Cote, J. M., Concannon, J. B., Jurdak, N. A., Minott, S. B., \& Markowski, V. P. (2005). Perinatal exposure to low levels of the environmental antiandrogen vinclozolin alters sex-differentiated social play and sexual behaviors in the rat. Environmental Health Perspectives, 113, 700-707.

Colciago, A., Casati, L., Mornati, O., Vergoni, A. V., Santagostino, A., Celotti, F., \& Negri-Cesi, P. (2009). Chronic treatment with polychlorinated biphenyls (PCB) during pregnancy and lactation in the rat: Part 2. Effects on reproductive parameters, on sex behavior, on memory retention and on hypothalamic expression of aromatase and 5alpha-reductases in the offspring. Toxicology and Applied Pharmacology, 239, 46-54. doi:10. 1016/j.taap.2009.04.023

Coslovsky, M., \& Richner, H. (2011). Predation risk affects offspring growth via maternal effects. Functional Ecology, 25, 878-888. doi:10.1111/ j.1365-2435.2011.01834.x

Crews, D. (2010). Epigenetics, brain, behavior, and the environment. Hormones, 9, 41-50.

Crews, D., Gore, A. C., Hsu, T. S., Dangleben, N. L., Spinetta, M., Schallert, T., ... Skinner, M. K. (2007). Transgenerational epigenetic imprints on mate preference. Proceedings of the National Academy of Sciences, 104, 5942-5946. doi:10.1073/pnas.0610410104

Cunha Fda, S., Dalle Molle, R., Portella, A. K., Benetti Cda, S., Noschang, C., Goldani, M. Z., \& Silveira, P. P. (2015). Both food restriction and high-fat diet during gestation induce low birth weight and altered physical activity in adult rat offspring: The "Similarities in the Inequalities" model. PLOS ONE, 10, e0118586. doi:10.1371/journal.pone. 0118586

Davidson, R. J. (1998). Anterior electrophysiological asymmetries, emotion, and depression: Conceptual and methodological conundrums. Psychophysiology, 35, 607-614.

Davis, E. P., Glynn, L. M., Dunkel Schetter, C., Hobel, C., Chicz-DeMet, A., $\&$ Sandman, C. A. (2007). Prenatal exposure to maternal depression and cortisol influences infant temperament. Journal of the American Academy of Child \& Adolescent Psychiatry, 46, 737-746.

De Bolle, M., De Clercq, B., De Caluwe, E., \& Verbeke, L. (2016). Exploring the complexity of the childhood trait-psychopathology association: Continuity, pathoplasty, and complication effects. Development and Psychopathology, 28, 139-148. doi:10.1017/S0954579415000346

Delaney-Black, V., Covington, C., Nordstrom, B., Ager, J., Janisse, J., Hannigan, J. H., . . . Sokol, R. J. (2004). Prenatal cocaine: Quantity of exposure and gender moderation. Journal of Developmental and Behavioral Pediatrics, 25, 254-263.

Della Vedova, A. D. (2014). Maternal psychological state and infant's temperament at three months. Journal of Reproductive and Infant Psychology, 32, 520-534. doi:10.1080/02646838.2014.947472

Deppermann, S., Storchak, H., Fallgatter, A. J., \& Ehlis, A. C. (2014). Stressinduced neuroplasticity: (Mal)adaptation to adverse life events in patients with PTSD_A critical overview. Neuroscience, 283, 166-177. doi:10.1016/ j.neuroscience.2014.08.037

Depue, R. A., \& Collins, P. F. (1999). Neurobiology of the structure of personality: Dopamine, facilitation of incentive motivation, and extraversion. Behavioral and Brain Sciences, 22, 491-517.

de Rooij, S. R., Painter, R. C., Phillips, D. I., Raikkonen, K., Schene, A. H., \& Roseboom, T. J. (2011). Self-reported depression and anxiety after prenatal famine exposure: Mediation by cardio-metabolic pathology? Journal of Developmental Origins of Health and Disease, 2, 136-143. doi:10.1017/ S2040174411000055

de Vries, A., Holmes, M. C., Heijnis, A., Seier, J. V., Heerden, J., Louw, J., Seckl, J. R. (2007). Prenatal dexamethasone exposure induces changes in nonhuman primate offspring cardiometabolic and hypothalamic-pituitary-adrenal axis function. Journal of Clinical Investigation, 117, 1058-1067. doi:10.1172/JCI30982

Diaz, A., \& Bell, M. A. (2012). Frontal EEG asymmetry and fear reactivity in different contexts at 10 months. Developmental Psychobiology, 54, 536545. doi: $10.1002 /$ dev. 20612

Diaz, A., Eisenberg, N., Valiente, C., VanSchyndel, S., Spinrad, T. L., \& Southworth, J. (2015). Relations of positive and negative expressivity and effortful control to kindergarteners' student-teacher relationship, academic engagement, and externalizing problems at school. Journal of Research in Personality. Advance online publication. doi:10.1016/ j.jrp.2015.11.002

Dickerson, P. A., Lally, B. E., Gunnel, E., Birkle, D. L., \& Salm, A. K. (2005). Early emergence of increased fearful behavior in prenatally stressed rats. Physiology \& Behavior, 86, 586-593. doi:10.1016/j.physbeh.2005. 08.025

Diego, M. A., Jones, N. A., Field, T., Hernandez-Reif, M., Schanberg, S., Kuhn, C., \& Gonzalez-Garcia, A. (2006). Maternal psychological distress, prenatal cortisol, and fetal weight. Psychosomatic Medicine, 68, 747-753. doi:10.1097/01.psy.0000238212.21598.7b

Dietrich, K. N., Ris, M. D., Succop, P. A., Berger, O. G., \& Bornschein, R. L. (2001). Early exposure to lead and juvenile delinquency. Neurotoxicology and Teratology, 23, 511-518.

DiNieri, J. A., Wang, X., Szutorisz, H., Spano, S. M., Kaur, J., Casaccia, P., ... Hurd, Y. L. (2011). Maternal cannabis use alters ventral striatal dopamine D2 gene regulation in the offspring. Biological Psychiatry, 70, 763 769. doi:10.1016/j.biopsych.2011.06.027

Eiden, R. D., Granger, D. A., Schuetze, P., \& Veira, Y. (2011). Child behavior problems among cocaine-exposed toddlers: Indirect and interactive effects. Development and Psychopathology, 23, 539-550. doi:10.1017/ S0954579411000058

El Marroun, H., Hudziak, J. J., Tiemeier, H., Creemers, H., Steegers, E. A., Jaddoe, V. W., . . Huizink, A. C. (2011). Intrauterine cannabis exposure leads to more aggressive behavior and attention problems in 18-month- 
old girls. Drug and Alcohol Dependence, 118, 470-474. doi:10.1016/ j.drugalcdep.2011.03.004

Eriksson, J. G., Kajantie, E., Osmond, C., Thornburg, K., \& Barker, D. J. (2010). Boys live dangerously in the womb. American Journal of Human Biology, 22, 330-335. doi:10.1002/ajhb.20995

Evans, D. E., \& Rothbart, M. K. (2007). Developing a model for adult temperament. Journal of Research in Personality, 41, 868-888. doi:10.1016/ j.jrp.2006.11.002

Factor-Litvak, P., Wasserman, G., Kline, J. K., \& Graziano, J. (1999). The Yugoslavia Prospective Study of environmental lead exposure. Environment and Health Perspectives, 107, 9-15.

Fatima, M., Srivastav, S., \& Mondal, A. C. (2017). Prenatal stress and depression associated neuronal development in neonates. International Journal of Developmental Neuroscience, 60, 1-7. doi:10.1016/j.ijdevneu.2017.04.001

Feil, R., \& Khosla, S. (1999). Genomic imprinting in mammals: An interplay between chromatin and DNA methylation? Trends in Genetics, 15, 431-435.

Ferguson, S. A., Berry, K. J., Hansen, D. K., Wall, K. S., White, G., \& Antony, A. C. (2005). Behavioral effects of prenatal folate deficiency in mice. Birth Defects Research Part A: Clinical and Molecular Teratology, 73, 249-252. doi:10.1002/bdra.20111

Filipowicz, W., Bhattacharyya, S. N., \& Sonenberg, N. (2008). Mechanisms of post-transcriptional regulation by microRNAs: Are the answers in sight? Nature Reviews Genetics, 9, 102-114. doi:10.1038/nrg2290

Flom, J. D., Ferris, J. S., Liao, Y., Tehranifar, P., Richards, C. B., Cho, Y. H., ... Terry, M. B. (2011). Prenatal smoke exposure and genomic DNA methylation in a multiethnic birth cohort. Cancer Epidemiology, Biomarkers \& Prevention, 20, 2518-2523. doi:10.1158/1055-9965.EPI-11-0553

Fowles, D. C. (1994). A motivational theory of psychopathology. Nebraska Symposium on Motivation, 41, 181-238.

Frankenhuis, W. E., Panchanathan, K., \& Belsky, J. (2016). A mathematical model of the evolution of individual differences in developmental plasticity arising through parental bet-hedging. Developmental Science, 19, 251-274. doi:10.1111/desc.12309

Froehlich, T. E., Lanphear, B. P., Auinger, P., Hornung, R., Epstein, J. N., Braun, J., \& Kahn, R. S. (2009). Association of tobacco and lead exposures with attention-deficit/hyperactivity disorder. Pediatrics, 124, e1054-e1063. doi:10.1542/peds.2009-0738

Fuemmeler, B. F., Lee, C. T., Soubry, A., Iversen, E. S., Huang, Z., Murtha, A. P., ... Hoyo, C. (2016). DNA methylation of regulatory regions of imprinted genes at birth and its relation to infant temperament. Genetics and Epigenetics, 8, 59-67. doi:10.4137/GEG.S40538

Gartstein, M. A., Bridgett, D. J., Young, B. N., Panksepp, J., \& Power, T. (2013). Origins of effortful control: Infant and parent contributions. Infancy, 18, 149-183. doi:10.1111/j.1532-7078.2012.00119.x

Gartstein, M. A., \& Fagot, B. I. (2003). Parental depression, parenting and family adjustment, and child effortful control: Explaining externalizing behaviors for preschool children. Journal of Applied Developmental Psychology, 24, 143-177. doi:10.1016/S0193-3973(03)00043-1

Gartstein, M. A., Hookenson, K. V., Brain, U., Devlin, A. M., Grunau, R. E., \& Oberlander, T. F. (2016). Sculpting infant soothability: The role of prenatal SSRI antidepressant exposure and neonatal SLC6A4 methylation status. Developmental Psychobiology, 58, 745-758.

Gartstein, M. A., Putnam, S. P., Aaron, E., \& Rothbart, M. K. (2016). Temperament and personality. In S. Matzman (Ed.), Oxford handbook of treatment processes and outcomes in counseling psychology (pp. 11-41). New York: Oxford University Press.

Gartstein, M. A., \& Rothbart, M. K. (2003). Studying infant temperament via the Revised Infant Behavior Questionnaire. Infant Behavior and Development, 26, 64-86. doi:10.1016/s0163-6383(02)00169-8

Georgieff, M. K. (2007). Nutrition and the developing brain: Nutrient priorities and measurement. American Journal of Clinical Nutrition, 85, 614S-620S.

Giesing, E. R., Suski, C. D., Warner, R. E., \& Bell, A. M. (2011). Female sticklebacks transfer information via eggs: Effects of maternal experience with predators on offspring. Proceedings Biological Sciences, 278, 1753-1759. doi:10.1098/rspb.2010.1819

Giusti, R. M., Iwamoto, K., \& Hatch, E. E. (1995). Diethylstilbestrol revisited: A review of the long-term health effects. Annals of Internal Medicine, 122, 778-788.

Godin, J. D., Poizat, G., Hickey, M. A., Maschat, F., \& Humbert, S. (2010). Mutant Huntington-impaired degradation of beta-catenin causes neurotoxicity in Huntington's disease. European Molecular Biology Organization Journal, 29, 2433-2445. doi:10.1038/emboj.2010.117
Goldschmidt, L., Day, N. L., \& Richardson, G. A. (2000). Effects of prenatal marijuana exposure on child behavior problems at age 10. Neurotoxicology and Teratology, 22, 325-336.

Golub, M. S., Kaufman, F. L., Campbell, M. A., Li, L. H., \& Donald, J. M (2006). "Natural" progesterone: Information on fetal effects. Birth Defects Research. Part B, Developmental and Reproductive Toxicology, 77, 455-470. doi:10.1002/bdrb.20089

Golub, Y., Canneva, F., Funke, R., Frey, S., Distler, J., von Horsten, S., . . Solati, J. (2016). Effects of in utero environment and maternal behavior on neuroendocrine and behavioral alterations in a mouse model of prenatal trauma. Developmental Neurobiology, 76, 1254-1265. doi:10.1002/dneu.22387

Gray, J. (1994). Framework for a taxonomy of psychiatric disorder. In S. H. M. van Goozen, N. E. Van de Poll, \& J. A. Sergeant (Eds.), Emotions: Essays on emotion theory (pp. 40-43). Hillsdale, NJ: Erlbaum.

Gray, K. A., Day, N. L., Leech, S., \& Richardson, G. A. (2005). Prenatal marijuana exposure: Effect on child depressive symptoms at ten years of age. Neurotoxicology and Teratology, 27, 439-448. doi:10.1016/j.ntt.2005. 03.010

Greenberg, E. R., Barnes, A. B., Resseguie, L., Barrett, J. A., Burnside, S. Lanza, L. L., . . Colton, T. (1984). Breast cancer in mothers given diethylstilbestrol in pregnancy. New England Journal of Medicine, 311, 1393-1398. doi:10.1056/nejm198411293112201

Griffin, A. S., \& Evans, C. S. (2003). Social learning of antipredator behaviour in a marsupial. Animal Behaviour, 66, 485-492. doi:10.1006/ anbe. 2003.2207

Gunnar, M. R., \& Vazquez, D. M. (2001). Low cortisol and a flattening of expected daytime rhythm: Potential indices of risk in human development. Development and Psychopathology, 13, 515-538.

Gur, T. L., Kim, D. R., \& Epperson, C. N. (2013). Central nervous system effects of prenatal selective serotonin reuptake inhibitors: Sensing the signal through the noise. Psychopharmacology, 227, 567-582. doi:10.1007/ s00213-013-3115-8

Gurnot, C., Martin-Subero, I., Mah, S. M., Weikum, W., Goodman, S. J., Brain, U., ... Hensch, T. K. (2015). Prenatal antidepressant exposure associated with CYP2E1 DNA methylation change in neonates. Epigenetics, 10, 361-372. doi:10.1080/15592294.2015.1026031

Gustafsson, H. C., Kuzava, S. E., Werner, E. A., \& Monk, C. (2016). Maternal dietary fat intake during pregnancy is associated with infant temperament. Development and Psychobiology, 58, 528-535. doi:10.1002/ dev. 21391

Haas, B. W., Filkowski, M. M., Cochran, R. N., Denison, L., Ishak, A., Nishitani, S., \& Smith, A. K. (2016). Epigenetic modification of OXT and human sociability. Proceedings of the National Academy of Sciences, 113, E3816-E3823. doi:10.1073/pnas.1602809113

Halas, E. S., Reynolds, G. M., \& Sandstead, H. H. (1977). Intra-uterine nutrition and its effects on aggression. Physiology \& Behavior, 19, 653-661.

Haley, D. W., Handmaker, N. S., \& Lowe, J. (2006). Infant stress reactivity and prenatal alcohol exposure. Alcoholism: Clinical and Experimental Research, 30, 2055-2064. doi:10.1111/j.1530-0277.2006.00251.x

Hamilton, D. A., Barto, D., Rodriguez, C. I., Magcalas, C. M., Fink, B. C., Rice, J. P., .. . Savage, D. D. (2014). Effects of moderate prenatal ethanol exposure and age on social behavior, spatial response perseveration errors and motor behavior. Behavioral Brain Research, 269, 44-54. doi:10. 1016/j.bbr.2014.04.029

Hammen, C. (2005). Stress and depression. Annual Review of Clinical Psychology, 1, 293-319. doi:10.1146/annurev.clinpsy.1.102803.143938

Hane, A. A., Fox, N. A., Henderson, H. A., \& Marshall, P. J. (2008). Behavioral reactivity and approach-withdrawal bias in infancy. Developmental Psychology, 44, 1491-1496. doi:10.1037/a0012855

Hanley, G. E., Brain, U., \& Oberlander, T. F (2013). Infant developmenta outcomes following prenatal exposure to antidepressants, and maternal depressed mood and positive affect. Early Human Development, 89, 519-524. doi:10.1016/j.earlhumdev.2012.12.012

Heijmans, B. T., Tobi, E. W., Stein, A. D., Putter, H., Blauw, G. J., Susser, E. S., . . Lumey, L. H. (2008). Persistent epigenetic differences associated with prenatal exposure to famine in humans. Proceedings of the National Academy of Sciences, 105, 17046-17049. doi:0806560105

Hentges, R. F., Davies, P. T., \& Cicchetti, D. (2015). Temperament and interparental conflict: The role of negative emotionality in predicting child behavioral problems. Child Development, 86, 1333-1350. doi:10.1111/cdev.12389

Hernández-Martínez, C., Canals, J., Aranda, N., Ribot, B., Escribano, J., \& Arija, V. (2011). Effects of iron deficiency on neonatal behavior at different stages of pregnancy. Early Human Development, 87, 165-169. doi:10.1016/j.earlhumdev.2010.12.006 
Hochberg, Z., Feil, R., Constancia, M., Fraga, M., Junien, C., Carel, J. C., . . . Albertsson-Wikland, K. (2011). Child health, developmental plasticity, and epigenetic programming. Endocrine Reviews, 32, 159-224. doi:10. 1210/er.2009-0039

Holz, N. E., Boecker, R., Baumeister, S., Hohm, E., Zohsel, K., Buchmann, A. F., .. L Laucht, M. (2014). Effect of prenatal exposure to tobacco smoke on inhibitory control: Neuroimaging results from a 25 -year prospective study. JAMA Psychiatry, 71, 786-796. doi:10.1001/jamapsychiatry.2014.343

Hompes, T., Izzi, B., Gellens, E., Morreels, M., Fieuws, S., Pexsters, A., . . . Claes, S. (2013). Investigating the influence of maternal cortisol and emotional state during pregnancy on the DNA methylation status of the glucocorticoid receptor gene (NR3C1) promoter region in cord blood. Journal of Psychiatric Research, 47, 880-891. doi:10.1016/j.jpsychires.2013. 03.009

Horabin, J. I. (2013). Long noncoding RNAs as metazoan developmental regulators. Chromosome Research, 21, 673-684. doi:10.1007/s10577013-9382-8

Hurley, K. M., Caulfield, L. E., Sacco, L. M., Costigan, K. A., \& Dipietro, J. A. (2005). Psychosocial influences in dietary patterns during pregnancy. Journal of the American Diet Association, 105, 963-966. doi:10.1016/ j.jada.2005.03.007

Hutchings, D. E., Gamagaris, Z., Miller, N., \& Fico, T. A. (1989). The effects of prenatal exposure to delta-9-tetrahydrocannabinol on the restactivity cycle of the preweanling rat. Neurotoxicology and Teratology, $11,353-356$.

Hyde, J. S., Mezulis, A. H., \& Abramson, L. Y. (2008). The ABCs of depression: Integrating affective, biological, and cognitive models to explain the emergence of the gender difference in depression. Psychological Review, 115, 291-313. doi:10.1037/0033-295X.115.2.291

Ivorra, C., Fraga, M. F., Bayon, G. F., Fernandez, A. F., Garcia-Vicent, C., Chaves, F. J., . . . Lurbe, E. (2015). DNA methylation patterns in newborns exposed to tobacco in utero. Journal of Translational Medicine, 13, 25. doi:10.1186/s12967-015-0384-5

Jacka, F. N., Ystrom, E., Brantsaeter, A. L., Karevold, E., Roth, C., Haugen, M., ... Berk, M. (2013). Maternal and early postnatal nutrition and mental health of offspring by age 5 years: A prospective cohort study. Journal of the American Academy of Child \& Adolescent Psychiatry, 52, 10381047. doi:10.1016/j.jaac.2013.07.002

Kabir, Z. D., Katzman, A. C., \& Kosofsky, B. E. (2013). Molecular mechanisms mediating a deficit in recall of fear extinction in adult mice exposed to cocaine in utero. PLOS ONE, 8, e84165. doi:10.1371/journal.pone. 0084165

Kabir, Z. D., Kennedy, B., Katzman, A., Lahvis, G. P., \& Kosofsky, B. E. (2014). Effects of prenatal cocaine exposure on social development in mice. Developmental Neuroscience, 36, 338-346. doi:10.1159/000360524

Kalin, N. H., \& Shelton, S. E. (2003). Nonhuman primate models to study anxiety, emotion regulation, and psychopathology. Annals of the New York Academy of Sciences, 1008, 189-200.

Kalmady, S. V., \& Venkatasubramanian, G. (2009). Evidence for positive selection on Protocadherin Y gene in Homo sapiens: Implications for schizophrenia. Schizophrinia Research, 108, 299-300. doi:10.1016/ j.schres.2008.09.015

Kaneko-Ishino, T., \& Ishino, F. (2010). Retrotransposon silencing by DNA methylation contributed to the evolution of placentation and genomic imprinting in mammals. Development, Growth and Differentiation, 52, 533-543. doi:10.1111/j.1440-169X.2010.01194.x

Karatayev, O., Lukatskaya, O., Moon, S. H., Guo, W. R., Chen, D., Algava, D., . . L Leibowitz, S. F. (2015). Nicotine and ethanol co-use in longEvans rats: Stimulatory effects of perinatal exposure to a fat-rich diet. Alcohol, 49, 479-489. doi:10.1016/j.alcohol.2015.03.002

Keenan, K., Bartlett, T. Q., Nijland, M., Rodriguez, J. S., Nathanielsz, P. W., \& Zurcher, N. R. (2013). Poor nutrition during pregnancy and lactation negatively affects neurodevelopment of the offspring: Evidence from a translational primate model. American Journal of Clinical Nutrition, 98, 396-402. doi:10.3945/ajcn.112.040352

Keeshin, B. R., Strawn, J. R., Out, D., Granger, D. A., \& Putnam, F. W. (2014). Cortisol awakening response in adolescents with acute sexual abuse related posttraumatic stress disorder. Depression and Anxiety, 31, 107-114. doi:10.1002/da.22154

Keil, K. P., \& Lein, P. J. (2016). DNA methylation: A mechanism linking environmental chemical exposures to risk of autism spectrum disorders? Environmental Epigenetics, 2, 1. doi:10.1093/eep/dvv012

Khulan, B., Cooper, W. N., Skinner, B. M., Bauer, J., Owens, S., Prentice, A. M., ... Affara, N. A. (2012). Periconceptional maternal micronutrient supplementation is associated with widespread gender related changes in the epigenome: A study of a unique resource in the Gambia. Human Molecular Genetics, 21, 2086-2101. doi:10.1093/hmg/dds026

Kobor, M. S., \& Weinberg, J. (2011). Focus on: Epigenetics and fetal alcohol spectrum disorders. Alcohol Research \& Health, 34, 29-37.

Konycheva, G., Dziadek, M. A., Ferguson, L. R., Krägeloh, C. U., Coolen, M. W., Davison, M., \& Breier, B. H. (2011). Dietary methyl donor deficiency during pregnancy in rats shapes learning and anxiety in offspring. Nutrition Research, 31, 790-804. doi:10.1016/j.nutres.2011.09.015

Kovacs, M., \& Devlin, B. (1998). Internalizing disorders in childhood. Journal of Child Psychology and Psychiatry, 39, 47-63.

Kundakovic, M., Gudsnuk, K., Franks, B., Madrid, J., Miller, R. L., Perera, F. P., \& Champagne, F. A. (2013). Sex-specific epigenetic disruption and behavioral changes following low-dose in utero bisphenol A exposure. Proceedings of the National Academy of Sciences, 110, 9956-9961. doi:10.1073/pnas.1214056110

Lacy, R. T., Morgan, A. J., \& Harrod, S. B. (2014). IV prenatal nicotine exposure increases the reinforcing efficacy of methamphetamine in adult rat offspring. Drug and Alcohol Dependence, 141, 92-98. doi:10.1016/ j.drugalcdep.2014.05.010

Ladd-Acosta, C., Shu, C., Lee, B. K., Gidaya, N., Singer, A., Schieve, L. A., ... Daniele Fallin, M. (2016). Presence of an epigenetic signature of prenatal cigarette smoke exposure in childhood. Environmental Research, 144, 139-148. doi:10.1016/j.envres.2015.11.014

Langley-Evans, S. C. (2015). Nutrition in early life and the programming of adult disease: A review. Journal of Human Nutrition and Dietetics, 28(Suppl. 1), 1-14. doi:10.1111/jhn.12212

Laufer, B. I., Kapalanga, J., Castellani, C. A., Diehl, E. J., Yan, L., \& Singh, S. M. (2015). Associative DNA methylation changes in children with prenatal alcohol exposure. Epigenomics, 7, 1259-1274. doi:10.2217/epi.15.60

Leasure, J. L., Giddabasappa, A., Chaney, S., Johnson, J. E., Jr., Pothakos, K., Lau, Y. S., \& Fox, D. A. (2008). Low-level human equivalent gestational lead exposure produces sex-specific motor and coordination abnormalities and late-onset obesity in year-old mice. Environmental Health Perspectives, 116, 355-361. doi:10.1289/ehp.10862

Lee, H., Chung, S., \& Noh, J. (2016). Maternal nicotine exposure during late gestation and lactation increases anxiety-like and impulsive decisionmaking behavior in adolescent offspring of rat. Toxicology Research, 32, 275-280. doi:10.5487/TR.2016.32.4.275

Lester, B. M., Conradt, E., \& Marsit, C. (2016). Introduction to the Special Section on epigenetics. Child Development, 87, 29-37. doi:10.1111/cdev. 12489

Levay, E. A., Paolini, A. G., Govic, A., Hazi, A., Penman, J., \& Kent, S. (2008). Anxiety-like behaviour in adult rats perinatally exposed to maternal calorie restriction. Behavior and Brain Research, 191, 164-172. doi:10.1016/j.bbr.2008.03.021

Lisboa, S. F., Oliveira, P. E., Costa, L. C., Venancio, E. J., \& Moreira, E. G. (2007). Behavioral evaluation of male and female mice pups exposed to fluoxetine during pregnancy and lactation. Pharmacology, 80, 49-56. doi: $10.1159 / 000103097$

Liu, T., Gatsonis, C. A., Baylin, A., Kubzansky, L. D., Loucks, E. B., \& Buka, S. L. (2011). Maternal smoking during pregnancy and anger temperament among adult offspring. Journal of Psychiatric Research, 45, 1648-1654. doi:10.1016/j.jpsychires.2011.08.007

Lock, L. F., Takagi, N., \& Martin, G. R. (1987). Methylation of the Hprt gene on the inactive $\mathrm{X}$ occurs after chromosome inactivation. Cell, $48,39-46$.

Lonigan, C. J., Carey, M. P., \& Finch, A. J., Jr. (1994). Anxiety and depression in children and adolescents: Negative affectivity and the utility of self-reports. Journal of Consulting Clinical Psychology, 62, 1000-1008.

Lonigan, C. J., Phillips, B. M., \& Hooe, E. S. (2003). Relations of positive and negative affectivity to anxiety and depression in children: Evidence from a latent variable longitudinal study. Journal of Consulting Clinical Psychology, 71, 465-481.

Luo, M., Xu, Y., Cai, R., Tang, Y., Ge, M. M., Liu, Z. H., . . Wang, H. L. (2014). Epigenetic histone modification regulates developmental lead exposure induced hyperactivity in rats. Toxicology Letters, 225, 78-85. doi:10.1016/j.toxlet.2013.11.025

Maccari, S., Darnaudery, M., Morley-Fletcher, S., Zuena, A. R., Cinque, C., \& Van Reeth, O. (2003). Prenatal stress and long-term consequences: Implications of glucocorticoid hormones. Neuroscience \& Biobehavioral Reviews, 27, 119-127.

Maccari, S., Polese, D., Reynaert, M. L., Amici, T., Morley-Fletcher, S., \& Fagioli, F. (2016). Early-life experiences and the development of adult 
diseases with a focus on mental illness: The Human Birth Theory. Neuroscience. Advance online publication. doi:10.1016/j.neuroscience.2016. 05.042

Maciag, D., Simpson, K. L., Coppinger, D., Lu, Y., Wang, Y., Lin, R. C., \& Paul, I. A. (2006). Neonatal antidepressant exposure has lasting effects on behavior and serotonin circuitry. Neuropsychopharmacology, 31, 47-57. doi:10.1038/sj.npp.1300823

Manikkam, M., Guerrero-Bosagna, C., Tracey, R., Haque, M. M., \& Skinner, M. K. (2012). Transgenerational actions of environmental compounds on reproductive disease and identification of epigenetic biomarkers of ancestral exposures. PLOS ONE, 7, e31901. doi:10.1371/journal.pone. 0031901

Marjonen, H., Sierra, A., Nyman, A., Rogojin, V., Gröhn, O., \& Linden, A. M., . . . Kaminen-Ahol, N. (2015). Early maternal alcohol consumption alters hippocampal DNA methylation, gene expression and volume in a mouse model. PLOS ONE, 10, e0124931. doi:10.1371/journal.pone. 0124931

Martel, M. M., Gremillion, M. L., \& Roberts, B. (2012). Temperament and common disruptive behavior problems in preschool. Personality and Individual Differences, 53, 874-879. doi:10.1016/j.paid.2012.07.011

Mattson, S. N., \& Riley, E. P. (1998). A review of the neurobehavioral deficits in children with fetal alcohol syndrome or prenatal exposure to alcohol. Alcoholism: Clinical and Experimental Research, 22, 279-294.

McAllister, B. B., Kiryanova, V., \& Dyck, R. H. (2012). Behavioural outcomes of perinatal maternal fluoxetine treatment. Neuroscience, 226, 356-366. doi:10.1016/j.neuroscience.2012.09.024

Mennes, M., Stiers, P., Lagae, L., \& Van den Bergh, B. (2006). Long-term cognitive sequelae of antenatal maternal anxiety: Involvement of the orbitofrontal cortex. Neuroscience \& Biobehavioral Reviews, 30, 10781086. doi:10.1016/j.neubiorev.2006.04.003

Meyer, J. S. (1985). Biochemical effects of corticosteroids on neural tissues. Physiological Reviews, 65, 946-1020.

Miyagawa, K., Tsuji, M., Fujimori, K., Saito, Y., \& Takeda, H. (2011). Prenatal stress induces anxiety-like behavior together with the disruption of central serotonin neurons in mice. Journal of Neuroscience Research, 70, 111-117. doi:10.1016/j.neures.2011.02.002

Mohler, E., Parzer, P., Brunner, R., Wiebel, A., \& Resch, F. (2006). Emotional stress in pregnancy predicts human infant reactivity. Early Human Development, 82, 731-737. doi:10.1016/j.earlhumdev.2006.02.010

Molteno, C. D., Jacobson, J. L., Carter, R. C., Dodge, N. C., \& Jacobson, S. W. (2014). Infant emotional withdrawal: A precursor of affective and cognitive disturbance in fetal alcohol spectrum disorders. Alcoholism: Clinical and Experimental Research, 38, 479-488. doi:10.1111/acer. 12240

Monk, C., Georgieff, M. K., \& Osterholm, E. A. (2013). Research review: Maternal prenatal distress and poor nutrition-Mutually influencing risk factors affecting infant neurocognitive development. Journal of Child Psychology and Psychiatry, 54, 115-130. doi:10.1111/jcpp.12000

Montirosso, R., Provenzi, L., Fumagalli, M., Sirgiovanni, I., Giorda, R., Pozzoli, U., . . . Borgatti, R. (2016). Serotonin transporter gene (SLC6A4) methylation associates with neonatal intensive care unit stay and 3month-old temperament in preterm infants. Child Development, 87, 38-48. doi:10.1111/cdev.12492

Moran, L., Lengua, L. J., Zalewski, M., Ruberry, E., Klein, M., Thompson, S., \& Kiff, C. (2016). Variable- and person-centered approaches to examining temperament vulnerability and resilience to the effects of contextual risk. Journal of Personality Research, 67, 61-74. doi:10.1016/j.jrp.2016.03.003

Morris, C. V., DiNieri, J. A., Szutorisz, H., \& Hurd, Y. L. (2011). Molecular mechanisms of maternal cannabis and cigarette use on human neurodevelopment. European Journal of Neuroscience, 34, 1574-1583. doi:10. 1111/j.1460-9568.2011.07884.x

Mulder, E. J., Ververs, F. F., de Heus, R., \& Visser, G. H. (2011). Selective serotonin reuptake inhibitors affect neurobehavioral development in the human fetus. Neuropsychopharmacology, 36, 1961-1971. doi:10.1038/ npp.2011.67

Murawski, N. J., Moore, E. M., Thomas, J. D., \& Riley, E. P. (2015). Advances in diagnosis and treatment of fetal alcohol spectrum disorders: From animal models to human studies. Alcohol Research, 37, 97-108.

Muris, P., \& Ollendick, T. H. (2005). The role of temperament in the etiology of child psychopathology. Clinical Child and Family Psychology Review, 8, 271-289. doi:10.1007/s10567-005-8809-y

Murray, K. T., \& Kochanska, G. (2002). Effortful control: Factor structure and relation to externalizing and internalizing behaviors. Journal of Abnormal Child Psychology, 30, 503-514.
Nazeri, M., Shabani, M., Ghotbi Ravandi, S., Aghaei, I., Nozari, M., \& Mazhari, S. (2015). Psychological or physical prenatal stress differentially affects cognition behaviors. Physiology \& Behavior, 142, 155-160. doi:10.1016/j.physbeh.2015.02.016

Newland, M. C., \& Paletz, E. M. (2000). Animal studies of methylmercury and PCBs: What do they tell us about expected effects in humans? Neurotoxicology, 21, 1003-1027.

Nieratschker, V., Massart, R., Gilles, M., Luoni, A., Suderman, M. J., Krumm, B., . . . Szyf, M. (2014). MORC1 exhibits cross-species differential methylation in association with early life stress as well as genomewide association with MDD. Translational Psychiatry, 4, e429. doi:10.1038/tp.2014.75

Nieto, S. J., Patriquin, M. A., Nielsen, D. A., \& Kosten, T. A. (2016). Don't worry; be informed about the epigenetics of anxiety. Pharmacology Biochemistry and Behavior, 146-147, 60-72. doi:10.1016/j.pbb.2016.05.006

Nolvi, S., Karlsson, L., Bridgett, D. J., Korja, R., Huizink, A. C., Kataja, E. L., \& Karlsson, H. (2016). Maternal prenatal stress and infant emotional reactivity six months postpartum. Journal of Affective Disorders, 199, 163-170. doi:10.1016/j.jad.2016.04.020

Novikova, S. I., He, F., Bai, J., Cutrufello, N. J., Lidow, M. S., \& Undieh, A. S (2008). Maternal cocaine administration in mice alters DNA methylation and gene expression in hippocampal neurons of neonatal and prepubertal offspring. PLOS ONE, 3, e1919. doi:10.1371/journal.pone.0001919

Nulman, I., Rovet, J., Stewart, D. E., Wolpin, J., Gardner, H. A., Theis J. G. W., . . Koren, G. (1997). Neurodevelopment of children exposed in utero to antidepressant drugs. New England Journal of Medicine, $336,258-262$.

Nulman, I., Rovet, J., Stewart, D. E., Wolpin, J., Pace-Asciak, P., Shuhaiber, S., \& Koren, G. (2002). Child development following exposure to tricyclic antidepressants or fluoxetine throughout fetal life: A prospective, controlled study. American Journal of Psychiatry, 159, 1889-1895.

Oberlander, T. F. (2012). Fetal serotonin signaling: Setting pathways for early childhood development and behavior. Journal of Adolescent Health 51(Suppl. 2), S9-S16. doi:10.1016/j.jadohealth.2012.04.009

Oberlander, T. F., Eckstein Grunau, R., Fitzgerald, C., Ellwood, A. L., Misri, S., Rurak, D., \& Riggs, K. W. (2002). Prolonged prenatal psychotropic medication exposure alters neonatal acute pain response. Pediatric Research, 51, 443-453. doi:10.1203/00006450-200204000-00008

Oberlander, T. F., Grunau, R., Mayes, L., Riggs, W., Rurak, D., Papsdorf, M., Weinberg, J. (2008). Hypothalamic-pituitary-adrenal (HPA) axis function in 3-month old infants with prenatal selective serotonin reuptake inhibitor (SSRI) antidepressant exposure. Early Human Development, 84, 689-697. doi:10.1016/j.earlhumdev.2008.06.008

O’Donnell, K. J., Bugge Jensen, A., Freeman, L., Khalife, N., O'Connor, T. G., \& Glover, V. (2012). Maternal prenatal anxiety and downregulation of placental 11beta-HSD2. Psychoneuroendocrinology, 37, 818-826. doi:10.1016/j.psyneuen.2011.09.014

O'Leary, C., Leonard, H., Bourke, J., D’Antoine, H., Bartu, A., \& Bower, C (2013). Intellectual disability: Population-based estimates of the proportion attributable to maternal alcohol use disorder during pregnancy. Developmental Medicine and Child Neurology, 55, 271-277. doi:10.1111/ dmcn.12029

Olivier, J. D., Valles, A., van Heesch, F., Afrasiab-Middelman, A., Roelofs, J. J., Jonkers, M., . . . Homberg, J. R. (2011). Fluoxetine administration to pregnant rats increases anxiety-related behavior in the offspring. Psychopharmacology, 217, 419-432. doi:10.1007/s00213-011-2299-Z

O’Loan, J., Eyles, D. W., Kesby, J., Ko, P., McGrath, J. J., \& Burne, T. H. (2007). Vitamin D deficiency during various stages of pregnancy in the rat; its impact on development and behaviour in adult offspring. Psychoneuroendocrinology, 32, 227-234. doi:10.1016/j.psyneuen. 2006.12.006

Ostlund, B. D., Conradt, E., Crowell, S. E., Tyrka, A. R., Marsit, C. J., \& Lester, B. M. (2016). Prenatal stress, fearfulness, and the epigenome: Exploratory analysis of sex differences in DNA methylation of the glucocorticoid receptor gene. Frontiers in Behavioral Neuroscience, 10, 147. doi:10.3389/fnbeh.2016.00147

Palanza, P., Parmigiani, S., Liu, H., \& vom Saal, F. S. (1999). Prenatal exposure to low doses of the estrogenic chemicals diethylstilbestrol and o,p'-DDT alters aggressive behavior of male and female house mice. Pharmacology Biochemistry and Behavior, 64, 665-672.

Palanza, P., Parmigiani, S., \& vom Saal, F. S. (2001). Effects of prenatal exposure to low doses of diethylstilbestrol, o,p'DDT, and methoxychlor on postnatal growth and neurobehavioral development in male and female mice. Hormones and Behavior, 40, 252-265. doi:10.1006/hbeh.2001.1697 
Pan, P., Jin, D. H., Chatterjee-Chakraborty, M., Halievski, K., Lawson, D., Remedios, D., . . . Fleming, A. S. (2014). The effects of vitamin D? during pregnancy and lactation on offspring physiology and behavior in SpragueDawley rats. Developmental Psychobiology, 56, 12-22. doi:10.1002/dev. 21086

Pawluski, J. L., Brain, U. M., Underhill, C. M., Hammond, G. L., \& Oberlander, T. F. (2012). Prenatal SSRI exposure alters neonatal corticosteroid binding globulin, infant cortisol levels, and emerging HPA function. Psychoneuroendocrinology, 37, 1019-1028. doi:10.1016/j.psyneuen.2011.11.011

Peleg-Raibstein, D., Luca, E., \& Wolfrum, C. (2012). Maternal high-fat diet in mice programs emotional behavior in adulthood. Behavioral Brain Research, 233, 398-404. doi:10.1016/j.bbr.2012.05.027

Perera, F., Vishnevetsky, J., Herbstman, J. B., Calafat, A. M., Xiong, W., Rauh, V., \& Wang, S. (2012). Prenatal bisphenol a exposure and child behavior in an inner-city cohort. Environmental Health Perspectives, 120, 1190-1194. doi:10.1289/ehp.1104492

Perez-Edgar, K., Schmidt, L. A., Henderson, H. A., Schulkin, J., \& Fox, N. A. (2008). Salivary cortisol levels and infant temperament shape developmental trajectories in boys at risk for behavioral maladjustment. Psychoneuroendocrinology, 33, 916-925. doi:10.1016/j.psyneuen.2008. 03.018

Piedrafita, B., Erceg, S., Cauli, O., \& Felipo, V. (2008). Developmental exposure to polychlorinated biphenyls or methylmercury, but not to its combination, impairs the glutamate-nitric oxide-cyclic GMP pathway and learning in 3-month-old rats. Neuroscience, 154, 1408-1416. doi:10.1016/j.neuroscience.2008.05.013

Porges, S. W. (2007). The polyvagal perspective. Biological Psychology, 74, 116-143. doi:10.1016/j.biopsycho.2006.06.009

Portales-Casamar, E., Lussier, A. A., Jones, M. J., MacIsaac, J. L., Edgar, R. D., Mah, S. M., . . . Kobor, M. S. (2016). DNA methylation signature of human fetal alcohol spectrum disorder. Epigenetics and Chromatin, 9, e25. doi:10.1186/s13072-016-0074-4

Posner, M. I., \& Peterson, S. E. (2011). The attention system of the human brain: 20 years after. Annual Review of Neuroscience, 35, 73-89.

Posner, M. I., Rothbart, M. K., Sheese, B. E., \& Voelker, P. (2012). Control networks and neuromodulators of early development. Developmental Psychology, 48, 827-835. doi:10.1037/a0025530

Putnam, S. P., \& Gartstein, M. A. (2016). Aggregate temperament scores from multiple countries: Associations with aggregate personality traits, cultural dimensions, and allelic frequency. Journal of Research in Personality. Advance online publication. doi:10.1016/j.jrp.2016.07.009

Putnam, S. P., Rothbart, M. K., \& Gartstein, M. A. (2008). Homotypic and heterotypic continuity of fine-grained temperament during infancy, toddlerhood, and early childhood. Infant and Child Development, 17, 387-405. doi:10.1002/icd.582

Reed, M. N., \& Newland, M. C. (2007). Prenatal methylmercury exposure increases responding under clocked and unclocked fixed interval schedules of reinforcement. Neurotoxicology and Teratology, 29, 492-502. doi:10.1016/j.ntt.2007.03.002

Reed, M. N., Paletz, E. M., \& Newland, M. C. (2006). Gestational exposure to methylmercury and selenium: Effects on a spatial discrimination reversal in adulthood. Neurotoxicology, 27, 721-732. doi:10.1016/j.neuro.2006. 03.022

Reik, W., Collick, A., Norris, M. L., Barton, S. C., \& Surani, M. A. (1987). Genomic imprinting determines methylation of parental alleles in transgenic mice. Nature, 328, 248-251. doi:10.1038/328248a0

Richardson, G. A., Goldschmidt, L., \& Willford, J. (2009). Continued effects of prenatal cocaine use: Preschool development. Neurotoxicology and Teratology, 31, 325-333. doi:10.1016/j.ntt.2009.08.004

Rodriguez, J. S., Rodriguez-Gonzalez, G. L., Reyes-Castro, L. A., Ibanez, C., Ramirez, A., Chavira, R., . . Zambrano, E. (2012). Maternal obesity in the rat programs male offspring exploratory, learning and motivation behavior: Prevention by dietary intervention pre-gestation or in gestation. International Journal of Developmental Neuroscience, 30, 75-81. doi:10.1016/j.ijdevneu.2011.12.012

Roseboom, T. J., Painter, R. C., de Rooij, S. R., van Abeelen, A. F., Veenendaal, M. V., Osmond, C., \& Barker, D. J. (2011). Effects of famine on placental size and efficiency. Placenta, 32, 395-399. doi:10.1016/j. placenta.2011.03.001

Roseboom, T. J., de Rooij, S., \& Painter, R. (2006). The Dutch famine and its long-term consequences for adult health. Early Human Development, 82, 485-491. doi:10.1016/j.earlhumdev.2006.07.001

Rothbart, M. K. (1989). Temperament and development. In G. A. Kohnstamm, J. E. Bates, \& M. K. Rothbart (Eds.), Temperament in childhood (pp. 59-73). Oxford: Wiley.
Rothbart, M. K., \& Ahadi, S. A. (1994). Temperament and the development of personality. Journal of Abnormal Psychology, 103, 55-56. doi:10.1037/0021-843X.103.1.55

Rothbart, M. K., \& Derryberry, D. (1981). Development of individual differences in temperament. In M. E. Lamb \& A. L. Brown (Eds.), Advances in developmental psychology (pp. 37-86). Hillsdale, NJ: Erlbaum.

Rothbart, M. K., Derryberry, D., \& Posner, M. I. (1994). A psychobiological approach to the development of temperament. In J. E. Bates \& T. D. Wachs (Eds.), Temperament: Individual difference at the interface of biology and behavior (pp. 83-116). Washington, DC: American Psychological Association.

Rothbart, M. K., \& Hwang, J. (2005). Temperament and the development of competence and motivation. In A. J. Elliot \& C. S. Dweck (Eds.), Handbook of competence and motivation (pp. 167-181). New York: Guilford Press.

Rueda, M. R. (2012). Effortful control. In M. Zentner \& R. L. Shiner (Eds.), Handbook of temperament (pp. 145-161). New York: Guildford Press.

Sado, T., Okano, M., Li, E., \& Sasaki, H. (2004). De novo DNA methylation is dispensable for the initiation and propagation of $\mathrm{X}$ chromosome inactivation. Development, 131, 975-982. doi:10.1242/dev.00995

Sagiv, S. K., Thurston, S. W., Bellinger, D. C., Tolbert, P. E., Altshul, L. M., \& Korrick, S. A. (2010). Prenatal organochlorine exposure and behaviors associated with attention deficit hyperactivity disorder in school-aged children. American Journal of Epidemiology, 171, 593-601. doi:10.1093/ aje/kwp427

Sasaki, A., de Vega, W. C., St.-Cyr, S., Pan, P., \& McGowan, P. O. (2013). Perinatal high fat diet alters glucocorticoid signaling and anxiety behavior in adulthood. Neuroscience, 240, 1-12. doi:10.1016/j.neuroscience. 2013.02.044

Schneider, T., Bizarro, L., Asherson, P. J., \& Stolerman, I. P. (2012). Hyperactivity, increased nicotine consumption and impaired performance in the five-choice serial reaction time task in adolescent rats prenatally exposed to nicotine. Psychopharmacology, 223, 401-415. doi:10.1007/s00213$012-2728-7$

Sheriff, M. J., Krebs, C. J., \& Boonstra, R. (2009). The sensitive hare: Sublethal effects of predator stress on reproduction in snowshoe hares. Journal of Animal Ecology, 78, 1249-1258. doi:10.1111/j.1365-2656.2009.01552.x

Sheriff, M. J., Krebs, C. J., \& Boonstra, R. (2010). The ghosts of predators past: Population cycles and the role of maternal programming under fluctuating predation risk. Ecology, 91, 2983-2994.

Sioen, I., Den Hond, E., Nelen, V., Van de Mieroop, E., Croes, K., Van Larebeke, N., . . . Schoeters, G. (2013). Prenatal exposure to environmental contaminants and behavioural problems at age 7-8 years. Environment International, 59, 225-231. doi:10.1016/j.envint.2013.06.014

Skinner, M. K. (2014). Endocrine disruptor induction of epigenetic transgenerational inheritance of disease. Molecular and Cellular Endocrinology, 398, 4-12. doi:10.1016/j.mce.2014.07.019

Skinner, M. K., Anway, M. D., Savenkova, M. I., Gore, A. C., \& Crews, D. (2008). Transgenerational epigenetic programming of the brain transcriptome and anxiety behavior. PLOS ONE, 3, e3745. doi:10.1371/journal. pone. 0003745

Smit-Rigter, L. A., Noorlander, C. W., von Oerthel, L., Chameau, P., Smidt, M. P., \& van Hooft, J. A. (2012). Prenatal fluoxetine exposure induces life-long serotonin 5-HT(3) receptor-dependent cortical abnormalities and anxiety-like behaviour. Neuropharmacology, 62, 865-870. doi:10. 1016/j.neuropharm.2011.09.015

Stewart, P., Reihman, J., Gump, B., Lonky, E., Darvill, T., \& Pagano, J. (2005). Response inhibition at 8 and $91 / 2$ years of age in children prenatally exposed to PCBs. Neurotoxicology and Teratology, 27, 771-780. doi:10.1016/j.ntt.2005.07.003

Stewart, P. W., Lonky, E., Reihman, J., Pagano, J., Gump, B. B., \& Darvill, T. (2008). The relationship between prenatal PCB exposure and intelligence (IQ) in 9-year-old children. Environmental Health Perspectives, 116, 1416-1422. doi:10.1289/ehp. 11058

Sullivan, E. L., Grayson, B., Takahashi, D., Robertson, N., Maier, A., Bethea, C. L., . . Grove, K. L. (2010). Chronic consumption of a high-fat diet during pregnancy causes perturbations in the serotonergic system and increased anxiety-like behavior in nonhuman primate offspring. Journal of Neuroscience, 30, 3826-3830. doi:10.1523/jneurosci.5560-09.2010

Sullivan, E. L., Nousen, E. K., \& Chamlou, K. A. (2014). Maternal high fat diet consumption during the perinatal period programs offspring behavior. Physiology \& Behavior, 123, 236-242. doi:10.1016/j.physbeh. 2012.07.014

Sullivan, E. L., Smith, M. S., \& Grove, K. L. (2011). Perinatal exposure to high-fat diet programs energy balance, metabolism and behavior in adulthood. Neuroendocrinology, 93, 1-8. doi:10.1159/000322038 
Suter, M. A., Takahashi, D., Grove, K. L., \& Aagaard, K. M. (2013). Postweaning exposure to a high-fat diet is associated with alterations to the hepatic histone code in Japanese macaques. Pediatric Research, 74, 252-258. doi:10.1038/pr.2013.106

Sutton, S. K., \& Davidson, R. J. (1997). Prefrontal brain asymmetry: A biological substrate of the behavioral approach and inhibition system. Psychological Science, 8, 204-210.

Svirsky, N., Levy, S., \& Avitsur, R. (2016). Prenatal exposure to selective serotonin reuptake inhibitors (SSRI) increases aggression and modulates maternal behavior in offspring mice. Developmental Psychobiology, 58, 71-82. doi:10.1002/dev.21356

Swan, S. H., \& vom Saal, F. S. (2001). Alterations in male reproductive development: The role of endocrine disrupting chemicals. In M. Metzler (Ed.), Endocrine disruptors in the environment (pp. 131-170). Heidelberg: Springer-Verlag.

Szyf, M., \& Bick, J. (2013). DNA methylation: A mechanism for embedding early life experiences in the genome. Child Development, 84, 49-57. doi:10.1111/j.1467-8624.2012.01793.x

Szyf, M., Tang, Y. Y., Hill, K. G., \& Musci, R. (2016). The dynamic epigenome and its implications for behavioral interventions: A role for epigenetics to inform disorder prevention and health promotion. Translational Behavioral Medicine, 6, 55-62. doi:10.1007/s13142-016-0387-7

Tees, M. T., Harville, E. W., Xiong, X., Buekens, P., Pridjian, G., \& ElkindHirsch, K. (2010). Hurricane Katrina-related maternal stress, maternal mental health, and early infant temperament. Maternal and Child Health Journal, 14, 511-518. doi:10.1007/s10995-009-0486-x

Thomas, A., \& Chess, S. (1977). Temperament and development. New York: Brunner-Mazel.

Tobi, E. W., Goeman, J. J., Monajemi, R., Gu, H., Putter, H., Zhang, Y., . . . Heijmans, B. T. (2014). DNA methylation signatures link prenatal famine exposure to growth and metabolism. Nature Communications, 5, 5592. doi:10.1038/ncomms6592

Trezza, V., Campolongo, P., Manduca, A., Morena, M., Palmery, M., Vanderschuren, L. J., \& Cuomo, V. (2012). Altering endocannabinoid neurotransmission at critical developmental ages: Impact on rodent emotionality and cognitive performance. Frontiers in Behavioral Neuroscience, 6 , 2. doi:10.3389/fnbeh.2012.00002

Trezza, V., Cuomo, V., \& Vanderschuren, L. J. (2008). Cannabis and the developing brain: Insights from behavior. European Journal of Pharmacology, 585, 441-452. doi:10.1016/j.ejphar.2008.01.058

Trofimova, I., \& Robbins, T. W. (2016). Temperament and arousal systems: A new synthesis of differential psychology and functional neurochemistry. Neuroscience \& Biobehavioral Reviews, 64, 382-402. doi:10.1016/ j.neubiorev.2016.03.008

Turner, C., Dalton, N., Inaoui, R., Fogelman, I., Fraser, W. D., \& Hampson, G. (2013). Effect of a 300 000-IU loading dose of ergocalciferol (Vitamin D2) on circulating 1,25(OH)2-vitamin D and fibroblast growth factor23 (FGF-23) in vitamin D insufficiency. Journal of Clinical Endocrinology and Metabolism, 98, 550-556. doi:10.1210/jc.2012-2790

Valenzuela, C. F., Morton, R. A., Diaz, M. R., \& Topper, L. (2012). Does moderate drinking harm the fetal brain? Insights from animal models. Trends in Neuroscience, 35, 284-292. doi:10.1016/j.tins.2012. 01.006

Van den Bergh, B. R., Van Calster, B., Smits, T., Van Huffel, S., \& Lagae, L. (2008). Antenatal maternal anxiety is related to HPA-axis dysregulation and self-reported depressive symptoms in adolescence: A prospective study on the fetal origins of depressed mood. Neuropsychopharmacology, 33, 536-545. doi:10.1038/sj.npp.1301450

van den Heuvel, M. I., Johannes, M. A., Henrichs, J., \& Van den Bergh, B. R. (2015). Maternal mindfulness during pregnancy and infant socio-emotional development and temperament: The mediating role of maternal anxiety. Early Human Development, 91, 103-108. doi:10.1016/j.earlhumdev.2014.12.003

Vermeir, G., \& Viaene, M. K. (2002-2007). Neurobehavioural and cognitive effects of prenatal exposure to persistent environmental toxicants in three year old children. Final results. Unpublished manuscript.

Vessey, M. P., Fairweather, D. V., Norman-Smith, B., \& Buckley, J. (1983). A randomized double-blind controlled trial of the value of stilboestrol therapy in pregnancy: Long-term follow-up of mothers and their offspring. British Journal of Obstetrics and Gynaecology, 90, 1007-1017.

Vucetic, Z., Kimmel, J., Totoki, K., Hollenbeck, E., \& Reyes, T. M. (2010) Maternal high-fat diet alters methylation and gene expression of dopamine and opioid-related genes. Endocrinology, 151, 4756-4764. doi:10.1210/en.2010-0505

Wadhwa, P. D., Buss, C., Entringer, S., \& Swanson, J. M. (2009). Developmental origins of health and disease: Brief history of the approach and current focus on epigenetic mechanisms. Seminars in Reproductive Medicine, 27, 358-368. doi:10.1055/s-0029-1237424

Wahlestedt, C. (2013). Targeting long non-coding RNA to therapeutically upregulate gene expression. Nature Reviews Drug Discovery, 12, 433446. doi: $10.1038 / \mathrm{nrd} 4018$

Ward, H. E., Johnson, E. A., Salm, A. K., \& Birkle, D. L. (2000). Effects of prenatal stress on defensive withdrawal behavior and corticotropin releasing factor systems in rat brain. Physiology \& Behavior, 70, 359-366.

Weaver, I. C., Cervoni, N., Champagne, F. A., D’Alessio, A. C., Sharma, S., Seckl, J. R., . . . Meaney, M. J. (2004). Epigenetic programming by maternal behavior. Nature Neuroscience, 7, 847-854. doi:10.1038/nn1276

Whittle, S., Allen, N. B., Lubman, D. I., \& Yücel, M. (2006). The neurobiological basis of temperament: Towards a better understanding of psychopathology. Neuroscience \& Biobehavioral Review, 30, 511-525.

Wieczorek, L., Fish, E. W., O'Leary-Moore, S. K., Parnell, S. E., \& Sulik, K. K. (2015). Hypothalamic-pituitary-adrenal axis and behavioral dysfunction following early binge-like prenatal alcohol exposure in mice. Alcohol, 49, 207-217. doi:10.1016/j.alcohol.2015.01.005

Xu, H., Bai, L., Collins, J. F., \& Ghishan, F. K. (1999). Molecular cloning, functional characterization, tissue distribution, and chromosomal localization of a human, small intestinal sodium-phosphate $(\mathrm{Na}+\mathrm{Pi})$ transporter (SLC34A2). Genomics, 62, 281-284. doi:10.1006/geno.1999.6009

Xu, L., Sun, Y., Gao, L., Cai, Y. Y., \& Shi, S. X. (2014). Prenatal restraint stress is associated with demethylation of corticotrophin releasing hormone $(\mathrm{CRH})$ promoter and enhances $\mathrm{CRH}$ transcriptional responses to stress in adolescent rats. Neurochemical Research, 39, 1193-1198. doi:10.1007/s11064-014-1296-0

Yehuda, R. (2002). Post-traumatic stress disorder. New England Journal of Medicine, 346, 108-114. doi:10.1056/NEJMra012941

Yehuda, R., Engel, S. M., Brand, S. R., Seckl, J., Marcus, S. M., \& Berkowitz, G. S. (2005). Transgenerational effects of posttraumatic stress disorder in babies of mothers exposed to the World Trade Center attacks during pregnancy. Journal of Clinical Endocrinology and Metabolism 90, 4115-4118. doi:10.1210/jc.2005-0550

Yehuda, R., \& Seckl, J. (2011). Minireview: Stress-related psychiatric disorders with low cortisol levels: A metabolic hypothesis. Endocrinology, 152, 4496-4503. doi:10.1210/en.2011-1218

Yong Ping, E., Laplante, D. P., Elgbeili, G., Hillerer, K. M., Brunet, A. O'Hara, M. W., \& King, S. (2015). Prenatal maternal stress predicts stress reactivity at 2(1/2) years of age: The Iowa Flood Study. Psychoneuroen docrinology, 56, 62-78. doi:10.1016/j.psyneuen.2015.02.015

You, L., Gazi, E., Archibeque-Engle, S., Casanova, M., Conolly, R. B., \& Heck, H. A. (1999). Transplacental and lactational transfer of p,p'-DDE in SpragueDawley rats. Toxicology and Applied Pharmacology, 157, 134-144.

Zaratiegui, M., Irvine, D. V., \& Martienssen, R. A. (2007). Noncoding RNAs and gene silencing. Cell, 128, 763-776. doi:10.1016/j.cell.2007.02.016

Zeskind, P. S., McMurray, M. S., Cox Lippard, E. T., Grewen, K. M., Garber, K. A., \& Johns, J. M. (2014). Translational analysis of effects of prenatal cocaine exposure on human infant cries and rat pup ultrasonic vocalizations. PLOS ONE, 9, e110349. doi:10.1371/journal.pone.0110349

Zeskind, P. S., \& Stephens, L. E. (2004). Maternal selective serotonin reuptake inhibitor use during pregnancy and newborn neurobehavior. Pediatrics, 113, 368-375.

Zhao, Q., Hou, J., Chen, B., Shao, X., Zhu, R., Bu, Q., . . Cen, X. (2015). Prenatal cocaine exposure impairs cognitive function of progeny via insulin growth factor II epigenetic regulation. Neurobiology of Disease, 82, 54-65. doi:10.1016/j.nbd.2015.05.014

Zhou, H., Hu, H., \& Lai, M. (2010). Non-coding RNAs and their epigenetic regulatory mechanisms. Biology of the Cell, 102, 645-655. doi:10.1042/ BC20100029 